\title{
Cost-Effectiveness of Conservation Upgrades in Manufactured Homes
}
A. D. Lee
R. G. Lucas
C. C. Conner
N. E. Miller
J. E. Englin
W.H. Monroe
D. L. Hadley

September 1988

Prepared for the

Office of Conservation

and Power Resources

Bonneville Power Administration

under a Related Services Agreement with

the U.S. Department of Energy

Contract DE-ACO6-76RLO 1830 


\title{
DISCLAIMER
}

This report was prepared as an account of work sponsored by an agency of the United States Government. Neither the United States Government nor any agency thereof, nor Battelie Memorial Institute, nor any or their employees, makes any warranty, expressed or implied, or assumes any legal liability or responsibility for the accuracy, completeness, or usefulness of any information, apparatus, product, or process disclosed, or represents that its use would not infringe privately owned rights. Reference herein to any specific commercial product, process, or service by trade name, trademark, manufacturer, or otherwise does not neccessarily constitute or imply its endorsement, recommendation, or favoring by the United States Government or any agency thereof, or Battelle Memorial institute. The views and opinions of authors expressed herein do not necessarily state or reflect those of the United States Government or any agency thereot.

\author{
PACIFIC NORTHWEST LABORATORY \\ operated by \\ BATTELLE MEMORIAL INSTITUTE \\ for the \\ UNITED STATES DEPARTMENT OF ENERGY \\ under Contract DE-AC06-76RLO 1830
}

\begin{tabular}{|c|c|}
\hline \multicolumn{2}{|c|}{ Printed in the Urited States of America } \\
\hline \multicolumn{2}{|c|}{ Available from } \\
\hline \multicolumn{2}{|c|}{ National Technical Information Service } \\
\hline \multicolumn{2}{|c|}{ United States Department of Commerte } \\
\hline \multicolumn{2}{|c|}{5285 Porl Royal Road } \\
\hline \multicolumn{2}{|c|}{ Springfield, virginia 22161} \\
\hline \multicolumn{2}{|c|}{ NTIS Price Codes } \\
\hline \multicolumn{2}{|c|}{ Microfiche $\mathbf{A 0 1}$} \\
\hline \multicolumn{2}{|c|}{ Printed Copy } \\
\hline & Price \\
\hline Puges & Codes \\
\hline Obi-025 & $\wedge 02$ \\
\hline $026-050$ & A03 \\
\hline $05+-075$ & A04 \\
\hline $076-100$ & Aa5 \\
\hline $101-125$ & AOB \\
\hline $126-150$ & ^07 \\
\hline $151-175$ & AOP \\
\hline $176-200$ & $\wedge 09$ \\
\hline 201.225 & Ato \\
\hline $226-250$ & $\wedge 11$ \\
\hline $251-275$ & At2 \\
\hline $276-300$ & A13 \\
\hline
\end{tabular}



A. D. Lee
R. C. Lucas
C. C. Conner
N. E. Miller
J. E. Englin
W. H. Monroe
D. L. Hadley

September 1988

Prepared for the Office of Conservation and Power Resources Bonneville Power Administration under a Related Services Agreement with the U.S. Department of Energy Contract DE-AC06-76RLO 1830

Pacific Northwest Laboratory Richland, Washington 99352 


\section{EXECUTIVE SUMMARY}

This study addresses the costs of upgrading the efficiency of electrically heated manufactured homes in the Bonneville Power Administration's (Bonneville's) service territory. It was prepared by the Battelle Pacific Northwest Laboratory (PNL) for Bonneville under a Related Services Agreement with the U.S. Department of Energy, Contract DE-AC06-76RLO 1830 .

Manufactured hoines (comonly called mobile homes) represent a significant lost conservation resource in the region. Hanufactured homes are required to meet national energy standards that do not reflect the recent increases in energy prices, and the preentive nature of the national standards prevents local Jurisdictions fron establishing stricter requirements.

Bonneville has undertaken several programs to analyze the efficiency of manufactured homes and encourage the industry to produce more efficient homes and consumers to increase their demand for efficient units. This study constitutes one portion of Bonneville's overall strategy.

\section{OYERVIEH}

This study is unique in its use of measured data from manufactured homes to estimate conservation cost-effectiveness. Me used both end-use and total house (billing) data to estimate the energy savings associated with the installation of energy conservation measures (ECMs). The cost data were collected from manufacturers' cost sheets (or invoices, in the case of retrofits).

The methodology led to cost-effectiveness estimates, levelized costs, and supply curves that were derived from empirical data. This approach was in contrast to more traditional analyses, which rely primarily on the application of simulation models to estimate energy savings. Both the empirical and modeling approaches have disadvantages. The empirical approach we developed utilized data from primarily one geographic region; its application to other areas, therefore, required making extrapolations involving assumptions and adjustments. Our empirical data also represented a 
snapshot in time, so that estimates of future energy consumption and savings would be affected by the differences between current conditions and future conditions. Simulation models, on the other hand, are tied to actual conditions only as well as their theory and assumptions apply to the real world.

Our empirically-based approach produced results that, in general, agree well with those produced thus far using modeling techniques. In future analyses, however, results might differ and choosing the appropriate approach would depend on policy and planning considerations, as well as the technical merits of the approaches.

We analyzed primarily the cost-effectiveness of new ho:me upgrades, but also exanined retrofit costs. Bonneville currently does not include manufactured homes in its retrofit weatherization programs. Our analysis provides new information that could be used to assess the benefits of manufactured housing retrofits.

\section{DATA SOURCES}

We relied on several sources of existing energy data to develop estimates of the space heating energy consumption of electrically-heated manufactured homes. Data from the Hood River Conservation Project (HRCP) provided information on nearly 600 manufactured homes, before and after conservation retrofit. We had billing data for most of these homes for a period of four years, including one year after retrofit. For 61 of these homes, we also had end-use energy consumption data collected at 15-minute intervals during one year before and one year after retrofit. Detailed enduse data were also available for 10 current practice manufactured homes in the End-Use Load and Consumer (formerly Conservation) Assessment Program (ELCAP). In addition, we had end-use data from 5 manufactured homes built to the regional Model Conservation Standards (MCS) and also monitored under ELCAP. Finally, 34 MCS homes built under a Bonneville pilot program (the Tulalip homes) provided heating and total consumption data on a weekly and bi-monthly basis. For all these homes, we also had data related to the physical characteristics of the buildings and characteristics of their. occupants. 
During the first stage of this study (see Harkreader et al. 1987), we collected extensive information to establish what current construction practices were in the industry. Ne surveyed manufacturers and collected state compliance data to determine what current homes look like and what trends have occurred and are expected to occur in the industry. Based on this information, we established that current construction practice produces homes that are, on the average, more efficient than the minimum HUD thermal requirements. For double-wide homes, for example, the industry averages in the region are R-14 wall, R-16 celling, and R-9 floor insulation compared to the HUD minima of R-11, R-11, and R-7, respectively. Currently, 93\% of the homes use electricity for space heating. About $80 \%$ of the homes are multwide units, about twice the national proportion. The manufacturer data also provided fairly complete information on the costs of efficiency options of fered by the industry and indicated that ECM consumer prices would be marked up, on the average, by $87 \%$ over manufacturer costs.

\section{ENERGY SAVINGS ANALYSIS METHODOLOGY}

We developed a heating energy estimating methodology that utilized primarily the HRCP billing data. We used the basic PRISM methodology to estimate space heating energy consumption for the HRCP homes. The results were adjusted using a methodology developed based on comparisons between the HRCP end-use and billing data. The adjustment involved a regression equation that included the PRISM reference temperature, heating degree-days (HDD), design heat loss coefficient (UA), and the ratio of the PRISM estimate of the heating component to total energy consumption. The adjustment produced a revised estimate of heating energy consumption in Hood River for each home analyzed in the HRCP. Recognizing the limitations on extrapolating the heating energy estimates to other climate regions (such as the three MCS climate zones), we developed a technique to adjust the estimates for Hood River to estimates for other climate zones. This technique included the effects of differences in HDD, temperature swing, and insolation.

We estimated a linear relationship between heating energy consumption and the design UA of individual buildings to provide estimates of changes in heating energy consumption for different ECMs. For Hood River and Seattle, 
Mashington (MCS climate zone 1), Spokane, Washington (MCS climate zone 2), and Missoula, Montana (MCS climate zone 3), we developed coefficients to calculate the change in energy consumption associated with changes in the UA of individual components. Me determined, based on simulation model results, that a different coefficient should apply to windows than for other components. Table 1 presents the coefficients that can be multiplied by the change in design UA associated with a given ECM (Btu/hr./ ${ }^{\circ} \mathrm{F}$ ) and the HDD (base $65^{\circ} \mathrm{F}$ ), for the selected climate, to give an estimate of energy savings (kth/yr.).

These coefficients provided the basis for estimating the energy savings due to ECHs applied to new homes or through retrofit of existing homes. For retrofit, savings would be estimated based on the insulation levels and window characteristics in an actual or prototypical existing hone; for new homes, the savings were estimated relative to current construction practice.

\section{COST-EFFECTIVENESS RESULTS}

We analyzed the cost-effectiveness of new home and retrofit upgrades based on the levelized cost associated with specific measures in selected climate zones. Levelized cost captures the effects of first cost and energy savings and gives an indication of how conservation measures compare to new electric-generating plants as resource investments.

He used the Bonneville supply curve and cost-effectiveness methodology and assumptions. Our analysis provided new empirically-based estimates of

IABLE 1. Coefficients for Estimating Changes in Heating Energy from Changes in Design UA

\begin{tabular}{llcccc} 
Component & \multicolumn{4}{c}{ Location } \\
Hindows & 0.00275 & & 0.00295 & 0.00284 & 0.00283 \\
Other & 0.00470 & & 0.00505 & 0.00486 & 0.00483
\end{tabular}


energy savings and costs that updated previous Bonneville assumptions. For parameters such as discount rate ( $3 \%$ real), line loss credit ( $10 \%$ savings), demolition rates, etc., we utilized Bonneville's assumptions.

To get a sense of the relative costs of these conservation measures, we compared the levelized costs to estimated levelized costs for new coal generating plants. For comparison purposes, we used a figure of $40 \mathrm{mi} / \mathrm{ls} / \mathrm{kWh}$ here.

Typically, the levelized costs were lower in the double-wide homes and each option had a lower levelized cost in the colder climate zones. The most cost-effective option for single-wide homes was the installation of R-19 ceiling insulation. Starting at the current practice average level of about $R-17$, the ceiling insulation could be increased to $R-19$ for as little as 13 to $19 \mathrm{mills} / \mathrm{kth}$ of savings across the climate zones. In double-wide homes the comparable levelized costs were even lower. Using the $40 \mathrm{mills} / \mathrm{kWh}$ threshold, up to R-30 in the ceiling was cost-effective in all climate zones for both single-wide and double-wide homes. R-38 ceiling insulation was cost-effective under this criterion only in double-wides in climate zone 3. The savings per dollar invested in ceiling insulation decreased substantially over the range from R-19 to R-30: it cost nearly twice as much per kWh saved to go from $R-22$ to $R-30$ as it did from current practice to $R-19$.

Probably the most surprising result was the cost-effectiveness of increasing current practice insulation levels in walls to $R-18(2 \times 4$ walls with R-13 batts plus R-5 insulated sheathing). The levelized cost of this option ranged from about 10 to $23 \mathrm{mill} / \mathrm{s} / \mathrm{kth}$. These estimates were based on assumed current construction practice of $2 \times 4$ walls with about R-11 insulation, which industry data indicated was the most typical construction. Manufacturers in the Northwest currently do not offer a $2 \times 4$ wall with insulated sheathing as an option and have indicated their preference to market energy-efficient homes with $2 \times 6$ walls and conventional R-19 insulation instead. Our results, however, suggested that the insulated sheathing approach is more cost-effective from the regional perspective. A few manufacturers have gained experience with this type of construction and 
its apparent cost-effectiveness warrants further discussions between Bonneville and the industry on its potential applicability.

The floor insulation upgrades appeared to be cost-effective up to about R-25. The cost per unit energy savings increased significantly at higher Rvalues; e.g., increases from $R-22$ to $R-25$ cost about twice as much as increases from current practice (about $R-10$ ) to $R-14$.

The storm window option had relatively low levelized costs (less than 24 mills/kwh) in all cases, but changing to the thermally improved metal (T.I.M.) window added levelized costs of about 200-300 mills. The storm door costs also were very high, up to 174 aills. The infiltration control package (including an air-to-air heat exchanger) exceeded 40 mills by a significant anount, and was at its lowest for the double-wide home in climate zone 3 (about 75 mills).

Table 2 presents the combined supply curve results for new single-wide and double-wide homes. The supply curve indicates the magnitude of the new manufactured home conservation resource available at different levelized costs. Table 2 is based on incremental levelized costs for potential ECMs. If average levelized costs were used instead of the marginal levelized costs, a larger resource would be estimated at each cost level. The results are average megawatts (MW) in the year 2007 within only the Bonneville customers' service area. The major assumption underlying these results was that $50 \%$ of all manufactured homes built between 1987 and 2007 would contain the measures at each levelized cost level. The three scenarios were based on low, base, and high assumptions. Because they are larger and they constitute a large proportion of the new manufactured housing stock, double-wides made up about $90 \%$ of the total potential savings.

For the base scenario, manufactured housing efficiency improvements costing $40 \mathrm{mills} / \mathrm{k}$ wh or less could contribute about 78 average MH in the year 2007. The average cost of these measures would be about $22 \mathrm{mills} / \mathrm{kWh}$.

Based on the HRCP cost and energy data, we also estimated levelized retrofit costs for existing manufactured homes in Hood River. They were calculated based on a prototypical existing Hood River home and Hood River long-term average climate data. 
The costs were calcualted under two different assumptions for the remaining lifetime of the home, 10 years and 30 years. The levelized costs varied dramatically between the 30 - and 10 -year lifetime assumptions. The

\section{IABLE_2. Cumulative Energy Savings at Different Levelized Costs, Average $m$}

\begin{tabular}{crrr} 
& \multicolumn{3}{c}{ Scenario } \\
\cline { 2 - 4 } Nills/klth & Base & High \\
\cline { 2 - 4 }$<10$ & 0.0 & 0.0 & 0.0 \\
$<20$ & 25.7 & 42.4 & 48.3 \\
$<30$ & 41.5 & 68.5 & 78.0 \\
$<40$ & 47.2 & 78.0 & 88.8 \\
$<50$ & 49.9 & 82.5 & 93.9 \\
$<60$ & 51.4 & 84.9 & 96.5 \\
$<70$ & 53.8 & 89.0 & 101.2 \\
$<80$ & 60.1 & 99.4 & 113.2 \\
$<90$ & 63.8 & 105.5 & 120.0 \\
$<100$ & 67.8 & 112.1 & 127.5
\end{tabular}

levelized costs were about 2-1/2 times as high for the 10-year lifetime assumption.

The most cost-effective way to save energy through retrofit was to insulate the ceiling. Going from R-14 to R-19 in the ceiling cost 17 mills per kWh for a 30-year 1 ifetime. If the home had an expected Iifetime of 10 years the levelized cost was 39 mills. The range of levelized costs varied greatly depending on the pre-retrofit level of insulation. The most cost-effective insulation retrofits would be for cases where initial insulation levels were the lowest.

All window retrofits started from a base of single glazing in these manufactured homes. Since window retrofits involved window removal as well as replacement, the levelized costs were much higher, compared to the insulation retrofits, than installation costs alone would indicate. For the 30-year lifetime, levelized cost of retrofitting metal sash single pane to a better thermal performer ranged from about $100 \mathrm{mills}$ to $150 \mathrm{mills}$. The addition of storm windows lowered levelized costs, suggesting that the 
addition of a storm was more cost-effective than the other measures. In general, window retrofits appeared to be an expensive way to reduce energy consumption.

The window retrofit levelized costs covered a fairly narrow band of values. Thts suggested that the ratio of additional energy savings to additional costs was fairly constant over the available measures. This differed frow the cases involving insulation measures in which increnental costs increased considerably faster than incremental energy savings as higher insulation levels were installed.

\section{CONCLUSIONS AND IMPLICAIIONS}

This study produced cost-effectiveness results for electrically heated hones, both through retrofit and new home upgrades, and supply curves for the potential resource available through new home upgrades. Because it relied to a large extent on empirical data, this work led to insights about existing analysis techniques and the development of new techniques. It provided the first estimates of manufactured home levelized costs for the Bonneville region based in part on empirical energy and cost data. It also raised issues about the role of empirical analysis in policy making and planning.

This analysis required the development of several new tools and approaches that were specifically needed because of the research goals and the diversity of the data sources. These tools augment existing analytic tools for the study of manufactured homes in the region, but may have applications to other housing types and regions as well.

By comparing PRISH heating component estimates with measured heating energy consumption data, we found that PRISM typically overestimates space heating consumption. The overestimate is more for homes, such as energyefficient homes, that use a relatively small share of their total electrical energy for space heating. Conversely, PRISM tends to underestimate space heating in homes that use a significant share of their energy for heating. Because of the relationship between the error in PRISM estimates and the level of space heating consumption, unadjusted PRISM results are 1 ikely to underestimate energy savings due to improvements in building efficiency. 
We have developed a technique for adjusting the split between the heating and base loads estimated by PRISM so that heating estimates agree better with actual data, particularly for homes that consume relatively little energy for heating. This methodology requires limited information, primarily weather data and the PRISM estimates. He also demonstrated that heating degree-day (HDD) based methods, such as PRISM, fail to account for significant effects of weather variables other than HDD when extrapolating results to different climate zones. We developed a correction for going from one climate zone to another that is positively related to the change in HDD and temperature swing, and negatively related to the change in insolation.

To estinate energy savings, we developed a relationship between changes in heating energy consumption and design UA. A linear fit between heating energy consumption and design UA fit the available measured energy data well.

By applying our methodology to new homes in the region, we demonstrated both the technical and economic feasibility of a wide range of ECMs. Levelized costs were typically lower in double-wide than single-wide homes, both because of the larger size of double-wide homes and lower prices (per unit area) at the retail level. As a result of the more severe weather conditions, levelized costs in MCS climate zone 2 were about $25 \%$ less than those in climate zone 1 , and costs in climate zone 3 were about 33\% 10wer than in climate zone 1.

Using the levelized cost of a new coal plant as the test of costeffectiveness, R-30 ceiling insulation and R-18 wall insulation were costeffective in new homes on an incremental levelized cost basis (i.e., based on cost and savings relative to the next less efficient ECM level) throughout the region. Storm windows were also cost-effective throughout the region, but the levelized costs of thermally improved metal windows, storm doors, and tight infiltration packages were well above the coal plant levelized cost. Using the $40 \mathrm{mills} / \mathrm{kWh}$ criterion and the average levelized cost (based on the total cost and savings to go from current practice to a given ECM level), rather than the incremental levelized cost, several additional ECMs were cost-effective. In double-wide homes, R-38 ceiling insulation was costeffective in all climate zones. R-26 wall insulation was nearly costeffective (levelized cost was less than 43 mills/kWh) and R-30 floor 
insulation was cost-effective in all climate zones. The thermally-improved metal window plus storm, however, was still not cost-effective by itself.

Bonneville has recently included manufactured housing in its Super Good Cents Progran (SGCP). Our results and analysis of data from homes built to these requirements should provide a sound basis for determining the actual cost-effectiveness of energy-efficient manufactured homes.

Based on our analysis of the HRCP, retrofit installation costs were too high given the resulting energy savings to make the highest $R$-values and most window retrofits cost-effective. Selected retrofits, on the other hand, were cost-effective assuming 30-year 1ifetimes. The number of years a home was expected to last after being retrofit played a dominant role in determining the cost-effectiveness of retrofit measures.

The levelfzed costs of new home upgrades provided the basis for developing a conservation supply curve for new manufactured housing. He estimated savings of about 78 average 1 in the year 2007 for a levelized cost of $40 \mathrm{mill} / \mathrm{s} / \mathrm{kth}$ or less.

This study produced other important empirical findings. Our analyses indicated that the average heating energy savings for the Hood River manufactured homes were about $10 \%$ after retrofit. Measured temperature data indicated no statistically significant evidence that occupants "took back" part of their energy savings through higher temperatures.

Analyses of two sets of homes built to the MCS indicated they consumed considerably more energy for space heating than their design estimates. Both sets of MCS homes, however, consumed about one-third to one-half less than comparable current practice homes.

As in prior studies, we found "as-operated" UAs, calculated using a linear model, were lower than design UAs. Though this observation is due, in part, to the interaction and correlations between internal/solar gains and heating requirements, the effect is not completely understood.

He found that average inside air temperatures were considerably above $65^{\circ} \mathrm{F}$, the value often assumed in simulation analyses. The higher air temperatures can contribute significantly to differences between heating 
energy estimates based on simulations and those based on measured energy data.

This study raises policy and planning issues because it assesses costeffectiveness through an approach that takes advantage of empirical data. Bonneville and the Northwest Power Planning Council typically utilize models to estimate conservation energy savings for policy and planning purposes. The modeling approach has the virtue of allowing the analyst to vary assumptions about occupant behavior, trends, and other factors that directly affect forecast energy savings. Our approach, on the other hand, accounts for some of these factors as they are reflected in the empirical data. The empirical approach has the benefit of taking these factors into account, but has the limitation of being based on only a snapshot in time. Our analysis also is tied to households in a single geographic area whose representativeness for the Northwest is uncertain.

Though the energy savings required considerable analysis to estimate, they are based in part on empirical data and a relatively simple and physically reasonable model of space heating energy consumption. The large amount of data underlying the estimates and the generally good fits to the data are solid evidence that the approach is reliable for the situations analyzed. This study constitutes a step toward integrating analysis of empirical data with the planning and policy making process. We recommend, however, due to the limitations of either the modeling or empirical approaches alone, that an analytic approach based on both techniques be pursued in the future to address questions related to the cost-effectiveness of conservation measures. 


\section{CONIEIS}

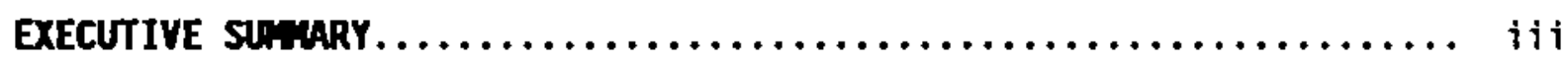

1.0 INTRODUCTION.,...................................... 1

1.1 BACKGROUND AND CONTEXT $. \ldots \ldots \ldots \ldots \ldots \ldots \ldots \ldots \ldots \ldots \ldots \ldots, 1.1$

1.2 RESEARCH GOALS AND OBJECTIVES $\ldots \ldots \ldots \ldots \ldots \ldots \ldots \ldots \ldots \ldots, 1.3$

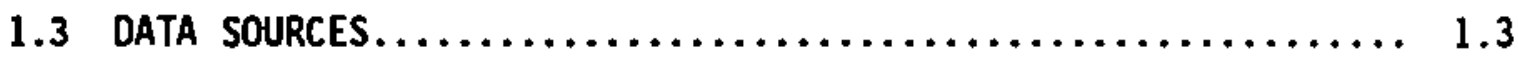

1.4 ANALYSIS APPROACH..............................

1.5 ORGANIZATION OF. REPORT $\ldots \ldots \ldots \ldots \ldots \ldots \ldots \ldots \ldots \ldots \ldots \ldots, 1.6$

2.0 DATA BASE DESCRIPTIONS $\ldots \ldots \ldots \ldots \ldots \ldots \ldots \ldots \ldots \ldots \ldots \ldots, 2.1$

2.1 TULALIP HOMES $. \ldots \ldots \ldots \ldots \ldots \ldots \ldots \ldots \ldots \ldots \ldots \ldots \ldots \ldots \ldots \ldots \ldots \ldots \ldots, 2.1$

2.1.1 Characteristics Data........................ 2.1

2.1.2 Billing and Weather Data....................... 2.4

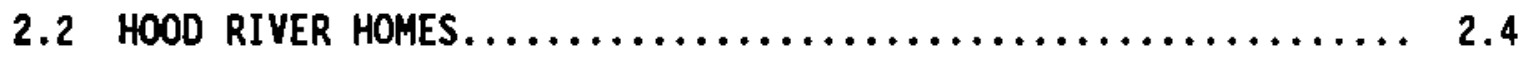

2.2.1 Characteristics Data....................... 2.4

2.2.2 Billing and Weather Data...................... 2.5

2.2.3 End-Use Monitored Manufactured Homes............. 2.5

2.3 ELCAP END-USE METERED MANUfACtUREd hOMES $\ldots \ldots \ldots \ldots \ldots \ldots \ldots 2.6$

2.3.1 Characteristics of the ELCAP Manufactured Homes...... 2.6

2.3.2 Consumption Data For the ELCAP Manufactured Homes..... 2.9

3.0 METHODOLOGY TO CALCULATE BUILding LOAD COEFFICIENT (UA) $\ldots \ldots \ldots 3.1$

3.1 CALCULATION OF CEILING UA......................... 3.2

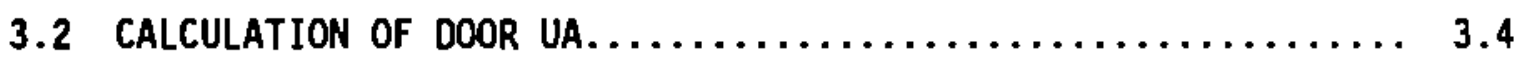

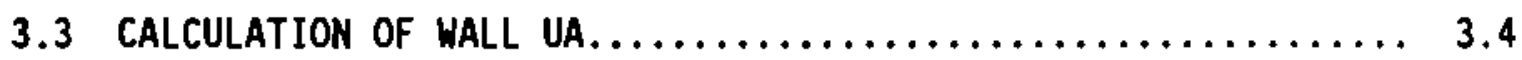

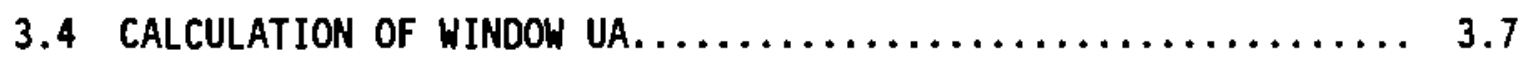

3.5 CALCULATION OF FLOOR UA............................

3.6 CALCULATION OF INFILTRATION UA....................... 3.11 


\section{CONTENTS (continued)}

3.7 HRCP MANUfaCtURED hOME Ua CALCULATIONS $\ldots \ldots \ldots \ldots \ldots \ldots \ldots \ldots . .13$

4.0 PRISH ANALYSIS AND ADJUSTMENT OF PRISH ESTIMATES, .......... 5.1

4.1 PRISH METHODOLOGY................................. 4.1

4.2 AMALYSIS. $\ldots \ldots \ldots \ldots \ldots \ldots \ldots \ldots \ldots \ldots \ldots \ldots \ldots \ldots \ldots \ldots, 4.2$

4.2.1 PRISM Results for Tulalip Homes................ 4.3

4.2.2 PRISH Results for Hood River Homes.............. 4.4

4.3 COMPARISON OF PRISH ESTIMATES MITH ACTUAL HEATING LOADS..... 4.6

4.4 ADJUSTMENT OF PRISM HEATING COMPONENT HITHIN CLIMATE ZONE... 4.11

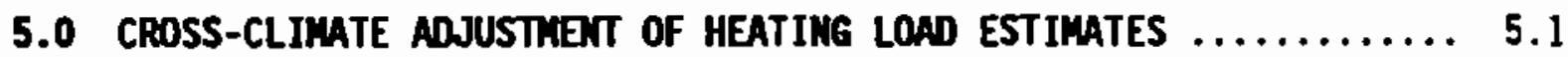

5.1 INTRODUCTION.................................... 5.1

5.2 POTENTIAL ERROR OF PRISM BASED HEATING LOAD PREOICTIONS...... 5.2

5.3 METHODOLOGY FOR TESTING CROSS-CLIMATE PREDICTIONS.......... 5.4

5.4 ERROR INTRODUCED BY HDD EXTRAPOLATION METHOD............ 5.9

5.5 GRAPHICAL ANALYSIS OF Climate ParAMETERS.............. 5.11

5.6 ADJUSTMENT OF HEATING LOAD BASED ON REGRESSION ANALYSIS..... 5.19

5.7 REGRESSION RESULTS $\ldots \ldots \ldots \ldots \ldots \ldots \ldots \ldots \ldots \ldots \ldots \ldots \ldots \ldots, 5.22$

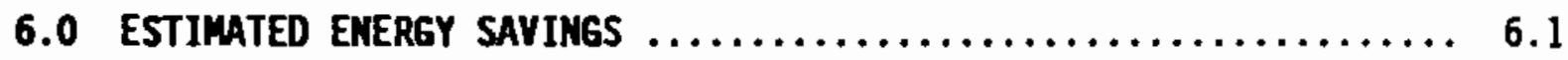

6.1 INTROOUCTION..................................... 6.1

6.2 APPROACH USED TO ESTIMATE ENERGY SAVINGS $\ldots \ldots \ldots \ldots \ldots \ldots \ldots, 6.1$

6.3 INITIAL WHOLE-HOUSE RESULTS $\ldots \ldots \ldots \ldots \ldots \ldots \ldots \ldots \ldots \ldots, 6.2$

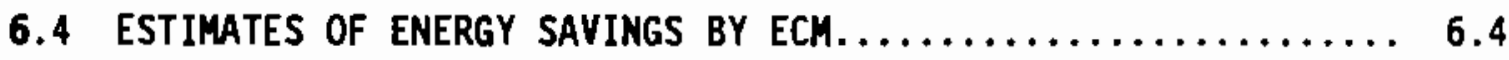

6.4.1 Variations in Energy Savings Across Components....... 6.4

6.4.2 Possible Non-Linear Effects of UA on Heating Energy Consumption............................... 6.8

6.4.3 Estimation of ECM Energy Savings............... 6.9 
CONTENTS (cont inued)

7.0 LEVELIZED COST AND SUPPLY CURYE AMALYSES, $\ldots \ldots \ldots \ldots \ldots \ldots \ldots, 7.1$

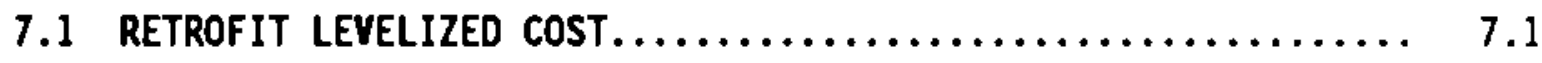

7.1.1 Retrofit Installation Cost Estimation............. 7.1

7.1 .2 Levelized Cost Methodology................... 7.6

7.1.3 Retrofit Analysis Results and Implications......... 7.6

7.1.4 Discussion of Retrofit Results................. 7.10

7.2 NEM HOME LEVELIZED COSTS ANO SUPPLY CURVES............. 7.11

7.2.1 Methodology and Assumptions................... 7.11

7.2.2 Energy Conservation Measures and First Costs........ 7.12

7.2.3 Levelized Costs and Supply Curve............... 7.16

7.3 COMPARISON OF RETROFIT AND NEW HOHE UPGRADE RESULTS........ 7.24

8.0 STUDY FIRDIMGS AND RESEARCH RECOHEMDATIONS............... 8.1

8.1 RESEARCH FINDINGS ANO CONCLUSIONS.................... 8.2

8.1.1 Levelized Costs and Conservation Supply Curve....... 8.2

8.1.2 Other Analytic Results and Findings............. 8.4

8.2 RESEARCH ISSUES ANO RECOHENDATIONS,................. 8.8

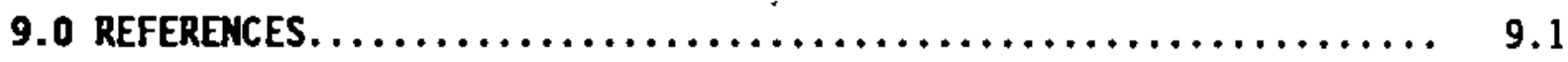

APPENDIX A - AMALYSIS OF ELCAP AND HOOD RIVER ERD-USE DATA......... A.1

APPENDIX B - PRISH HEATING COMPONENT ADJUSTTENT WITHIN CLIMATE ZONE. . B.1 


\subsection{INTRODUCTION AND OVERVIEW}

This report presents the results of a study of the energy consumption characteristics of HUD-code manufactured homes in the Northwest. The study was conducted for the Bonneville Power Administration (Bonneville) by the Pacific Northwest Laboratory (PNL) with the purpose of assessing costeffectiveness of conservation upgrades in these dwellings. This first section provides the context for the study, the objectives, data sources, and analytic approach.

\subsection{BACKGROUND AND CONTEXI}

Since 1976 the U.S. Deparment of Housing and Urban Development (HUD) has preemptively regulated construction of manufactured homes under the federal Manufactured Home Construction and Safety Standards. The Standards require that all new manufactured homes meet energy performance criteria. These standards, however, have been largely unchanged since 1976, while state standards for site-built homes have become more stringent over the last 10 years. A recent study indicates that, in the Northwest, application of existing state standards for site-built housing, rather than the HUD code, would increase first costs to home buyers by some $\$ 1000$, but would decrease energy consumption enough to more than offset the increase in first costs and reduce 1 ife cycle costs by about $\$ 1000$ (Nesse et al. 1988). Improved energy efficiency in manufactured homes would decrease overall costs to buyers and occupants, reduce demand for electricity, and reduce the disparity in therma 1 characteristics and energy consumption between site-built and manufactured homes.

Bonneville recognizes the importance of the energy consumption characteristics of HUD-code manufactured homes (often referred to, simply, as mobile homes or manufactured homes). Manufactured housing represents a significant component of the new housing market in the Northwest. In 1984, manufactured homes represented over $21 \%$ of new single-family housing starts (Hendrickson et al. 1985). The share of multi-wide manufactured homes sited in the region has increased substantially in recent years, so that in 1986 about $80 \%$ of the homes were multi-wide homes (NCSBCS 1987). Multi-wide 
homes are typically larger than single-wide units, with floor areas comparable to conventional site-built housing. High market share combined with large square footage increases the impact of manufactured homes on Bonneville's electric load.

The preemptive nature of the HUD code, however, prevents implementation of local codes that would require increased efficiency in manufactured homes. The Model Conservation Standards (MCS) developed by the Northwest Power Planning Council (the Council) were designed to increase the efficiency of new housing in the region to regionally cost-effective levels. The code prescribes requirements for new homes that vary by climate zone. The MCS defines three climate zones based on heating degree-days (HDD, relative to a base temperature of $65^{\circ} \mathrm{F}$ ) as follows: climate zone 1 has 6,000 HDD or less; climate zone 2 has more than 6,000 HDD, but no more than 8,000 HDD; and cl imate zone 3 has more than 8,000 HDD. In our analysis, we use Seattle, WA to represent climate zone 1; Spokane, WA to represent zone 2; and Missoula, MT to represent zone 3.

The HUD regulations, however, prevent direct application of the MCS to new manufactured homes. Under current conditions, new manufactured housing represents a significant lost opportunity for energy conservation in the Bonneville region.

In recognition of the importance of improving the efficiency of manufactured homes, Bonneville has embarked on a multi-faceted program to encourage efficiency improvements in this housing sector. One facet of this program is to improve the understanding of manufactured homes' characteristics and their role in the housing market so effective programs can be designed and implemented to reach consumers, manufacturers, and dealers. The research described in this report addresses another specific objective related to the program's overall goal, and that is to determine the energy consumption of manufactured homes and the cost-effectiveness of efficiency upgrades.

The results presented here are based on measured data, largely from existing research programs. Our results are an effort to use measured data to analyze conservation cost-effectiveness. Most of the energy data have been obtained from homes that represent current construction practices rather 
than higher efficiency levels. Bonneville has initiated a Residential Construction Demonstration Program (RCDP) that will collect cost and energy data on manufactured homes built to the MCS. Information collected under that program will provide the basis for improved estimates of conservation cost-effectiveness.

\subsection{RESEARCH GOALS AND OBJECTIVES}

This research has three major goals related to determining the costeffectiveness of energy efficiency improvements in manufactured housing: 1) estimate levelized costs for retrofitting existing manufactured homes to increase their efficiency, 2) estimate levelized costs for upgrading new manufactured homes, and 3) develop a supply curve relating energy savings in new manufactured homes to the consumer cost of upgrading their efficiency.

The project has been designed to satisfy these goals through several research objectives. The research objectives include:

- determine which energy features of new manufactured homes typify current construction practice and identify recent trends (see results reported in Harkreader, Lee, and Sherman 1987);

- determine manufacturers' costs for adding energy conservation measures (ECMs) to their new homes;

- determine consumer costs of ECMs;

- determine costs to retrofit existing manufactured homes;

- determine changes in the energy consumption of new manufactured homes that result from adding ECMs to homes built to current practice; and

- determine changes in the energy consumption of homes that have been retrofit with ECMs.

\subsection{DATA SOURCES}

During the design of this project, Bonneville emphasized the importance of relying on existing data to the maximum extent practicable to meet the research goals and objectives. Several recent Bonneville projects have 
provided extensive data on the characteristics and performance of residential buildings, including manufactured homes. This study relies on data derived from four different projects: 1) Hood River Conservation Project (see for example, BPA 1987), 2) Tulalip energy-efficient manufactured housing project (Onisko 1986), 3) MCS manufactured home pilot project (Lee et al. 1986), and 4) the End-Use Load and Consumer Assessment Progran, ELCAP (Tomich and Schuster 1985).

The Hood River Conservation Project (HRCP) is a large project undertaken to test the reasonable upper liaits of a residential weatherization retrofit progran. The project installed as many cost-Justiffed ECMs in as many electrically heated homes in Hood River, Oregon, as possible. About 3,200 households participated. PNL obtained machine-readable HRCP data from both Oak Ridge National Laboratory (ORNL) and Pacific Power and Light (PP\&L), and extracted the data for manufactured homes included in the sample. of the 3,200 homes in the project, a large proportion - 594 or approximately $18 \%$ are manufactured homes. Billing data are available for all of these homes for several years prior to conservation retrofits and for about one year after retrofit. In addition, end-use load data for space heat, water heat (or wood stove use), and total load are available on approximately 60 homes that were subnetered about one year before and one year after retrofit. In sum, we have billing data on nearly 600 manufactured homes located in the Hood River area, before and after retrofit, and space heating energy consumption data on a subset of about 60 homes.

The Tulalip project consists of 34 new manufactured homes bujlt to the MCS for climate zone 1. They are all located in Marysville, Mashington, and each is equipped with a conventional electric meter to measure whole-house electricity consumption, and a meter to measure heating energy use alone. Weekly data covering a one-year period were available for this analysis.

In the MCS pilot project, five new manufactured homes were built to the MCS; at least one home was manufactured for each of the three MCS climate zones. They were monitored for a short period, while unoccupied, with ELCAF data loggers and the results of that analysis are reported in Lee et al. (1986). After being moved, sited, and occupied, four of the homes have beer 
submetered under ELCAP for various lengths of time up to 1 year, and we have end-use data for these homes.

The ELCAP sample includes an additional 10 manufactured homes of different vintages, taken from the existing stock and sited at various locations throughout the region. More than a year of end-use level data for these homes are available.

\subsection{ANALYSIS APPROACH}

One of the major challenges of this study has been to develop an approach to integrate the available data sources and produce meaningful results. Most of the energy data are from homes for which only billing data are available. Triple-metering of a subset of the HRCP homes and doublemetering of the Tulalip hones, however, has provided essential information that has permitted calibration and extrapolation of results based on data from the large majority of the homes for which only billing data are avatlable. The methodology (see Appendix A) developed by PNL in an earlier study (Drost et al. 1986) has been applied to ELCAP and Hood River homes for which high-resolution end-use metered data were avallable. This methodology was applied previousiy to the Residential Standards Demonstration Program (RSDP) homes and is referred to here as the "PNL RSDP" methodology.

However, our analysis has relied primarily on billing data and the PRISM model (Goldberg 1982): both because most of the homes had only billing data available and because Bonneville has a strong interest in future analysis of billing data. The PRISM model utilizes billing data and weather data to estimate base load and heating (temperature-sensitive) load in residences and provides a basis for extrapolating to other climate zones or weather years. Many anaiysts have noted, however, that while PRISM typically produces a good estimate of total household energy consumption, it frequently fails to estimate heating and base loads accurately. Further, its ability to extrapolate estimates to different climate zones is in doubt because of its strict reliance on changes in heating degree-days (HDD) to characterize climate variations.

The PNL RSDP methodology demands daily average end-use data, but is likely to better characterize and estimate energy consumption than a method 
that relies on whole-house, monthly data. Unfortunately, the number of manufactured homes for which detailed end-use data were available was very small, and many of them used supplemental wood heat, which excluded them from this analysis. We applied the PNL RSDP methodology to the end-use metered homes primarily to test the application of the technique to manufactured homes and compare the results with other analytic techniques.

This study establishes a relationship between energy conservation measures installed in manufactured homes and resultant changes in their heating energy consumption. This relationship is based on actual billing and electric heating data for homes in the samples and on the building load coefficient (UA) for the same homes. He developed and applied a technique to improve heating energy consumption estimates based on the billing data.

A figure (1.1) showing the flow of the analysis identifies the three data sets used and the methodologies developed and applied. The flow chart also indicates the process employed to estimate the change in space heating consumption due to each energy conservation measure (ECM). The number of homes in each data set is indicated, but a significant proportion of each data set was eliminated from analysis due to incomplete data or confounding factors (such as wood heat use). Note that the Hood River homes provided data both before and after retrofit, so each home had the potential to provide two data points.

\subsection{ORGANIZATION OF REPORT}

Section 2 describes in more detail the housing samples used. All samples contained good information on building characteristics which allowed us to estimate the design UA for each home. Section 3 describes the methodology developed to calculate load coefficients for each component (the average $U$-value for the component times $i t s$ area) and the building load coefficient (total UA).

Section 4 presents the PRISM analysis of the HRCP and Tulalip homes. We had anticipated, based on prior studies, that the PRISM Split between base load and heating load would require adjustment to provide sufficiently accurate results for this study. Section 4 briefly discusses a methodology 
developed to adjust PRISM heating energy estimates within the $\mathrm{climate}$ zone analyzed and presents adjusted estimates of heating energy consumption.

Since both the PRISM and the PNL-developed methodologies rely strictly on heating degree-days to extrapolate estimates to other climate zones, they ignore the effects of variations in insolation on space heating. Section 5 presents a generic technique developed for correcting the climate zone extrapolations to include solar and other effects. Section 6 applies these climate zone adjustments to extrapolate the energy consumption results to climate zones 2 and 3.

Section 7 integrates the energy consumption information with economic data to estimate levelized costs and supply curves for energy conservation measures throughout the region. It provides an indication of the levelized costs of retrofitting homes located in Hood River.

The last section presents the study's findings, conclusions and reconnendations.

Appendix A discusses the PNL methodology developed to analyze the RSDP data and presents the results of applying it to the end-use metered homes in our samples. Appendix B presents a detalled description of the methodology developed to adjust PRISM heating component estimates within a given climate zone. 
TULALIP HOMES

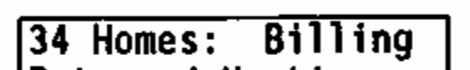

Data and Heating

Data

Billing Data $\checkmark$

PRISM Analysis

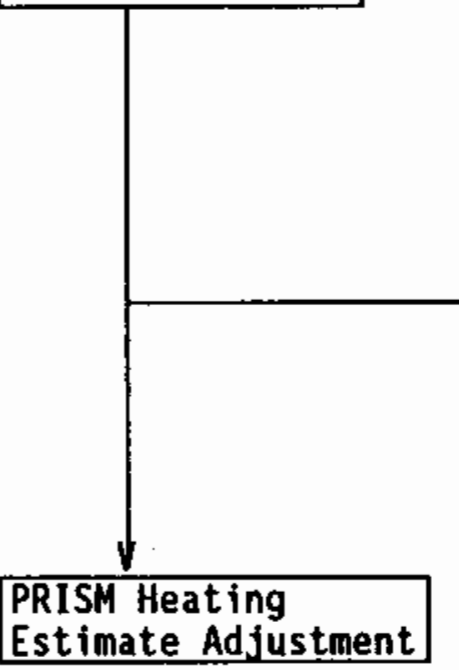

HOOD RIVER HOMES

594 Homes: Billing

Heating Data

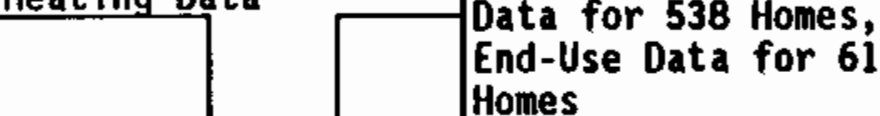
Homes

End-Use Data Billing Data

PRISM Analysis

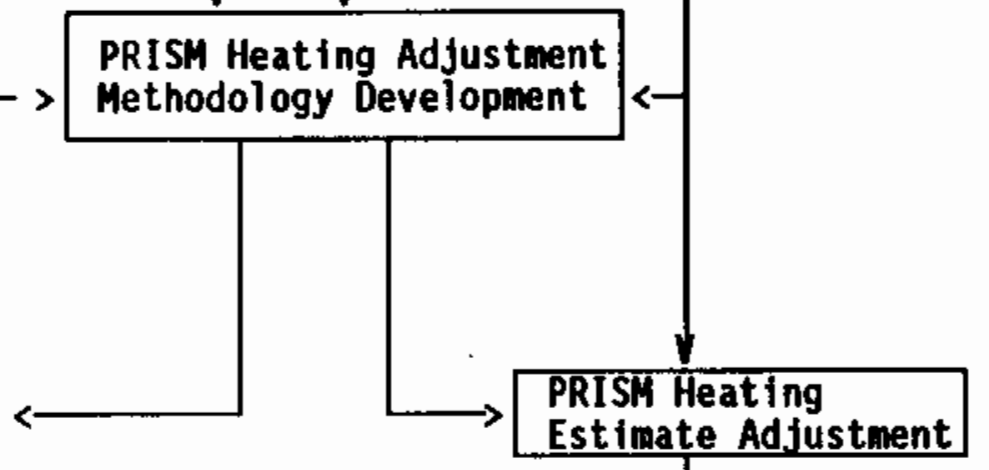
$\begin{aligned} & \text { SUNCODE Cl imate } \\ & \text { Adjustment Development }\end{aligned}>>\begin{aligned} & \text { Climate Adjust } \\ & \text { Results }\end{aligned}$
End-Use

Data
ELCAP BASE AND

MCS HOMES

15 End-Use Metered Homes, 10 Current Practice, 5 MCS

Homes

End-Use

Data

PNL RSDP Analysis

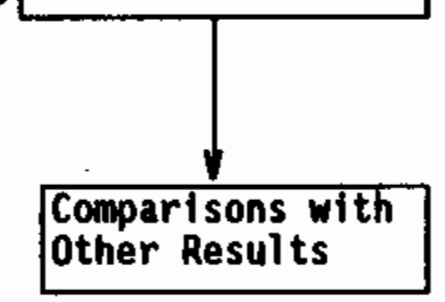

Develop and Apply

Design UA Calculation

Methodology 


\subsection{DATA BASE DESCRIPTIONS}

Bonneville has collected extensive data on energy use and housing and occupant characteristics for several sets of electrically heated manufactured homes (see Figure 1.1). The HRCP set of homes was part of a larger set of both site-built and manufactured homes that were weatherized and were all located in the Hood River, Oregon area. The Tulalip set of homes was part of a demonstration profect sponsored by Bonneville to evaluate the performance of new manufactured homes built to meet the MCS. They were all sited near Marysville in western Hashington. Two sets of homes were monitored under the ELCAP - base case homes taken from the existing building stock and new homes built to the MCS as part of Bonneville's manufactured homes pilot project. Though the various homes were scattered throughout Bonneville's service territory, nearly all the usable data cane from sites located within climate zone 1.

The HRCP data were provided by Oak Ridge National Laboratory (ORNL) and PP\&L. The data were provided on a tape that was converted to PNL format and entered into a PNL data base. Richard Goeltz of ORNL and Karen Schoch of PP\&L provided information for interpreting the Hood River data. Bonneville provided the Tulalip data, which were available in tabular form. Sheila Riewer of Bonneville assisted with the interpretation of those data. PNL collected the data for the ELCAP homes and maintained it in a magnetic format. PNL screened all data for quality control. Some homes were el iminated from the analyses, particularly those with wood heat use, as described in subsequent sections.

\subsection{TULALIP HOMES}

Two types of data were available for the 34 Tulalip homes: energy use data and characteristics data. Characteristics data included information on the structure and on the occupants. Energy use data were derived from billing records and weather data.

\subsubsection{Characteristics Data}

The Tulalip homes are newly-constructed, highly-insulated, all-electric homes that were designed to meet the requirements of the MCS. Three 
different designs were built, all with the same insulation levels, but with some differences in window glazing and floor area. Detailed characteristics of each model are given in Table 2.1. These homes were set up in a small manufactured home park on the Tulalip Indian Reservation. All were first occupied between June and July 1986.

Records were available on the dates of occupancy, total number of occupants, and number of occupants by age category. There was a change of occupants in six of the homes during the study period. The orientation of the homes as set up in the park was inferred from examining a plat of the park. All of the homes were equipped with woodburning equipment, but 24 of the 34 occupants efther signed an agreement to not burn wood (and did not) or simply happened not to burn wood during the 1-year study period. Information on occupant characterịtics for each home is shown in. Table 2.2. The table indicates among other things whether the occupant planned to burn wood, the distribution of occupants by age, and whether one or more occupants would normally be home during the day.

\section{Iable 2.1. Tulalip Manufactured Home Characteristics}

Model 1: 4 bedroom, 1190 sq. ft., $24^{\prime} \times 52^{\prime}$

R-19 wall insulation

$R-38$ ceiling insulation

R-30 floor insulation

3 pane $w /$ thermal break windows

Model 2: 3 bedroom, 1050 sq. ft., $24^{\prime} \times 48^{\prime}$

R-19 wall insulation

$R-38$ ceiling insulation

R-30 floor insulation

2 pane $w /$ thermal break windows

Model 3: 2 bedroom, 850 sq. ft., $24^{\prime} \times 38^{\prime}$

R-19 wall insulation

R-38 ceiling insulation

R-30 floor insulation

2 pane $w /$ thermal break windows 
Iable_2.2. Tulalip Home Occupant Characteristics(a)

\begin{tabular}{|c|c|c|c|c|c|c|c|c|}
\hline $\begin{array}{l}\text { House } \\
\text { ID }\end{array}$ & $\begin{array}{l}\text { Burn } \\
\text { Wood? }\end{array}$ & $\begin{array}{l}\text { Area, } \\
\text { Sq. Ft. }\end{array}$ & $\frac{10 \mathrm{cel}}{<13}$ & $\begin{array}{l}\text { ants } \\
\text { n Year } \\
13-59\end{array}$ & $\begin{array}{l}\text { y Age } \\
\text { s } \\
59\end{array}$ & $\begin{array}{l}\text { Home } \\
\text { During } \\
\text { Day? }\end{array}$ & $\begin{array}{l}\text { Date } \\
\text { Moved } \\
\text { In }\end{array}$ & $\begin{array}{l}\text { Home } \\
\text { Orientation }\end{array}$ \\
\hline $\begin{array}{l}506 \\
2402 \\
2404 \\
2510 \\
2510^{\star} \\
2516 \\
2524 \\
2524^{\star} \\
2532 \\
2600 \\
2601 \\
2611 \\
2705 \\
2706 \\
2714 \\
2717 \\
2722 \\
2722^{\star} \\
2725 \\
2730 \\
2730^{\star} \\
2731 \\
2731 \star \\
2810 \\
2812 \\
2828 \\
2828 \star \\
6420 \\
6429 \\
6431 \\
6432 \\
6502 \\
6505 \\
6506 \\
6508 \\
6511 \\
6512 \\
6515 \\
6516 \\
6518\end{array}$ & $\begin{array}{l}N \\
Y \\
N \\
Y \\
Y \\
Y \\
N \\
Y \\
N \\
N \\
Y \\
Y \\
N \\
Y \\
N \\
N \\
N \\
N \\
N \\
N \\
N \\
N \\
N \\
N \\
Y \\
N \\
N \\
N \\
N \\
N \\
N \\
N \\
Y \\
Y \\
Y \\
N \\
Y \\
Y\end{array}$ & $\begin{array}{r}1190 \\
850 \\
1050 \\
850 \\
\\
850 \\
850 \\
\\
850 \\
850 \\
1050 \\
1190 \\
1050 \\
850 \\
1050 \\
1050 \\
1050 \\
1050 \\
1050 \\
1050 \\
850 \\
850 \\
850 \\
1190 \\
1050 \\
1050 \\
1190 \\
1050 \\
1050 \\
1190 \\
1050 \\
1050 \\
1050 \\
1050 \\
1050 \\
1050\end{array}$ & $\begin{array}{l}2 \\
3 \\
2 \\
2 \\
2 \\
1 \\
2 \\
0 \\
1 \\
0 \\
3 \\
4 \\
0 \\
2 \\
3 \\
2 \\
3 \\
3 \\
4 \\
2 \\
1 \\
3 \\
0 \\
1 \\
0 \\
0 \\
2 \\
2 \\
1 \\
4 \\
0 \\
0 \\
3 \\
3 \\
1 \\
2 \\
3 \\
2 \\
0\end{array}$ & $\begin{array}{l}2 \\
1 \\
2 \\
3 \\
3 \\
1 \\
1 \\
2 \\
2 \\
3 \\
1 \\
2 \\
1 \\
2 \\
2 \\
2 \\
2 \\
1 \\
2 \\
1 \\
2 \\
2 \\
0 \\
2 \\
0 \\
1 \\
3 \\
2 \\
1 \\
2 \\
2 \\
3 \\
1 \\
2 \\
2 \\
2 \\
2 \\
2 \\
3\end{array}$ & $\begin{array}{l}0 \\
0 \\
0 \\
0 \\
0 \\
0 \\
0 \\
0 \\
0 \\
0 \\
0 \\
0 \\
1 \\
0 \\
0 \\
0 \\
0 \\
0 \\
0 \\
0 \\
0 \\
0 \\
1 \\
0 \\
1 \\
0 \\
1 \\
0 \\
0 \\
0 \\
0 \\
0 \\
0 \\
0 \\
0 \\
0 \\
0 \\
0 \\
0\end{array}$ & 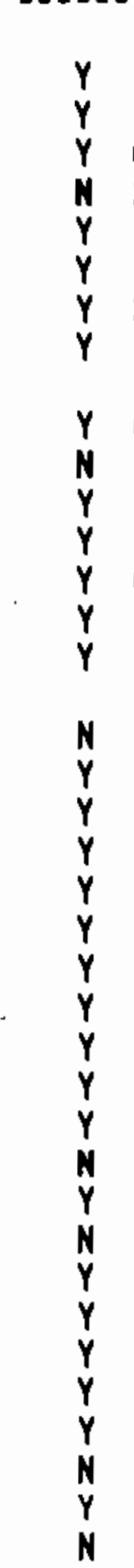 & $\begin{array}{r}6 / 7 / 86 \\
6 / 7 / 86 \\
6 / 20 / 86 \\
2 / 20 / 87 \\
6 / 7 / 86 \\
6 / 7 / 86 \\
2 / 20 / 87 \\
6 / 7 / 86 \\
6 / 7 / 86 \\
6 / 17 / 86 \\
6 / 7 / 86 \\
6 / 7 / 86 \\
6 / 7 / 86 \\
6 / 21 / 86 \\
6 / 7 / 86 \\
6 / 7 / 86 \\
1 / 16 / 87 \\
6 / 7 / 86 \\
6 / 7 / 86 \\
1 / 8 / 87 \\
6 / 7 / 86 \\
9 / 23 / 86 \\
6 / 7 / 86 \\
6 / 21 / 86 \\
6 / 18 / 86 \\
12 / 6 / 86 \\
6 / 13 / 86 \\
6 / 7 / 86 \\
6 / 8 / 86 \\
7 / 11 / 86 \\
6 / 7 / 86 \\
6 / 7 / 86 \\
6 / 9 / 86 \\
6 / 7 / 86 \\
6 / 7 / 86 \\
6 / 7 / 86 \\
6 / 7 / 86 \\
6 / 7 / 86 \\
6 / 7 / 86\end{array}$ & $\begin{array}{l}N-S \\
N-S \\
N-S \\
N-S \\
N-S \\
N-S \\
N-S \\
N-S \\
N-S \\
E-W \\
N-S \\
N-S \\
N-S \\
N-S \\
N-S \\
N-S \\
N-S \\
E-W \\
N E-S W \\
N-S \\
N E-S W \\
E-W \\
E-W \\
E-W \\
E-W \\
E-W \\
E-W \\
E-W \\
E-W \\
E-W \\
E-W \\
E-W \\
E-W\end{array}$ \\
\hline
\end{tabular}

(a) * indicates that data are for new occupants in house previously listed. Several pieces of data were missing for home $\# 506$. 


\subsubsection{Billing and Weather Data}

The Tulalip homes were equipped with two standard utility-grade electrical meters for monitoring total energy use and the space heating load. The meters were read weekly by an employee of the Tribal Housing Authority: Even though weekly meter readings were available, only 12 meter readings: closest to the first day of each month were selected for use in the analysis. Previous studies have shown that the PRISM energy analysis methodology is most reliable when used with monthly billing data spanning a single 12-month period (Rachlin et al. 1986). A preliminary comparison of the results of PRISM analysis for these homes using billing data at both weekly and monthly resolution suggested there was no improvenent in the results with the higher resolution data, and the additional effort required to process the weekly data was not justified.

The daily average outdoor temperature data for Tulalip homes came. froman ELCAP weather station located in Bothe11, Mashington, approximately 29 . miles south of where the homes were sited. The Seattle Typical Meteorological Year (TMY) data were used for the long-term historical temperature data needed in the normalized energy consumption calculations.

\subsection{HOOD RIVER HOMES}

This section describes the HRCP manufactured home data sets used in our analysis. Extensive characteristics data were available for each home. Utility billing data over several years were available for all the homes, and detailed end-use metered data were available for a subset of about $10 \%$ in: the homes.

\subsubsection{Characteristics Data}

The HRCP characteristics data base included information on occupants, home size, year of manufacture, Energy Conservation Measures (ECM) before and after retrofit, and costs of retrofits. The ECM data were used to estimate UA values of the individual components and the total building design (see Section 3). The cost data were used to analyze the cost-effectiveness of retrofitting the homes; this analysis is reported in Section 7.2.

The ECM data were derived from two sources: 1) an audit conducted on each home to provide pre-retrofit data, and 2) documented modifications made 
to each home during retrofit to provide post-retrofit data. These data included information on walls, floors, ceilings, windows, doors, and infiltration control measures. Information on each component was disaggregated to allow for multiple types of each component in a given home. For example, up to 10 ceiling categories are provided in the data base to reflect the different types of ceilings that might be found in different sections of a dwelling, such as with or without an attic, with wood or asphalt shingles, etc. Fortunately, most of the manufactured homes were represented in only one category for each building component.

\subsubsection{Billing and Weather Data}

Billing data for up to 538 manufactured homes located in or near Hood River, Oregon were available from the HRCP for the 4-year period from June 1982 to June 1986. The data were divided into annual analysis periods beginning in June of each year. Homes were systematically retrofitted with weatherization measures during the summer of 1985, so 3 years of pre-retrofit billing data and 1 year of post-retroftt data were available for analysis.

Daily average outdoor temperatures for the Hood River homes were available from the Hood River Experiment Station for the 10-year period July 1977 through June 1986. Additional weather data were collected as part of HRCP, but because of extensive periods of missing data, the data were judged to be unacceptable for use in the PRISM analysis.

\subsubsection{End-Use Monitored Manufactured Homes}

To better evaluate installed conservation measures, 61 of the Hood River manufactured homes were end-use metered. Data were collected at fifteenminute intervals on total loads, space heating and, in most cases, water heating electrical consumption. In 18 of the homes, data from a woodstove sensor were collected rather than hot water consumption data; the magnitude of the woodstove sensor signal was related to the heat output of the woodstove. In addition, all the end-use metered homes had inside temperatures recorded at the same time intervals.

Between the spring and late fall of 1985, a variety of conservation measures was installed in these homes. These measures were designed to improve the thermal performance of the structure's envelope. End-use metered data were collected both before and after installation of these retrofit 
measures for at least one heating season. These data make it possible to compare changes in the "as-operated" thermal performance of the structures before and after installation of the particular package of ECMs appl ied to each site.

The thermal performance of these'homes was characterized during the heating seasons of 1984-85 and 1985-86. Me excluded from our analyses those homes falling into one of three categories: 1) homes with too few data points available to characterize the heating requirements of the structure, 2) homes with essentially no electric heating on days that the wood stove was not used, and 3) homes whose space heating load was not a linearly increasing function of the inside-outside temperature difference for the structure. In the third case, the non-linearity of heating load as a function of outside temperature was usually due to strong dependence on supplementary fuel sources, such as wood. After excluding homes failing these tests, approximately half of the Hood River end-use metered homes had enough days' worth of data remaining to allow us to analyze space heating consumption and reliably characterize envelope performance.

\subsection{ELCAP END-USE METERED MANUFACTURED HOMES}

Fifteen manufactured homes were instrumented with a field data acquisition system developed for the ELCAP. This system provides detailed end-use consumption data. This set of homes comprises two subsets. Ten older homes were recruited as part of the ELCAP Residential Base Case Study. Five new homes were built as part of a research pilot project to study thermal performance and indoor air quality for manufactured homes built to the MCS for the three designated climate zones. The characteristics of these homes are described in Section 2.3.1. The associated electrical consumption data, collected as part of ELCAP, are described in Section 2.3.2.

\subsubsection{Characteristics of the ELCAP Manufactured Homes}

The 10 base case manufactured homes are located in the states of Washington, Oregon, and Idaho and represent climate zones 1 and 2. All of these manufactured homes were built after 1960, with two built after 1978 . The conditioned floor area for these homes ranges from around $900 \mathrm{sq}$. $\mathrm{ft}$. up to approximately $1,800 \mathrm{sq}$. $\mathrm{ft}$. The design UAs, based on an on-site inspection, vary from 225 to $742 \mathrm{BTU} / \mathrm{hr}-{ }^{\circ} \mathrm{F}$, neglecting the infiltration 
component. (See Section 3 for a description of design UA.) Most of these homes are served by private utilities, although a few public non-generating utilities provide service to a few homes. This information is summarized in Table 2.3 for each of the ten ELCAP base case study homes.

Table 2.3 also lists the type of permanent electrical space-heating equipment for the 10 homes. Most of these systems are forced air furnaces, with one home having no permanent electrical space-heating equipment at all. The four footnoted homes have no woodburning equipinent installed in the home, while the other six homes have a wood stove, wood furnace, or fireplace with an insert. Those six households with woodburning equipment report using it as the main source of heat for the structure. This was confirmed by the metered data as well. Of the 10 homes above, only the four sites reporting electricity as their main fuel source had sufficient heater usage reflected in the metered data to be characterized using the techniques described in Appendix A. One of these four sites lacked a reliable inside temperature sensor (site 209), which further reduced the sample of usable homes to three.

The other subset of ELCAP manufactured homes consists of five new homes built as part of a BPA study to investigate the thermal performance and indoor air quality of homes manufactured to the MCS. All five homes were

\section{IABLE 2.3. Characteristics of ELCAP Base Manufactured Homes}

\begin{tabular}{|c|c|c|c|c|c|c|}
\hline $\begin{array}{l}\text { MCS } \\
\mathrm{CZ}\end{array}$ & Region & Yintage & $\begin{array}{l}\text { Floor } \\
\text { Area, } \\
\text { soft. }\end{array}$ & $\begin{array}{l}\text { Design UA } \\
\text { Btu/hr/०F }\end{array}$ & $\begin{array}{c}\text { Utility } \\
\text { Type } \\
\end{array}$ & $\begin{array}{l}\text { Heating } \\
\text { Systen }\end{array}$ \\
\hline $\begin{array}{l}2 \\
2 \\
2 \\
2 \\
1 \\
1 \\
1 \\
2 \\
1 \\
1\end{array}$ & $\begin{array}{l}\text { E. Oregon } \\
\text { Idaho } \\
\text { Idaho } \\
\text { W. Oregon } \\
\text { W. Oregon } \\
\text { W. Oregon } \\
\text { E. Wash. } \\
\text { E. Oregon } \\
\text { W. Wash. } \\
\text { W. Wash. }\end{array}$ & $\begin{array}{l}1978+ \\
1960+ \\
1960+ \\
1960+ \\
1960+ \\
1960+ \\
1960+ \\
1960+ \\
1960+ \\
1960+\end{array}$ & $\begin{array}{r}1704 \\
1344 \\
1366 \\
1840 \\
1039 \\
952 \\
868 \\
1351 \\
1792 \\
889\end{array}$ & $\begin{array}{l}742 \\
370 \\
385 \\
451 \\
313 \\
290 \\
272 \\
459 \\
411 \\
225\end{array}$ & $\begin{array}{l}\text { Public } \\
\text { Private } \\
\text { Private } \\
\text { Private } \\
\text { Private } \\
\text { Private } \\
\text { Private } \\
\text { Public } \\
\text { Private } \\
\text { Public }\end{array}$ & $\begin{array}{l}\text { Baseboard } \\
\text { Forced Air } \\
\text { Forced Air } \\
\text { Forced Air } \\
\text { Heat Pump } \\
\text { Forced Air } \\
\text { Forced Air } \\
\text { None } \\
\text { Forced Air } \\
\text { Forced Air }\end{array}$ \\
\hline
\end{tabular}

(a) CZ indicates MCS climate zone. The design UA excludes infiltration.

(b) Only these homes had sufficient heating data available to perform the therma? analyses described in Appendix A. 
constructed by a single manufacturer and delivered in the spring of 1986 . These homes included both single- and double-wides, ranging in size from approximately 900 to $1800 \mathrm{sq}$. ft. At least one home was built to the requirements of each of the three climate zones. The UAs for these homes in Btu/hr- ${ }^{\circ} \mathrm{F}$ computed from building descriptions vary from 190 to approximately 340. (For a detailed description of the experiment conducted and methodology used to compute design UAs, see Lee et al. 1986.) All homes were equipped with forced air furnaces. This information is sumarized in Table 2.4.

These homes were set up initially in two Mashington state testing locations, Richland and Vancouver, and were first tested while unoccupied. During this time a series of indoor air quality measurements were taken both with and without the air-to-air heat exchangers operating. Since these homes were not delivered until most of the heating season had passed, the thermostats were turned up to approximately $85^{\circ} \mathrm{F}$ during this testing period to insure a cross-shell temperature difference in the structures. This thermostat control strategy, in effect, created a psuedo-heating season. During this time of unoccupied testing, only the heating system was turned on in the home. All other appliances were off, effectively setting internal gains to zero.

After performing these tests, all of the manufactured homes were sold and moved to new locations (see Table 2.4). The homes were then occupied (except unit 302), and metering equipment was in place during part of the

Iable 2.4. Characteristics of the MCS Manufactured Homes

\begin{tabular}{|c|c|c|c|c|c|}
\hline Unit & $\begin{array}{l}\text { MCS } \\
\text { Zone }\end{array}$ & $\begin{array}{l}\text { Target } \\
\text { Test } \\
\text { Location } \\
\end{array}$ & $\begin{array}{l}\text { Floor } \\
\text { Area, } \\
\text { ft? }\end{array}$ & $\begin{array}{c}\text { Designa } \\
\text { UA } \\
\text { Btu/hr-•F }\end{array}$ & New Location \\
\hline $\begin{array}{l}101 \\
203 \\
211 \\
302\end{array}$ & $\begin{array}{l}1 \\
3 \\
1 \\
2\end{array}$ & $\begin{array}{l}\text { Vancouver } \\
\text { Richland } \\
\text { Vancouver } \\
\text { Richland }\end{array}$ & $\begin{array}{r}924 \\
1400 \\
1848 \\
1512\end{array}$ & $\begin{array}{l}209 \\
226 \\
337 \\
268\end{array}$ & $\begin{array}{l}\text { Neah Bay, WA } \\
\text { Nevada } \\
\text { Neah Bay, WA } \\
\text { Unoccupied, } \\
\text { Pendleton. }\end{array}$ \\
\hline 2 & 1 & Vancouver & 1350 & 257 & Neah Bay, WA \\
\hline
\end{tabular}

(a) This is the UA calculated with the air-to-air heat exchanger operating (Lee et al., 1986, Table 5.2, pg. 5.10). 
1986-87 heating season. This provided a period of occupied end-use consumption data for four of the five MCS mobile homes.

\subsubsection{Consumption Data For the ELCAP Manufactured Homes}

For these 15 manufactured homes, detailed electrical consumption data are available for all end-uses having dedicated circuitry at the circuit panel leve1. Typical end-use disaggregation may include total building load, heating load, hot water load, major appliances, and the lighting load. The data collection equipment at each site can be set remotely to collect measurements at almost any time interval, with 1 hour most commonly used. The field data collection system and data processing/verification protocols used in the ELCAP project are described in detail in Tomich and Schuster (1985) and Pearson, Stokes, and Crowder (1985).

In addition to electrical consumption data, both inside and outside temperatures were also collected for the metered sites. There is one indoor air temperature sensor in the main living area in each of the base case manufactured homes. The MCS manufactured homes have two or three indoor air temperature sensors placed within the home. A meteorological station was installed at each of the five MCS manufactured home sites in their original locations. These stations moved with the homes to their new locations. For the base case manufactured homes, another weather station, either an ELCAP meteorological tower or a National Meather Service Site, was used to provide outside temperatures for each site. 
a.

. 


\subsection{METHODOLOGY TO CALCULATE BUILOING LOAD COEFFICIENT (UA)}

A standard measure of a building's thermal performance, or thermal performance of a particular component (wall, door, etc.) in the building, is the U-value, which refers to a material's ability to conduct heat. It is the reciprocal of the more familiar "R-value," the thermal resistance. U-values are used to calculate the overall thermal efficiency of a building's shell. These calculations take into account the area and the $U$-value for each component of a buflding such as windows, doors, and walls and result in an overall conductance for the entire area of the structure (UA).

The component UA means "U-value" times "area" where the "U-value" is the thermal transmittance of a building component and the "area" is the surface area of that component. An effective UA value also can be assigned to heat losses due to air infiltration. The total UA of the entire building is simply the sum of the individual component UAs and the infiltration UA. The overall UA is the theoretical steady-state rate of heat flow through the outer shell of a structure that is driven by a temperature differential across the butlding shell.

This study relies on the design UA, estimated from known design and construction characteristics, to derive a relationship for estimating energy savings as a function of different energy conservation measures (ECMs) that change UA values. Because the design UAs were unavailable for the HRCP homes, we developed the procedure described in this section to calculate the component and total UA values for each home. Our calculations include five distinct shell components: cetling, walls, windows, doors, and floor. The UA values of each component are calculated and, with the calculated UA attributable to air infiltration, are summed to give the total design UA of the structure. (a)

We used data from the HRCP's Main Project Data Base, which was collected from an on-site audit. These data included R-values for existing components

(a) We contrast the design UA described in this section with subsequent estimates of "as-operated" UAs (see Appendix A), which are a measure of how heating energy consumption actually responds to inside-outside temperature differences. 
(pre-retrofit), final component R-values (post-retrofit), and construction materials. The R-values for materials were taken from the 1985 ASHRAE Fundamentals Handbook (ASHRAE 1985). In most cases, the UA calculations are consistent with those presented in ASHRAE (1985) though they are tailored here to conditions pertinent to manufactured hones. Exceptions occur when there is insufficient information on the structure. In this case, assumed constants substitute for derived values with references noted.

\subsection{CALCULATION OF CEILING UA}

The ceiling UA is dependent on six variables: 1) the type of roofing material; 2) the presence or absence of an attic; 3) the slope of the roof; 4) the attic ventilation rate; 5) the type of celling board; and 6) the Rvalue of the cefling insulation. The heat flow is assumed to be a combination of parallel paths through the ceiling joists and cavity, in series with a path through the roof.

The ceiling trusses are assumed to be 2 in. $x 3$ in., with a rafter and joist fraction of 11 percent of the ceiling area. The roof slope is set to 16 degrees for double-wide homes and to 18 degrees for single-wide homes. Homes with floor areas greater than $1000 \mathrm{sq}$. $\mathrm{ft}$. are assumed to be doublewide. A certain proportion of the ceiling insulation is compressed because of the slope of the roof; the average value of compressed insulation is assumed to be 90 percent of the uncompressed insulation R-value. Further compression takes place in the framing section because of the presence of joists, which limit the vertical space. The R-value of compressed insulation in this section of the ceiling, assuming that batt insulation is used, is assumed to be 80 percent of the uncompressed insulation (Onisko 1987). The $R$-values are calculated as follows:

$$
\begin{aligned}
R \text { of joist path } & =\text { ceiling board } R \text {-value } \\
& + \text { ceiling and outside air film R-value } \\
& + \text { framing and joist } R \text {-value } \\
& +.8 * \text { (insulation R-value) } \\
& + \text { roof R-value. }
\end{aligned}
$$




$$
\begin{array}{ll}
\text { R of cavity path } & =\text { ceiling board R-value } \\
\text { (compressed) } & + \text { ceiling and outside air film R-value } \\
& +.9 \pm \text { (insulation R-value) } \\
& + \text { roof R-value. }
\end{array}
$$

$R$ of cavity path = cefling board R-value

(uncompressed) + ceiling and outside air film R-value

+ insulation $R$-value

+ roof $R$-value.

If an attic is present, a default R-value is given for the attic. This is because there is nothing in the HRCP data base which provides information about the size or nature of the attic. Based on industry building standards, an attic space of about 12 inches is assumed for manufactured homes. The default $R$-value for the roof takes into account the roofing material, the air film on the inner roof, and the attic vent rate. The attic vent rate is assumed to be 0.03 cubic feet per minute $(\mathrm{cfm}) / \mathrm{ft}^{2}$ (Conner 1987). The default R-value has been taken from a previous study (Onisko 1987), which investigated a method to estimate heating loads in manufactured homes. This value is added to the ceiling's R-value in each parallel path of heat flow.

The R-values (Table 3.1) are used to derive the U-value of the ceiling, a weighted average of the U-values of the parallel paths.

$U$ of ceiling $-[(1 /(R$ of joist path $))$ * joist fraction

$+(1 /(R$ of compressed cavity path $))$ * compressed fraction $+(1 /(R$ of cavity path $)) *(1$ - joist fraction - compressed fraction)].

The UA of the ceiling is then the product of the ceiling area times the ceiling U-value.

UA of ceiling = $U$ of ceiling * area of ceiling. 
IABLE 3.1. R-values Used for Roof and Ceiling Materials

$\begin{array}{ll}\text { Inside air film } & 0.61 \\ \text { Outside air film } & 0.25 \\ \text { Asphalt roofing material } & 0.30 \\ \text { Hood shingles } & 0.94 \\ \text { 1/2 in. piywood } & 0.62 \\ \text { Gypsum board } & 0.45 \\ \text { 2X4 wood deck ceiling } & 1.54 \\ \text { 2x3 trusses } & 2.20 \\ \text { 2X10 joists } & 11.38\end{array}$

\subsection{CALCULATION OF DOOR UA}

The UAs of doors were calculated (Table 3.2) using the winter U-values from ASHRAE (1985). If there were a storm door in the data base, the mean between the wood and metal storm door U-values was used since the HRCP data base did not identify the type of storm door. If the core of a wood door was unknown, it was assumed to be solid. If the type of door was unknown, it was assumed to be solid wood. A foan core wood door was assumed to have an $R$ value of 7 (this type of door is not mentioned in the referenced ASHRAE table) (Conner 1987). Glazing in doors was separately accounted for as a window by the auditors, so only the opaque door surface was considered. All metal doors were assumed to have foam cores.

Some doors adjoin unconditioned buffer zones in the house. For example, the door may open to an unheated garage. The door and adfacent wall are part of the she11, and heat is lost to the outside through the door or wall. In this study, the buffer zone is assumed to have no effect on the UA of an adjoining door or wall. (a) The door's UA is simply calculated as follows:

UA of door $=U$ of door $*$ area of door

\subsection{CALCULATION OF WALLUA}

The UA of a wall depends upon the R-value of the wall material, the Rvalue of wall insulation, whether the wall is above- or below-grade, and

(a) Under this assumption, when a buffer zone is present, our value would be an overestimate of the $U$-value. For typical buildings in the HRCP, this assumption would introduce an error of only about $5 \%$ in the building UA. 
IABLE 3,2. Door U-values (Btu/(hr*ft*0F))

Door Types

Hollow Hood

Sol id Hood

Foan Core Hood

Unknown Core Hood

Metal Door (a)
Ne Storm Door

0.47

0.39

0.14

0.39

0.40
With Storm Door

0.31

0.27

0.13

0.27

0.28

(a) The U-value is for a conventional metal door. The value with the storm door was estinated from the data in ASHRAE (1985).

whether the wall contains studs. The UA for all walls is computed by suming the UAs for each exterior wall in the structure.

If an above-grade wall contains studs, the wall UA is the sum of the UAs associated with the path through the studs and the path through the cavity. In our analysis, the proportion of the wall area which contains framing is assumed to be 15 percent. This figure was taken to be the most reasonable estimate of a "typical" manufactured home as characterized in BPA (1987). Hood frame walls with less than R-13 cavity insulation are assumed to be $2 \times 4$ stud construction while wood frane walls with R-13 or greater cavity insulation are assumed to be $2 \times 6$ stud construction. The assumed $R$-values of wall construction are given in Table 3.3.

IABLE 3.3. R-Values of Materials Used in Walls $\left({ }^{\circ} \mathrm{F}^{*} \mathrm{ft}{ }^{2 * h r} / \mathrm{Btu}\right)$

\begin{tabular}{|c|c|c|}
\hline $\begin{array}{l}\text { Inside air film } \\
\text { Outside air film } \\
\text { One inch air space }\end{array}$ & $\begin{array}{l}0.61 \\
0.25 \\
1.02\end{array}$ & $\begin{array}{l}\text { (assumed between two } \\
\text { layers of brick) }\end{array}$ \\
\hline $\begin{array}{l}2 \times 4 \text { stud } \\
2 \times 6 \text { stud } \\
\text { Gypsum board interior }\end{array}$ & $\begin{array}{l}4.31 \\
6.77 \\
0.45\end{array}$ & $\begin{array}{l}\text { (assumed as interior } \\
\text { of all walls) }\end{array}$ \\
\hline $\begin{array}{l}\text { Hood siding } \\
\text { Vinyl siding } \\
\text { Brick veneer } \\
\text { Tar shingles } \\
\text { Metal siding } \\
\text { Asbestos } \\
1 / 2^{\prime \prime} \text { plywood } \\
\text { Logs }\end{array}$ & $\begin{array}{r}1.05 \\
1.82 \\
0.11 \\
0.44 \\
1.82 \\
0.06 \\
0.62 \\
10.00\end{array}$ & $\begin{array}{l}\text { (assumes } .375^{n} \text { backing) } \\
\text { (assumes .25") } \\
\text { (sheathing wood walls) } \\
\text { (assumes } 10^{\circ} \text { solid log) }\end{array}$ \\
\hline
\end{tabular}


R-values of above-grade walls with conventional construction are calculated as follows:

$R$ of stud path = outside air film R-value + outside material R-value + sheathing $R$-value + stud $R$-value + gypsum board $R$-value + inside air film $R$-value

$R$ of cavity path = outside air film $R$-value + outside material $R$-value

+ sheathing $R$-value + cavity $R$-value + gypsum board $R$-value + inside air film R-value.

The UA for. the wall can then be calculated as follows, using the proper split between stud and cavity paths:

UA of above grade wall = Hall area * $[1 /(R$-value of stud path $)$ * stud fraction $+1 /(R-v a l u e$ of cavity path $) *(1$ - stud fraction)]

The HRCP data base has a few manufactured homes with basements and, thus, below-grade walls. The UA of a below-grade wall (basement) includes the path through the ground to the outside in series with the wall path. The total resistance of a below-grade wall past any point is the sum of the sequential resistance of the wall $R$-value and the $R$-value of the soil at that depth below grade.

The calculation of the below-grade wall $R$-value is similar to that used to estimate the U-value for above-grade walls, except that the outside air film has a value of R-O and the wall is assumed to be 4 in. of concrete with no outside finish.

The R-value of the soil is a function of the path length through the soil and the conductivity of the soil. We used the methodology outlined in ASHRAE (1985) to calculate the soil's R-value. The soil conductivity is

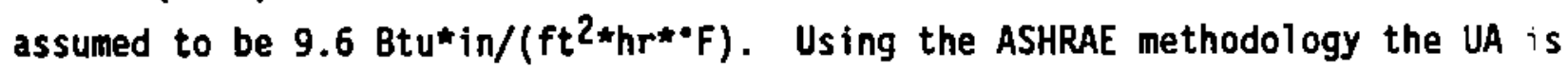
estimated per foot of perimeter using the following relationship:

$$
\begin{aligned}
U A / f t= & (1 / 1.9635) *[\ln (1.9635 * \text { depth }+ \text { Wal1 R-value })- \\
& \ln (\text { Wall R-value })] .
\end{aligned}
$$


The total UA of a below-grade wall is then the UA per 1 ineal foot times the length of the wall (determined by dividing the gross area by the belowgrade depth).

UA of below-grade wa11 = (Wa11 area below grade/below-grade depth)*UA/ft

\subsection{CALCULATION OF WINDON UA}

U-values for windows were derived from Tables $13 \mathrm{~A}, 13 \mathrm{C}$, and 14 in Chapter 27 of ASHRAE (1985). The design U-values of Table 13A for winter were first scaled to a $7.5 \mathrm{mph}$ average wind speed using Table 14 (ASHRAE 1985). Next, the U-values were multiplied by the mean of the range of sash adjustment factors given in Table $13 \mathrm{C}$ to arrive at the $U$-value used in our calculation. The sash adjustment factors are repeated here in Table 3.4 and the estimated UA values for windows are shown in Table 3.5. The window UA is calculated as follows:

UA of window $=U$-value $97.5 \mathrm{MPH} *$ sash factor * window area

IABLE 3.4. Sash AdJustment Factors for Hindows

\begin{tabular}{llcc} 
Glazing type & Hood & Metal & $\begin{array}{c}\text { Metal with } \\
\text { thermal break }\end{array}$ \\
\cline { 4 - 4 } Single & 0.90 & 1.05 & 0.95 \\
Double & 0.95 & 1.25 & 1.05 \\
Triple & 0.97 & 1.40 & 1.13 \\
Single + storm & 0.95 & 1.30 & 1.05 \\
Double + storm & 0.97 & 1.40 & 1.10 \\
Triple + storm & 0.97 & 1.40 & 1.10
\end{tabular}


IABLE 3.5. Estimated U-Values for Windows (Btu/hr/ $\mathrm{ft}^{2} /{ }^{\circ} \mathrm{F}$ )

\begin{tabular}{ccc}
$\begin{array}{c}\text { Glazing Iype } \\
\text { No storm window } \\
\text { Single }\end{array}$ & $\begin{array}{c}\text { Air Gap Width, } \\
\text { Inches }\end{array}$ & U-Value \\
\cline { 2 - 3 } $\begin{array}{c}\text { Double } \\
\text { Double }\end{array}$ & -- & 1.01 \\
Double & $>=3 / 16$ & 0.59 \\
Triple & $>1 / 4$ & 0.55 \\
Triple & $<=1 / 4$ & 0.47 \\
With storm window & $>1 / 4$ & 0.37 \\
Single & -- & 0.30 \\
Double & $<=3 / 16$ & \\
Double & $>3 / 16,<=1 / 4$ & 0.48 \\
Double & $>1 / 4$ & 0.36 \\
Triple & $<=1 / 4$ & 0.34 \\
Triple & $>1 / 4$ & 0.30 \\
& & 0.26 \\
\end{tabular}

\subsection{CALCULATION OF FLOOR UA}

To calculate the floor UA, we estimated the combined UA of the floor materials and the foundation. The UA of the foundation was somewhat complicated to derive because of the structure of the HRCP data base. The data base contains multiple record entries for floors, which may give information about the type of foundation. Four types of foundations are indicated in the data base: crawlspace, basement, exposed to ambient air, or concrete slab. There is no information on insulation in the footings of the foundation. This lack of specific information required that some assumptions be made about the construction and resistance of each foundation type.

The data base provided no details on the characteristics of basements. Based on information in BPA (1987), we used a default R-value of 5 for unheated basements. 
A very few manufactured homes (5 of 594) have floors which were over slabs. In these cases, only a part of the total floor area is reported to be over a slab. Known methods for estimating a slab floor's UA depend upon knowing the perimeter length of the slab. Since the perimeter of partial slabs was not known, we deleted these few sites from our analysis.

Most of the manufactured homes are sited over crawlspaces, either skirted or exposed to ambient conditions. Crawlspaces contribute an added $R$-value to the $R$-value of the floors above then. Since the data base does not contain detailed information on the crawlspace or $j$ ts ventilation, crawlspaces are assumed to have a default $R$-value of 3 , derived from information provided in BPA (1987).

The method used to calulate the floor UA and described in this section pertains only to those floors over crawlspaces, unconditioned zones (basements), or exposed to the outside. The total floor UA is caiculated using the foundation UA and floor structure UA.

The UA for floor structures is calculated assuming parallel heat flow through floor joists and cavity. If a crawlspace or basement is underneath the floor, the Joist and cavity paths are in series with the effective crawlspace or basement R-value.

Based on available information (Knight 1986), we made different assumptions about floor construction and insulation practices before and after 1976. For manufactured homes built before 1976, the floor insulation is assumed to be below the floor joists for R-values of 22 or less. Insulation above a value of $R-22$ is assumed to be between the floor joists. For homes built after 1976, floor insulation is assumed to be between floor joists for values of R-19 and below. Additional insulation is assumed to be below the floor joists for values greater than R-19.

If there is no insulation between the floor joists but some below the joists, a special condition is assumed to exist. Under these circumstances, the ducts are assumed to be heating the zone below the floor. Consequently, the floor is not considered part of the shell since these sites have a "conditioned" zone below the floor. For such conditions, the R-value of the 
floor structure is set to zero and only the components below the floor structure are considered.

The calculation assumes that fotsts for all floors are $2 \times 6$ and that floor framing comprises 11 percent of the floor area. A certain proportion of the insulation under the floor area is compressed because of the presence of structural members and space limitations below the foists. The effect of this compression on the R-value of floor insulation was estimated based on BPA (1987) and was used to develop a compression correction factor for the insulation below the floor foists. (a) The calculation of the floor R-value 1s:

$$
\text { floor } \begin{aligned}
R \text {-value } & =1 /[\text { joist fraction } /(R \text {-value of joist }) \\
& +(1 \text { - joist fraction }) /(R \text {-value of cavity })]
\end{aligned}
$$

The R-value of the cavity in the above equation is the R-value of the insulation (between and below floor joists) plus the R-value of floor material and R-1.22 for the air space. The R-value of the joist is the Rvalue of the insulation below the joists plus the $R$-value of floor material and R-7.5 for the joists (see Table 3.6).

The total floor UA is calculated as follows:

total floor UA $=$ floor area * $1 /($ floor $R$-value + foundation $R$-value $)$ where the foundation $R$-value is assumed to be $R-0$ if exposed to ambient, $R-3$ for crawlspaces, and R-5 for basements.

(a) The compression factor was estimated based on the data in BPA (1987). It provides an adjustment for R-values greater than R-7 for insulation installed below the floor joists. 
IABLE 3.6. R-Values Used for Floor Materials

$\begin{array}{lc}\text { Floor Air Film } & .92 \\ \text { Floor Covering } & 1.26 \\ \text { Subflooring } & 1.30^{\star} \\ \text { Air Space in Floor Cavity } & 1.22 \\ \text { Bottom Board } & .15 \\ \text { Outside Film } & .25 \\ \text { 2x6 Floor Joists } & 7.50^{\star} \\ \text { ons from information in Onisko }(1987) \text { are due to other } \\ \text { characteristics of the floor construction that provide } \\ \text { areenent with BPA (1987). }\end{array}$

\subsection{CALCULAIION OF INFILTRATION UA}

The infiltration UA can be characterized as the product of the volumetric air exchange rate in a given building and the volumetric heat capacity of air. The volunetric heat capacity of air is $0.018 \mathrm{Btu} / \mathrm{ft}^{2} /{ }^{\circ} \mathrm{F}$ (ASHRAE 1985, p.25.7). An estimate of the volume of air exchanged per hour is obtained by following guidelines established in ASHRAE (1985). The ASHRAE procedure requires estimates of the leakage area and specific infiltration rate.

The leakage area of each building is determined from "best estimate" values in ASHRAE (1985) for four components of leakage area: 1) between the foundation sill and wal1;2) between the ceiling and wall; 3) around windows and window frames; and 4) around doors and door frames. Based on the type and condition of each component, a leakage area is estimated. The sum of the component leakage areas characterizes the leakage area of the structure.

If the foundation sill were caulked, the leakage area was assumed to be $0.0376 \mathrm{sq}$. in./ft. of floor perimeter; if not caulked, the leakage area was taken to be $0.188 \mathrm{sq}$. in./ft. The leakage area between the ceiling and wall was taken to be zero if there were a vapor barrier in the ceiling. Otherwise, leakage area was assumed to be $0.07 \mathrm{sq}$. in./ft. of ceiling perimeter. Window and door leakage areas were determined from Tables 3.7 through 3.10. 
IABLE 3.7. Component Leakage: Windows (in. $2 / \mathrm{ft}^{2}$ )

Component

Single hung, weather stripped

Single hung, not weather stripped.

Double hung, weather stripped

Double hung, not weather stripped
Estimate

0.032

0.064

0.043

0.086

IABLE 3.8. Component Leakage: Mindow Franes (in. ${ }^{2} / \mathrm{ft} .{ }^{2}$ )

Component

Wall wood frame, caulked

Wall wood frame, not caulked

Wall masonry, caulked

Wall masonry, not caulked
Estimate

0.004

0.024

0.019

0.094

IABLE 3.9. Component Leakage: Doors

Component

Estimate

Single Door, weatherstripped

Single Door, not weatherstripped

0.115

Double Door, weatherstripped

0.158

Double Door, not weatherstripped

0.115

0.158

IABLE 3.10. Component Leakage: Door Frames (in. ${ }^{2} / \mathrm{ft} .{ }^{2}$ )

Component

Wall wood frame, caulked

Wall wood frame, not caulked

Wall masonry, caulked

Wall masonry, not caulked
Estimate

0.004

0.024

0.014

0.072

Our calculation also required an estimate of specific infiltration rate. Specific infiltration rate denotes the volume in cubic feet of air exchanged per minute per square inch of leakage area given specific wind and temperature effects. Specific infiltration is assumed to be 1.39 and is determined by using the formula for specific infiltration on page 22.16 in ASHRAE (1985). The buildings in our study are assumed to be single story with a moderate shielding class (i.e., some obstructions within 20 feet of the building). The average windspeed was taken to be 15 miles per hour and 
an average temperature difference of $\mathbf{3 0}$ degrees Farenheit was assumed between inside and outside temperature.

The volume of atr exchanged in an hour is taken to be the product of the leakage area (calculated using values estimated above), the specific infiltration of a building (1.39), and $60 \mathrm{~min} . / \mathrm{hr}$. From this value the hourly UA associated with infiltration is as follows:

Infiltration UA $=.018^{\star}$ volume of air exchanged per hour

For typical values of component leakages and home dimensions, this methodology gave estimates of air exchange rates around 0.4 air changes per hour. The figure is in good agreement with recent test data from Bonneville (EK 1987).

\subsection{HRCP MANUFACTURED HOME UA CALCULATIONS}

The procedures described here have been incorporated in a computer program that reads data for individual manufactured homes in the HRCP data base. The program calculates component UAs based on the data available and assumptions about the dimensions of specific components. It sums the component UAs to estimate the bullding load coefficient. The calculation is performed for homes, both before and after retrofit, based on component data. The calculated UAs range from about 166 to $8008 \mathrm{tu} / \mathrm{hr} .{ }^{\circ} \mathrm{F}$. 


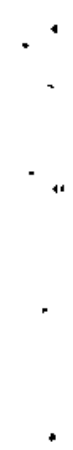

1 


\subsection{PRISH ANALYSIS AND ADJUSTMENT OF PRISH ESTIMATES}

The PRInceton scorekeeping घethod (PRISM) is a conmonly used methodology for normalizing household total electrical energy consumption, accounting for both year-to-year and geographtc variations in weather. The methodology also provides an estimate of baseload electricity use and heating (or temperaturesensitive) energy consumption. The methodology is discussed in detail in Fels (1986) and the reader is referred there for a detailed development of the PRISM methodology.

This section first describes the model and then presents unadjusted PRISM estimates of normalized annual electrical energy consumption and the normalized heating component for selected homes in the HRCP and Tulalip data sets. It also presents measured space heating energy data for comparison purposes for a subset of HRCP homes and the Tulalip homes analyzed here. In

Section 4.4 we present a theoretically-based methodology for correcting PRISM estimates of heating energy consumption within a climate zone. The methodology was developed using the billing and measured heating data from HRCP and Tulalip homes. In Section 5, we present a technique we developed to extrapolate the adjusted PRISM estimates of heating energy consumption to other climate zones.

\subsection{PRISM METHODOLOGY}

PRISM is a statistical procedure for calculating changes in energy consumption over time in response to outdoor temperature (Fels 1986). PRISH requires as input three readily available pieces of information: 1) monthly utility billing information, 2) daily average temperatures for the period covered by the billing data, and 3) long-term (generally 10 years or more) daily average temperatures or typical weather year temperatures.

PRISM results are generated in two steps. The first is to estimate baseload consumption (beta), a reference temperature (T-ref) and the heating slope (alpha), based on the performance of the house during the period covered by the billing data. The second step of PRISM uses these parameters to estimate the normalized annual consumption (NAC) and a normalized heating component. 
For readers unfamiliar with PRISH terminology, definitions of the following key terms are offered:

Reference Temperature (I-ref): The outside temperature below which heating in the home is required. The reference temperature varies from house to house, and is primarily influenced by the indoor temperature, which is dependent on 1) thermostat setting, 2) buflding thermal characteristics, 3) internal gain from occupants' activity and appliance operation, and 4) gain from solar energy.

Heating Slope: The heat-loss rate that is dependent on the conductive and infiltration heat losses. It is the incremental increase in electrical heating energy consumption per unit decrease in outside temperature below the reference temperature.

NAC: The total annual household electrical energy consumption, normalized to long-term average or typical annual heating-degreedays.

Baseload: The seasonally-independent component of NAC.

Heating Component: The seasonally varying component of the NAC. It is a combination of the temperature-dependent heating energy consumption and the seasonally-dependent non-heating loads, such as water heating and lighting.

\subsection{ANALYSIS}

After we applied the PRISM model to the selected billing data, the PRISM analysis results were screened using acceptance criteria similar to those used by Bronfman (1987) to identify "good-fit" homes. These are homes where PRISM results indicate a robust 1 inear fit to the data. Homes that failed to satisfy these criteria were eliminated from further analysis. The criteria were:

- R-squared greater than .75

- standard error of the reference temperature less than $25^{\circ} \mathrm{F}$, and

- standard error of the baseload coefficient less than $25 \mathrm{kwh}$.

Tulalip homes known to use wood to heat any part of the time were eliminated from the analysis even though some of their PRISM results may have satisfied the "good-fit" criteria. No specific information on wood heating or other supplemental heating was available for the Hood River manufactured homes. However, homes whose ratio of heating load to total load (heating component/NAC) was less than 0.25 were considered to be using an abnormally 
low fraction of their total energy for heating, possibly because of significant supplemental heating with wood or other non-electric appliances (kerosene heaters) at least part of the time. These homes were also dropped frow further analysis.

\subsubsection{PRISH Results for IUlalip Homes}

Monthly billing data (based on weekly meter readings) for 34 Tulalip homes were available for the PRISM analysis. Ten homes were dropped from the analysis because they were known wood burners and eight were dropped because they failed the "good-fit" criteria. The 16 homes retained for further analysis used a substantial amount of normalized annual energy consumption for heating (greater than $2000 \mathrm{kth} /$ year), and the ratio of the heating component to total load was greater than 0.25 .

Results of the PRISM analysis of the remaining 16 homes are all based on Seattle TAY weather data and are shown in Table 4.1. The mean NAC for these homes was 15,228 kwh/year, with an estimated mean space heat component of $6779 \mathrm{kth} /$ year (45\% of $\mathrm{NAC}$ ). The outdoor reference temperature ranged between $49.3^{\circ} \mathrm{F}$ and $61.3^{\circ} \mathrm{F}$, and averaged $57.0^{\circ} \mathrm{F}$.

Annual heating consumption was estimated with PRISM for the three different sizes of manufactured homes in the Tulalip data set $(850,1050$, and 1190 square feet). The average annual heating energy consumption was 6.8 $\mathrm{kWh} / \mathrm{ft}^{2}$ and $7.0 \mathrm{kWh} / \mathrm{ft}^{2}$ for the $850 \mathrm{ft}^{2}$ and $1050 \mathrm{ft}^{2}$ homes, respectively. The estimated annual heating energy consumption for the one $1190 \mathrm{ft}^{2}$ home was $4.5 \mathrm{kth} / \mathrm{ft}^{2}$. The average for the 16 homes was $6.8 \mathrm{kthh} / \mathrm{ft}^{2}$, but ranged from 4.3 to $9.7 \mathrm{kth} / \mathrm{ft}^{2}$ for individual homes. These figures are significantly higher than the MCS equivalent requirement of $3.2 \mathrm{kth} / \mathrm{ft}^{2} / \mathrm{yr}$, to which the homes were constructed (Eckman 1988b). While these results suggest this set of homes does not perform as well as design predictions, we note that they are based on PRISM estimates rather than measured end-use data. Section 4.3 takes up the question of the accuracy of the PRISM estimates. 
Table 4.1. Results of the PRISM Analys is of the Tulalip Homes Based on Seattle TMY Weather Data.

\begin{tabular}{|c|c|c|c|c|c|c|}
\hline Site ID & $\begin{array}{c}\text { T-ref } \\
\bullet \mathbf{F}\end{array}$ & $\begin{array}{l}\text { Tyoic } \\
\text { Heat } \\
\text { kWh }\end{array}$ & 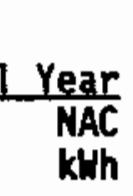 & $\begin{array}{c}\text { Heat } \\
\text { Ratioa }\end{array}$ & $\begin{array}{l}\text { Home } \\
\text { Size } \\
\mathrm{ft}^{2}\end{array}$ & $\begin{array}{c}\text { PRISH } \\
\text { Annual } \\
\text { Heat } \\
\text { kWh/ft' }\end{array}$ \\
\hline $\begin{array}{l}2828 \\
2722 \\
2810 \\
6512 \\
2600 \\
2601 \\
6431 \\
6515 \\
6505 \\
2725 \\
2812 \\
2706 \\
2717 \\
6429 \\
6511 \\
2611\end{array}$ & $\begin{array}{l}49.3 \\
60.6 \\
55.0 \\
59.0 \\
56.2 \\
57.5 \\
55.6 \\
55.9 \\
56.4 \\
58.0 \\
60.4 \\
57.0 \\
54.5 \\
57.7 \\
61.3 \\
58.0\end{array}$ & $\begin{array}{l}\overline{3618} \\
6933 \\
4519 \\
7278 \\
5525 \\
7159 \\
6666 \\
6500 \\
6516 \\
7552 \\
8232 \\
7126 \\
8124 \\
8262 \\
9144 \\
5313\end{array}$ & $\begin{array}{r}9897 \\
16006 \\
9208 \\
12834 \\
13046 \\
16038 \\
14777 \\
16575 \\
15297 \\
16492 \\
19288 \\
11665 \\
22806 \\
16508 \\
14070 \\
19139\end{array}$ & $\begin{array}{l}0.37 \\
0.43 \\
0.49 \\
0.57 \\
0.42 \\
0.45 \\
0.45 \\
0.39 \\
0.43 \\
0.46 \\
0.43 \\
0.61 \\
0.36 \\
0.50 \\
0.65 \\
0.28\end{array}$ & $\begin{array}{r}850 \\
1050 \\
850 \\
1050 \\
850 \\
1050 \\
1050 \\
1050 \\
1050 \\
1050 \\
850 \\
850 \\
1050 \\
1050 \\
1050 \\
1190\end{array}$ & $\begin{array}{l}4.3 \\
6.6 \\
5.3 \\
6.9 \\
6.5 \\
6.8 \\
6.3 \\
6.2 \\
6.2 \\
7.2 \\
9.7 \\
8.4 \\
7.7 \\
7.9 \\
8.7 \\
4.5\end{array}$ \\
\hline maximum & $\begin{array}{l}57.0 \\
61.3 \\
49.3\end{array}$ & $\begin{array}{l}6779 \\
9144 \\
3618\end{array}$ & $\begin{array}{r}15228 \\
22806 \\
9208\end{array}$ & $\begin{array}{l}0.45 \\
0.65 \\
0.28\end{array}$ & ------ & $\begin{array}{r}6.8 \\
9.7 \\
4.3\end{array}$ \\
\hline
\end{tabular}

(a) PRISM heat estimate divided by PRISH MAC.

\subsubsection{PRISM Results for Hood River Homes}

Four years of monthly utility billing data for 538 manufactured homes in the vicinity of Hood River, Oregon were used in the PRISM analysis. The first three heating seasons (1982/83, 1983/84, and 1984/85) were before any weatherization measures were installed, while the last year $(1985 / 86)$ was after all weatherization measures were installed. Estimates of the thermal performance characteristics of the HRCP manufactured homes for each of the four heating seasons are summarized in Table 4.2. The normalized annual energy consumption and the estimated heating loads for the same set of homes are shown in Table 4.3, based on long-term average weather data. 
Iable 4.2. Summary of PRISH Parameters for the Hood River Homes

\begin{tabular}{|c|c|c|c|c|c|}
\hline Parameter & & \multicolumn{3}{|c|}{ Pre-Retrofit } & $\begin{array}{c}\text { Post- } \\
\text { Retrofit } \\
1985 / 86\end{array}$ \\
\hline T-ref $(\operatorname{deg} F)$ & $\begin{array}{l}\text { average } \\
\text { std. dev. }\end{array}$ & $\begin{array}{r}57.5 \\
5.6\end{array}$ & $\begin{array}{r}57.1 \\
4.3\end{array}$ & $\begin{array}{r}57.1 \\
5.4\end{array}$ & $\begin{array}{r}58.0 \\
6.3\end{array}$ \\
\hline Base Load (kWh/day) & $\begin{array}{l}\text { average } \\
\text { std. dev. }\end{array}$ & $\begin{array}{l}25.5 \\
13.0\end{array}$ & $\begin{array}{l}25.3 \\
12.4\end{array}$ & $\begin{array}{l}24.2 \\
11.7\end{array}$ & $\begin{array}{l}23.5 \\
12.5\end{array}$ \\
\hline slope (kth/degree-day) & $\begin{array}{l}\text { average } \\
\text { std. dev. }\end{array}$ & $\begin{array}{l}3.56 \\
3.35\end{array}$ & $\begin{array}{l}3.15 \\
1.26\end{array}$ & $\begin{array}{l}3.11 \\
2.01\end{array}$ & $\begin{array}{l}2.72 \\
1.33\end{array}$ \\
\hline Number of Residences & & 295 & 313 & 314 & 295 \\
\hline
\end{tabular}

Table 4.3. Normalized Annual Energy Consumption for the Hood River Homes for Al1 Four Heating Seasons

\begin{tabular}{|c|c|c|c|c|c|}
\hline Parameter & & $1982 / 83$ & 1983/84 & $1984 / 85$ & $1985 / 86$ \\
\hline $\operatorname{NAC}(\mathrm{kWh})$ & $\begin{array}{l}\text { average } \\
\text { std. dev. }\end{array}$ & $\begin{array}{r}20621 \\
6580\end{array}$ & $\begin{array}{r}19817 \\
6416\end{array}$ & $\begin{array}{r}19106 \\
5967\end{array}$ & $\begin{array}{r}17962 \\
5319\end{array}$ \\
\hline Heating Component(kWh) & $\begin{array}{l}\text { average } \\
\text { std. dev. }\end{array}$ & $\begin{array}{r}11315 \\
4168\end{array}$ & $\begin{array}{r}10586 \\
3815\end{array}$ & $\begin{array}{r}10266 \\
4085\end{array}$ & $\begin{array}{l}9721 \\
3401\end{array}$ \\
\hline Heating Component/ $\mathrm{ft}^{2}$ & $\begin{array}{l}\text { average } \\
\text { std. dev. }\end{array}$ & $\begin{array}{r}12.7 \\
6.0\end{array}$ & $\begin{array}{r}12.0 \\
5.1\end{array}$ & $\begin{array}{r}12.1 \\
6.6\end{array}$ & $\begin{array}{r}11.2 \\
5.0\end{array}$ \\
\hline
\end{tabular}

Table 4.2 shows considerable stability of the PRISM parameters across different years. The slope declines as expected after retrofit. The value for T-ref increases slightly in the year after retrofit (though the UA change would suggest about a $1.5^{\circ} \mathrm{decline)}$, indicative of a small "take-back" effect. For a subset of HRCP homes, Appendix A reports a similar, but even smaller, increase in measured, average indoor temperatures, but argues that 
the small change observed may be due to changes in thermal response rather than occupant behavior. (a)

The results shown in Table 4.3 are for the subset of homes each year which were "good-fit" homes and which had a heating component greater than 25\% of MAC. The results are normalized using 10-year average weather data for Hood River. As shown in the table, the normalized heating component decreased after the homes were retrofit with weatherization measures (1985/86 data). The heating component declined in 1985/86 by $1001 \mathrm{kth} /$ year compared to the mean of the values for the three previous years, and the total energy consumption (NAC) declined by $1886 \mathrm{kth} /$ year. The heating component is reduced by some 9.3\%. This change agrees well with the results reported in Appendix $A$ and the previous studies cited there.

The weather-normalized PRISM heating component declines after retrofit desolte an increase in the mean T-ref, which would tend to increase heating energy consumption. The decline in the mean slope appears to more than offset the increase in T-ref to produce an overall decrease in the mean heating component. Since the slope is a measure of the as-operated UA of the homes, the observed decline in the mean slope is consistent with the expected decline in the mean UA of the homes resulting from the weatherization retrofits.

\subsection{COMPARISON OF PRISM ESTIMATES WITH ACTUAL HEATING LOADS}

The ability of PRISM to accurately decompose total residential energy consumption into its heating and baseload components can be tested by comparing measured component load data for a given year to PRISM estimates based on the same year of temperature data as the energy data, instead of normalizing to long-term temperature data. Hirst and Goeltz (1986), in a study of site-built, electrically heated Hood River homes, demonstrated that PRISM estimates of the normalized annual consumption (NAC) are extremely accurate. On the other hand, a systematic bias is known to exist in the estimation of the PRISM coefficients (Bronfman et al. 1987; Hestman and

(a) Note that changes in solar gains or internal gains have not been accounted for and such changes could either be causing the observed shift in reference temperature or could be masking occupant behaviorat changes. 
Monroe 1986; Hirst and Goeltz 1986), resulting typically in an overestimation of the heating component (underestimation of the baseload). This difference between PRISM estimates and actual measurements of electricity use can be attributed to at least four possible sources:

- inaccurate billing data

- inaccurate load data

- misinterpretation of baseload because of summer peak loads (e.g., air conditioning)

- seasonality of non-space heating loads.

The effects of the first three error sources were considered minimal in our study. The impact of inaccurate data can be mininized by implementing a thorough quality control program, both in the collection of the end-use metered data and in the review of the raw load and utility billing data. Oak Ridge, Pacific Power and Light, Bonneville, and PWL have implemented extensive quality control efforts to minimize data errors. Sumer air conditioning or other predominately summer electrical loads result in PRISM overestimating the baseload and underestimating the heating component. Air conditioning loads in both Hood River and Tulalip, however, are quite small, so we do not expect this error source to be significant in these analyses.

On the other hand, differences between end-use energy measurements and PRISM estimates of the heating component and baseload are likely to be influenced by other non-heating loads that exhibit seasonality. Examples of loads known to be temperature or seasonally sensitive include: 1) interior/exterior lighting in response to shorter and less intense daylight hours during winter and 2) electric hot water heater energy use, which increases because of lower supply water temperatures during the winter.

As a result, it is necessary to clarify that the PRISM term identified as the heating component implicitly captures some of the non-heating, seasonally dependent loads (Fels et al. 1986), which should be considered as baseload. In reality, the "heating component" is the temperature/seasonally dependent component of the total household energy consumption, of which space heating is usually the largest part. 
We compared PRISH heating component estimates to measured heating consumption data to determine how well the PRISM estimates matched actual data. For the Tulalip homes, we used PRISH to estimate the heating component for the year over which billing data were collected. The PRISM estimate, therefore, was not normalized to long-tern weather. We repeated this analysis for the HRCP homes for the data one year before retrofit and one year after.

Results for the Tulalip homes (Table 4.4) indicate that PRISN's heating component substantially overestimates actual heating energy consumption for these homes and their occupants. The average overestimate is 52\%. At the individual house level the difference ranges from $-8 \%$ to $102 \%$. Though the magnitude of this error is larger than reported in other studies, these results are consistent with earlfer studies that showed that PRISM overestimates heating energy consumption more in cases where heating constitutes a relatively small fraction of total energy consumption. In such cases, the other seasonally dependent loads represent a larger fraction of the space heating load and PRISH identifies part of the seasonal base load with the heating component estimate. In energy-efficient homes, such as the Tulalip hones analyzed here, the heating load is significantly overestimateo because the seasonal base loads are likely to be quite large relative to the heating load.

Table 4.4 also presents two estimates of heating energy per square foot. The values based on measured data are typically one-third to orie-half less than the values based on the PRISH estimates. The average measured value for the group, $4.8 \mathrm{kWh} / \mathrm{sq}$. $\mathrm{ft}$., is much closer to the design value of $3.2 \mathrm{kWh} / \mathrm{sq}$. ft. for these homes (see Section 4.2.1). While we point out that these results are for a specific year and may not be accurate for long-run weather conditions, the agreement between the PRISM results for this year and the long-run weather year (Table 4.1) suggest that the measured consumption per square foot is a good indicator of the long-run average. 
IABLE 4.4. Comparison of PRISM Estimates with Actual Measured Heat and Total Annual Consumption (kWh/year) for Tulalip Homes

\begin{tabular}{|c|c|c|c|c|c|c|c|c|}
\hline \multirow[b]{3}{*}{ Site ID } & \multicolumn{3}{|c|}{ PRISM Estimates } & \multicolumn{3}{|c|}{ Measured } & \multirow{3}{*}{$\begin{array}{l}\text { Heat } \\
\text { Errora }\end{array}$} & \multirow{3}{*}{$\begin{array}{c}\text { Actual } \\
\text { Heat/Total }\end{array}$} \\
\hline & \multicolumn{2}{|c|}{ Heat. } & \multirow{2}{*}{$\begin{array}{r}\text { Total } \\
\text { kwh }\end{array}$} & \multicolumn{2}{|c|}{ Heat } & \multirow{2}{*}{$\begin{array}{l}\text { Tota1 } \\
\text { kWh }\end{array}$} & & \\
\hline & kWh & kWh/ft? & & KWh & kWh/ft ${ }^{2}$ & & & \\
\hline \multirow{12}{*}{$\begin{array}{l}2828 \\
2722 \\
2810 \\
6512 \\
2600 \\
2601 \\
6431 \\
6515 \\
6505 \\
2725 \\
2812 \\
2706 \\
2717 \\
6429 \\
6511 \\
2611\end{array}$} & 3429 & 4.0 & 9707 & 3720 & 4.4 & 9909 & -0.08 & 0.38 \\
\hline & $\begin{array}{l}7035 \\
4482\end{array}$ & $\begin{array}{l}6.7 \\
5.3\end{array}$ & $\begin{array}{r}16107 \\
9170\end{array}$ & $\begin{array}{l}5900 \\
3640\end{array}$ & $\begin{array}{l}5.6 \\
4.3\end{array}$ & $\begin{array}{r}14870 \\
9333\end{array}$ & $\begin{array}{l}0.19 \\
0.23\end{array}$ & $\begin{array}{l}0.40 \\
0.39\end{array}$ \\
\hline & $\begin{array}{l}7383 \\
5544\end{array}$ & $\begin{array}{l}7.0 \\
6.5\end{array}$ & $\begin{array}{l}12939 \\
13065\end{array}$ & $\begin{array}{l}5720 \\
4120\end{array}$ & $\begin{array}{l}5.4 \\
4.8\end{array}$ & $\begin{array}{l}13079 \\
13183\end{array}$ & $\begin{array}{l}0.29 \\
0.35\end{array}$ & $\begin{array}{l}0.44 \\
0.31\end{array}$ \\
\hline & $\begin{array}{l}7231 \\
6655\end{array}$ & & $\begin{array}{l}16110 \\
14767\end{array}$ & $\begin{array}{l}5160 \\
4740\end{array}$ & & $\begin{array}{l}15558 \\
14968\end{array}$ & & $\begin{array}{l}0.33 \\
0.32\end{array}$ \\
\hline & $\begin{array}{l}6505 \\
6546\end{array}$ & 6.2 & $\begin{array}{l}16580 \\
15327\end{array}$ & $\begin{array}{l}4440 \\
4320\end{array}$ & & $\begin{array}{l}16901 \\
15623\end{array}$ & $\begin{array}{l}0.47 \\
0.52\end{array}$ & 0.26 \\
\hline & $\begin{array}{l}0540 \\
7641\end{array}$ & $\begin{array}{l}0.6 \\
7.3\end{array}$ & $\begin{array}{l}15527 \\
16581\end{array}$ & $\begin{array}{l}4520 \\
5020\end{array}$ & $\begin{array}{l}4.1 \\
4.8\end{array}$ & 16817 & & 0.30 \\
\hline & 8352 & 9.8 & 19408 & 4960 & 5.8 & & & \\
\hline & 7187 & 8.5 & 11 & 4120 & 4.8 & 118 & & 0.3 \\
\hline & 8026 & 7.6 & 708 & 4580 & & & & \\
\hline & $\begin{array}{l}8551 \\
9277\end{array}$ & $\begin{array}{l}8.0 \\
8.8\end{array}$ & 1420 & & 4.1 & & & \\
\hline & & 4.5 & & & 2.2 & & & \\
\hline & 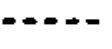 & ---- & $m-\infty$ & $\infty-\infty$ & $\cdots$ & ---- & ---- & $-\cdots$ \\
\hline average & 6814 & 6.9 & 15262 & 4513 & 4.8 & 15298 & 0.52 & 0.31 \\
\hline maximur & 9277 & 9.8 & 22708 & 5900 & 5.8 & 22478 & 1.02 & 0.44 \\
\hline & 3429 & 4.0 & & 2660 & 2.2 & 9333 & -0.08 & 0.14 \\
\hline
\end{tabular}

(a) Heat error = (PRISM heating component - actual heat)/actual heat.

Results of the PRISM analysis of the end-use metered HRCP manufactured homes are shown in Tables 4.5 and 4.6 for the pre- and post-retrofit data, respectively. For the pre-retrofit period, the PRISM heating component underestimated the actual heating energy consumption by an average of about $1 \%$, while the difference ranged from $-42 \%$ to $+33 \%$ at the individual house level. The mean error for the post-retrofit time period was $-9 \%$, indicating PRISM underestimated the heating load and by more after retrofit than before.

The underestimation observed here is not consistent at first glance with an earlier study of Hood River data (Hirst and Goeltz 1986), which found PRISM to over estimate heating load. The underestimation of Hood River results is consistent with the Tulalip results and previous studies 
IABLE 4.5 Comparison of PRISM estimates and measured space heat for the Hood River homes in the Pre-Retrofit year ( $\mathrm{kWh} / \mathrm{yr}$ )

\begin{tabular}{|c|c|c|c|c|c|c|c|}
\hline \multirow[b]{2}{*}{ Site ID } & \multirow[b]{2}{*}{$\begin{array}{c}\text { T-ref } \\
\bullet_{F}\end{array}$} & \multicolumn{3}{|c|}{ PRISM Estimates } & \multirow{2}{*}{\multicolumn{2}{|c|}{ Measured Heat }} & \multirow[b]{2}{*}{$\begin{array}{l}\text { Heat } \\
\text { Error }\end{array}$} \\
\hline & & $\frac{\text { Heat }}{\mathrm{kWh}}$ & $\frac{t}{k W h} / \mathrm{ft}^{2}$ & $\begin{array}{c}\text { Total, } \\
\text { kWh }\end{array}$ & & & \\
\hline $\begin{array}{l}4298 \\
4341 \\
4322 \\
4356 \\
4370 \\
4390 \\
4397 \\
4412 \\
4146 \\
4076 \\
4090 \\
4133 \\
4196 \\
4185 \\
4078 \\
4059 \\
4034 \\
4062 \\
4016\end{array}$ & $\begin{array}{l}60.9 \\
52.5 \\
46.3 \\
55.9 \\
66.0 \\
68.5 \\
58.9 \\
63.5 \\
54.1 \\
55.0 \\
57.7 \\
59.8 \\
61.4 \\
63.3 \\
59.5 \\
58.9\end{array}$ & $\begin{array}{r}16265 \\
9456 \\
10539 \\
6757 \\
12462 \\
15770 \\
12028 \\
15167 \\
11226 \\
12257 \\
15326 \\
15154 \\
17300 \\
4272 \\
14957 \\
9148 \\
15608 \\
10220 \\
11128\end{array}$ & $\begin{array}{r}24.2 \\
7.9 \\
7.6 \\
10.1 \\
18.5 \\
11.7 \\
13.0 \\
16.9 \\
7.7 \\
8.6 \\
8.9 \\
26.3 \\
12.0 \\
3.2 \\
22.5 \\
12.7 \\
16.6 \\
12.2 \\
10.5\end{array}$ & $\begin{array}{l}25271 \\
21291 \\
42279 \\
15232 \\
19439 \\
26396 \\
21610 \\
21843 \\
20707 \\
27775 \\
27181 \\
19588 \\
29504 \\
17493 \\
23461 \\
22580 \\
25220 \\
17511 \\
17906\end{array}$ & $\begin{array}{r}13677 \\
13249 \\
18146 \\
7758 \\
12837 \\
11882 \\
11091 \\
14019 \\
9493 \\
11721 \\
15927 \\
14947 \\
17190 \\
6159 \\
17450 \\
9446 \\
13088 \\
8421 \\
12236\end{array}$ & $\begin{array}{r}20.4 \\
11.0 \\
13.0 \\
11.5 \\
19.1 \\
8.8 \\
12.0 \\
15.6 \\
6.5 \\
8.2 \\
9.2 \\
25.9 \\
11.9 \\
4.6 \\
26.3 \\
13.1 \\
14.0 \\
10.0 \\
11.5\end{array}$ & $\begin{array}{r}0.189 \\
-0.286 \\
-0.419 \\
-0.129 \\
-0.029 \\
0.327 \\
0.085 \\
0.082 \\
0.183 \\
0.046 \\
-0.038 \\
0.014 \\
0.006 \\
-0.306 \\
-0.143 \\
-0.032 \\
0.193 \\
0.214 \\
-0.091\end{array}$ \\
\hline $\begin{array}{l}\text { faximum } \\
\text { inimum }\end{array}$ & $\begin{array}{l}58.4 \\
68.5 \\
46.3\end{array}$ & $\begin{array}{r}12370 \\
17300 \\
4272\end{array}$ & $\begin{array}{r}13.2 \\
26.3 \\
3.2\end{array}$ & $\begin{array}{l}23278 \\
42279 \\
15232\end{array}$ & $\begin{array}{r}12565 \\
18146 \\
6159\end{array}$ & $\begin{array}{r}13.3 \\
26.3 \\
4.6\end{array}$ & $\begin{array}{r}-0.007 \\
0.327 \\
-0.419\end{array}$ \\
\hline
\end{tabular}

(a) Heat error = (PRISM heating component - actual heat)/actual heat. 
IABLE 4.6: Comparison of PRISM estimates and measured space heat for the Hood River homes in the post-retrofit period (kwh/year).

\begin{tabular}{|c|c|c|c|c|c|c|c|}
\hline \multirow[b]{2}{*}{ Site ID } & \multirow[b]{2}{*}{$\begin{array}{c}\text { T-ref } \\
\cdot \boldsymbol{F}\end{array}$} & \multicolumn{3}{|c|}{ PRISH Estimates } & \multirow{2}{*}{\multicolumn{2}{|c|}{$\frac{\text { Measured Heat }}{k^{1+h / \mathrm{ft}^{2}}}$}} & \multirow[b]{2}{*}{$\begin{array}{l}\text { Heat } \\
\text { Error }\end{array}$} \\
\hline & & $k$ Wh & $\frac{\text { Heat }}{k \mathrm{k}^{\mathrm{h} h} / \mathrm{ft}^{2}}$ & $\begin{array}{c}\text { Total, } \\
\text { kWh }\end{array}$ & & & \\
\hline $\begin{array}{l}4298 \\
4341 \\
4322 \\
4397 \\
4306 \\
4076 \\
4090 \\
4185 \\
4062 \\
4016\end{array}$ & $\begin{array}{l}49.4 \\
54.2 \\
51.3 \\
63.3 \\
58.5 \\
55.0 \\
53.7 \\
45.0\end{array}$ & $\begin{array}{r}\overline{11141} \\
9379 \\
12560 \\
14972 \\
11132 \\
10578 \\
12690 \\
4431 \\
10851 \\
12064\end{array}$ & $\begin{array}{r}16.6 \\
7.8 \\
9.0 \\
16.2 \\
7.7 \\
7.4 \\
7.3 \\
3.3 \\
12.9 \\
11.4\end{array}$ & & $\begin{array}{r}14770 \\
12288 \\
17987 \\
11712 \\
9991 \\
12297 \\
14924 \\
7505 \\
9452 \\
11860\end{array}$ & $\begin{array}{r}12 \\
12 \\
6 \\
8 \\
8 \\
5 \\
11 \\
11\end{array}$ & $\begin{array}{r}-0.23 \\
-0.30 \\
0.27 \\
0.11 \\
-0.14 \\
-0.15 \\
-0.41 \\
0.14 \\
0.01\end{array}$ \\
\hline & 3 & $\begin{array}{r}10980 \\
14972 \\
4431\end{array}$ & $\begin{array}{r}10.0 \\
16.6 \\
3.3\end{array}$ & & & & \\
\hline
\end{tabular}

(a) Heat error $=$ (PRISM heating component - actual heat) $/$ actual heat.

however, when the ratio of the heating load to total loads is considered, Table 4.7 displays the PRISM heating estimate error and the ratio of the heating load to total load. PRISM overestimates heating more when the heating load is a small proportion of total load. The three samples illustrate a clear trend as the heating load becomes a larger share of the total. The error declines and, for our HRCP sample, reverses signs when the heating load comprises about $50 \%$ of the total load. It thus appears that PRISM can underestimate the heating load if heating constitutes a large enough share of the total load and our results are consistent with other data when this behavior is taken into account.

\subsection{ADJUSTMENT OF PRISH HEATING COMPONENT WITHIN CLIMATE ZONE}

As the results in Tables 4.4 through 4.6 indicate, PRISM estimates of the heating component can differ substantially from metered heating energy consumption. The errors ranged from $-42 \%$ to $+102 \%$ for the homes analyzed here, and the mean value of the errors tended to obscure the large variance 
Iable 4.7. Variation in PRISM Heating Estimate Error with Space Heat Proportion of Total Loada

\begin{tabular}{|c|c|c|c|}
\hline \multirow[b]{3}{*}{$\begin{array}{l}\text { Average heat } \\
\text { load over } \\
\text { total load }\end{array}$} & \multicolumn{2}{|r|}{ Samole } & \multirow[b]{2}{*}{$\begin{array}{c}\text { Hood River } \\
\text { Manufactured Homes }\end{array}$} \\
\hline & $\begin{array}{c}\text { Tulal ip } \\
\text { Homes }\end{array}$ & $\begin{array}{l}185 \text { Hood River } \\
\text { All Electric Homes }\end{array}$ & \\
\hline & 0.31 & 0.48 & 0.54 \\
\hline $\begin{array}{l}\text { Average PRISM } \\
\text { heating } \\
\text { estimate errorC }\end{array}$ & $+52 x$ & $+14 x$ & $-3.6 \%$ \\
\hline
\end{tabular}

(a) Average heat load over total load is the average across the homes in each data set except the set of 185 hones which is calculated as the average heat load for all the homes divided by the average total load.

(b) Hirst and Goeltz (1986).

(c) The error is calculated as the difference between the PRISM heating component estimate and the measured load divided by the measured load.

in the differences. Particularly troubling was the fact that the errors tended to be positive and larger for energy-efficient homes. (a)

Our research objective required estimating the energy savings attributable to substantial efficiency improvements. More efficient homes should have a smaller share of their load consumed by space heating and, based on our observations, PRISH would overestimate their heating loads. One consequence is that PRISM would underestimate substantially the heating energy savings_of energy-efficient homes. As a result, we felt it was essential to develop procedures that would improve the energy consumption and savings estimates based on PRISH.

This section briefly discusses a methodology developed to adjust PRISM's estimates of heating consumption based on measured data. The methodology is fully discussed in Appendix B. The technique was developed to increase the utility of information from PRISM in estimating heating loads within a giver

(a) The effects of seasonal, non-heating loads, occupant behavior, heating system zoning, and other factors contribute to the increased error observed with efficient homes. 
climate zone. Section 5 presents a methodology that can be used to improve extrapolations to other climate zones.

One principle observed in developing the adjustment methodology was to restrict the required information to two kinds of data. One kind is provided by PRISM ttself, such as the PRISH-based reference temperature (T-ref). The second kind consists of data readily obtained for specific homes being analyzed with PRISM, such as weather data or the design UA.

We assume that a true, but hypothetical, linear relationship with a form similar to that of the PRISH heating component term exists for predicting heating energy consumption. Next, we use measured space heating data and the PRISM estinates to create a proportional measure of the error resulting from using the PRISH heating component to estimate the actual heating consumption. We assume that the difference between the actual and PRISM-estimated heating energy consumption can be explained in terms of the differences between the PRISH coefficients and the "true" coefficients in the hypothetical linear relationship. The next assuaption is that the PRISM estimates of each term in the heating consumption relationship can be written as the actual value of that term plus what we might call an error term. Next, we select variables that can serve as proxies for unobserved variables (such as the reference temperature error, or difference between the actual and PRISM estimates of the reference temperature). Finally, we use regression analysis to estimate a set of parameters that allow us to adjust the PRISM heating component estimate to better fit the measured heating data.

This procedure provided the equation below. It was estimated based on data from the end-use metered HRCP homes and the Tulalip homes.

Adjusted heating consumption $=0.982$ * PRISH heating component $-0.841 *$ HDD + 61.8*UA $-567.5 *$ PRISH reference temperature * UA

HDD is based on $65^{\circ} \mathrm{F}$ and UA refers to the design UA. The adjusted R-squared for this regression was 0.88 and all the coefficients were significant at the 99\% level or better. 
This relationship contains, as desired, only variables that are readily measured or are produced by PRISM. It indicates that the adjusted estimate of heating consumption is $\mathbf{9 8 . 2 \%}$ of the PRISM estimate plus the correction due to the other terms.

We compared the adjusted heating energy estimates with the measured heating data for the HRCP and Tulalip homes. Comparing averages, the adjusted estimates were about $69 \%$ better than the basic PRISM estimates. The standard deviation of the error for the adjusted estimates was about half the standard deviation of the errors for the PRISM-based estimates. The adjusted estimates are considerably closer to the medsured heating consumption values and the adjustment procedure worked well for both energy-efficient and conventional homes.

We used this equation to adjust our PRISH heating component estimates for the Hood River homes for which only billing data were available. The PRISH estimates and this adjustment provided heating energy values for these homes that were used as the basis for estimating energy savings. In conjunction with the technique described in Section 5, we extrapolated the Hood River results to the MCS climate zone cities. 


\subsection{CROSS-CLIMATE ADJUSTMENT OF HEATING LOAD ESTIMATES}

This section discusses a methodology developed to adjust for the effects of climate differences in heating energy consumption estimates. This adjustment allows us to extrapolate energy consumption estimates from Hood River to the three target cittes used to represent the three MCS climate zones: Seattle for zone 1, Spokane for zone 2, and Missoula for zone 3.

\subsection{INTRODUCTION}

The geographic distribution of the bulldings available for analysis presented a problen for this study, because essentially the whole data set resides in climate zone 1 . Assuming that a pre- and post-retrofit home can be considered to be two data points, the distribution of data points across climate zones is shown in Table 5.1; this includes all homes that could be analyzed for this study using either the PRISH methodology (Section 4) or the PNL RSDP methodology (Appendix A) after deleting those homes for which data were contaninated by wood heat use or poor statistics.

IABLE 5.1. Number of Data Points in Each Climate Zone MCS Climate Zone

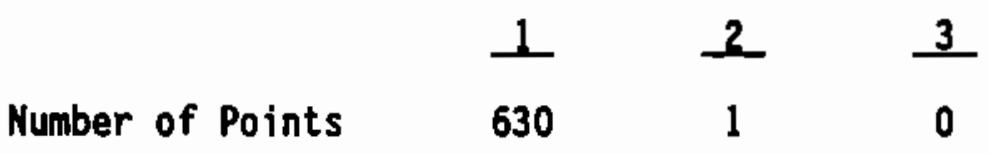

One response to the lack of measured data for zones 2 and 3 would be to base this report on simulated, rather than measured, data. However, extensive data were available at the billing level and it was deemed prudent to use the large amount of billing data available for manufactured homes, rather than to rely solely on simulations.

Since this study must predict energy use in zones 2 and 3 , even though the data come from zone 1, the method of extrapolating from zone 1 to zones 2 and 3 demands careful examination. PRISM, the tool used with these billing data, is typically used to extrapolate energy use estimates from one climate to another climate. It uses the measured data from the first climate to 
establish the functional relationship between energy use and temperature. As described in Section 4, PRISH determines the best fit to an equation of this form:

Energy = baseload + slope * HDD based on calculated T-ref

To predict the heating energy use in the second location, PRISM simply computes the heating degree-days (HDO) for the new climate based on the calculated T-ref and multiplies the HOD by the slope. This implies that any relationship between $c l$ inatic variables and temperature in the first $c$ limate will hold in the PRISM extrapolation to the second climate.

\subsection{POTEMTIAL ERROR OF PRISM-BASED HEATING LOAD PREDICTIONS}

This section focuses on the correlation between temperature, which PRISM assumes is the driving variable for heating loads, and other climatic variables which may affect the heating load. This relationship will be explored graphicaliy, focusing on the relationship between heating energy use and temperature in four different locations.

The climates in the Northwest have a wide range of temperature and solar characteristics, which may cause difficulties when using PRISM to extrapolate heating energy consumption results from one climate to another. The variation between climatic factors that influence heating consumption is not a smooth transition from warmest to coldest climate. For example, Hood River, where most of the measured data were produced, may be climatically atypical compared to climates in other Northwest cities. In total annual solar radiation (for the period studied), Hood River lies between Spokane and Missoula, while in terms of HDD Hood River has fewer than either Spokane or Missoula. In range of temperatures over the year, Hood River is similar to Spokane; however, in mean annual temperature Hood River is very close to Seattle which has fewer HDD than Hood River. Because Hood River's climate is more severe than other $\mathrm{climates}$ based on some measures and less severe based on others, controlling for climatic variables other than HDD may produce a more accurate extrapolation of energy usage to other locations.

Figure 5.1 illustrates two potential biases that may result from using temperature data alone to extrapolate measured heating energy data from one 


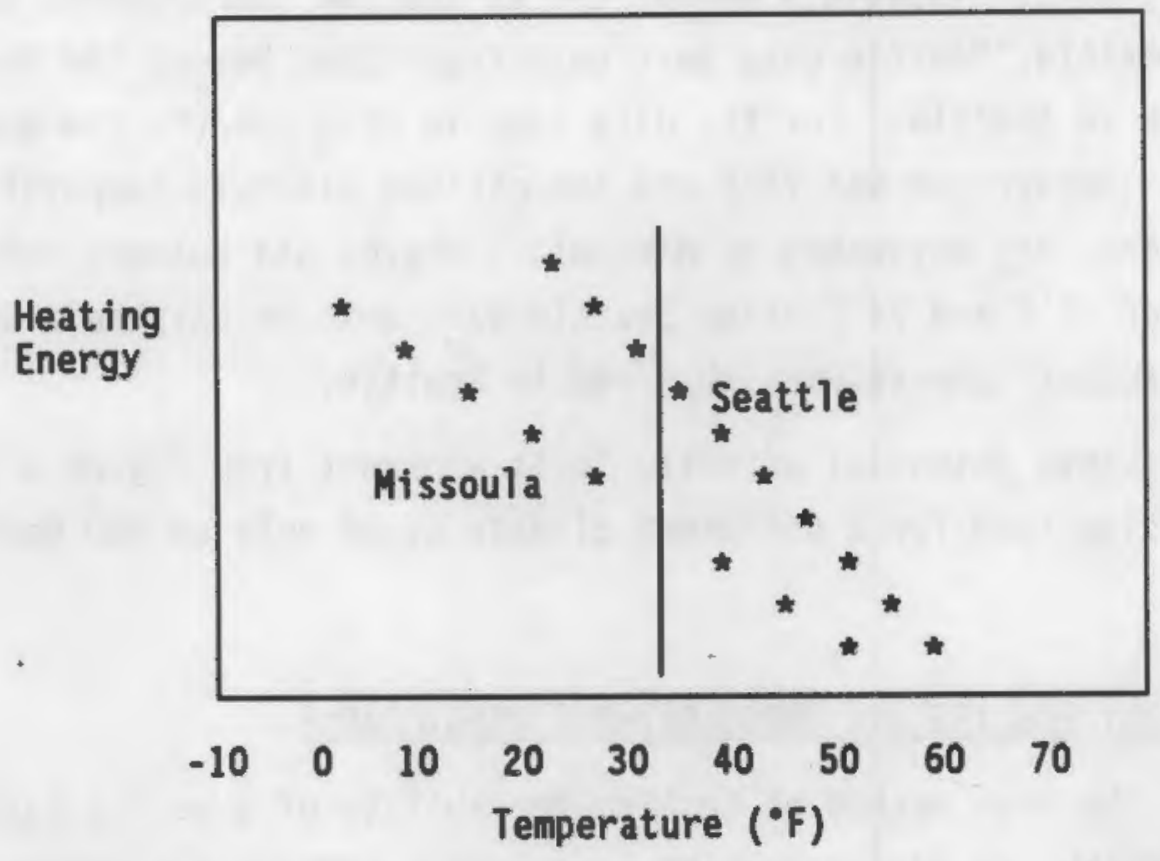

Eiqure 5.1. Hypothetical Heating Energy Use Versus Temperature

climate to another climate. This is a hypothetical plot of heating energy use versus outdoor temperature. The $Y$-axis is the heating load in arbitrary units. The $X$-axis is the outdoor temperature. The upper points show the hypothetical relationship between heating energy and temperature for Seattle, while the lower points show the relationship for Missoula. The heating energy used increases as the temperature decreases in both cases. However, there are two significant differences in the points for Seattle and Missoula that are discussed below.

The first hypothesized bias is apparent in the difference in heating energies required at specific temperatures in the two climates. The vertical line on the graph shows a higher heating energy required in Seattle at $35^{\circ} \mathrm{F}$ than required in Missoula at $35^{\circ} \mathrm{F}$. At $35^{\circ} \mathrm{F}$, Seattle days are more likely to be cloudy and, therefore, the solar gains available to offset the heating loads are lower than in Missoula. Lower solar gains in Seattle translate into the higher heating loads seen on the graph at all temperatures.

The second potential bias results from the different distributions of temperatures in the two cities. Missoula has more severe winters than Seattle and, therefore, experiences lower temperatures than are reached in 
Seattle. To predict Missoula's energy use at the low temperatures based on results for Seattle, Seattle data must be extrapolated beyond the temperature range observed in Seattle. For the data used in this report, the minimum Seattle daily temperature was $24^{\circ} \mathrm{F}$ and the minimum Missoula temperature was $-1^{\circ} \mathrm{F}$. Therefore, any estimates of Missoula's energy use between the temperatures of $-1^{\circ} \mathrm{F}$ and $24^{\circ} \mathrm{F}$ using Seattle data must be extrapolated beyond the range of actual temperatures observed in Seattle.

Based on these potential effects, it is apparent from Figure 5.1 that a predicted heating load for a different climate based only on HDD may not be accurate.

\subsection{METHODOLOGY FOR TESTING CROSS-CLIMATE PREDICTIONS}

Ideally, the best method of testing the ability of a method based on HDD, such as PRISM, to adjust heating load across different climates would be to use PRISM on real building data for all the elimates of interest. The PRISM results from buildings in one climate could be applied to buildings in the second $\mathrm{cl}$ imate and compared to the actual energy use. In practice this testing procedure for examining the performance of a single building in two locations is difficult because of the variations in building placement, building construction, and occupant behavior in the different sites. For this reason "synthetic data" generated by a simulation model were used to examine the ability of PRISM to adfust heating loads across different climates. The synthetic data were generated for the climates representing Hood River and MCS zones 1, 2, and 3 over a range of building characteristics. For simplicity in the rest of this section, the synthetic data will sometimes be referred to simply as "data" with the understanding that simulations can not produce "real" or measured data.

The use of synthetic data to examine the biases in HDD-based extrapolation models has significant advantages which allow a systematic investigation of the bias associated with the problem. It is relatively simple to generate simulation data for a range of buildings and climates. Each specific building design can be placed in several climates, holding many factors constant that would otherwise confound the results. Uncertainties regarding energy use or temperatures and the noise likely to be present in 
measured data are eliminated. Occupant effects, building orientation, and shading can be held constant. Most significantly, the exact "answer" is known for all situations of interest.

For instance, the heating energy in Spokane can be projected from the PRISM estimate (based on the synthetic Hood River billing data) by applying Spokane's weather conditions (HDD). The projection can then be compared to the "answer" from the Spokane simulation. Generation of a range of synthetic data allows testing of the temperature-based model and derivation of a correction factor based on the difference between the temperature-based model and the synthetic data.

The use of synthetic data to correct models, like PRISM, does not require that a specific real building be simulated. In fact, simulation of a particular real building is difficult because several variables, especially occupancy behavior, are difficult to model. The important requirement is that the simulated buildings behave like the real buildings in their response to the parameters of interest. For instance, if the solar gains are of interest, the simulated building heating load must respond to the sun in a manner similar to the real building. Solar transmission through glazing can be calculated fairly accurately with the model we used, consequently the simulations can be used to study overall solar effects. If the simulation does not reasonably model a parameter being studied, then its results should not be used to study that parameter. For instance, the infiltration model used here was simplistic, a constant infiltration rate, while it is known that infiltration actually is a function of temperature difference and wind speed. Therefore, the results used here are not appropriate for the study of cross-climate heating energy variations related to infiltration. The other important simplification in our model is the use of an internal gains schedule that is constant from day to day.

The hourly simulation program SUNCODE (Palmiter and Wheeling 1984) was used to generate the synthetic heating data for the different climates. SUNCODE is a thermal analysis model intended primarily for residential applications. SUNCODE models the significant weather variables, building construction, and occupant behavior that affect heating loads. Typical Meteorological Year (TMY) (NOAA 1979) weather data for Seattle (zone 1), 
Spokane (zone 2), and Missoula (zone 3) were used as SUNCODE input. TMY weather data are based on long-term average weather data. The TMY data are composed of months of real measured data which represent average data and are in agreement with long-term weather patterns for the location represented. TMY data selection was weighted strongly on solar parameters, which we believe are primary climatic variables that PRISM does not model. TMY data were not available for Hood River so, instead, measured Hood River weather data for the period of mid-1985 to mid-1986 were used.

As a subjective graphical comparison, real data and simulated data are shown in the next two graphics. Figure 5.2 presents real data for a house in Hood River. Figure 5:3 shows simulation data for a prototypical house in Hood River. In both figures, the $Y$-axis is the heating energy in kWh per day and the $X$-axis is the daily average outdoor temperature. Note that the simulation data look similar to the real Hood River data, al though the simulation data exhibit slightly less scatter.

We used SUNCODE to produce output for both daily and monthly periods. Previous work by Palmiter and Toney (1987) has shown that linear HDD models, like PRISM, may be sensitive to the aggregation of time periods. The monthly period corresponds to the usual billing data period utilized by PRISM. The graphical examination presented later, however, is done primarily at the daily level to allow a more detailed examination of the parameters believed to be important in adjusting PRISM results across climates.

We ran SUNCODE for three UA levels, which cover a wide range of construction. These will be referred to as low-UA, medium-UA, and high-UA, and are defined by the ECM levels shown in Table 5.2. The low-UA correponded approximately to the Model Conservation Standards (MCS) requirements for zone 3 (Collette 1987); medium-UA levels represented typical construction (Collette 1987); and the high-UA values approximated a relatively uninsulated home. The effects of infiltration are included in the UA. 


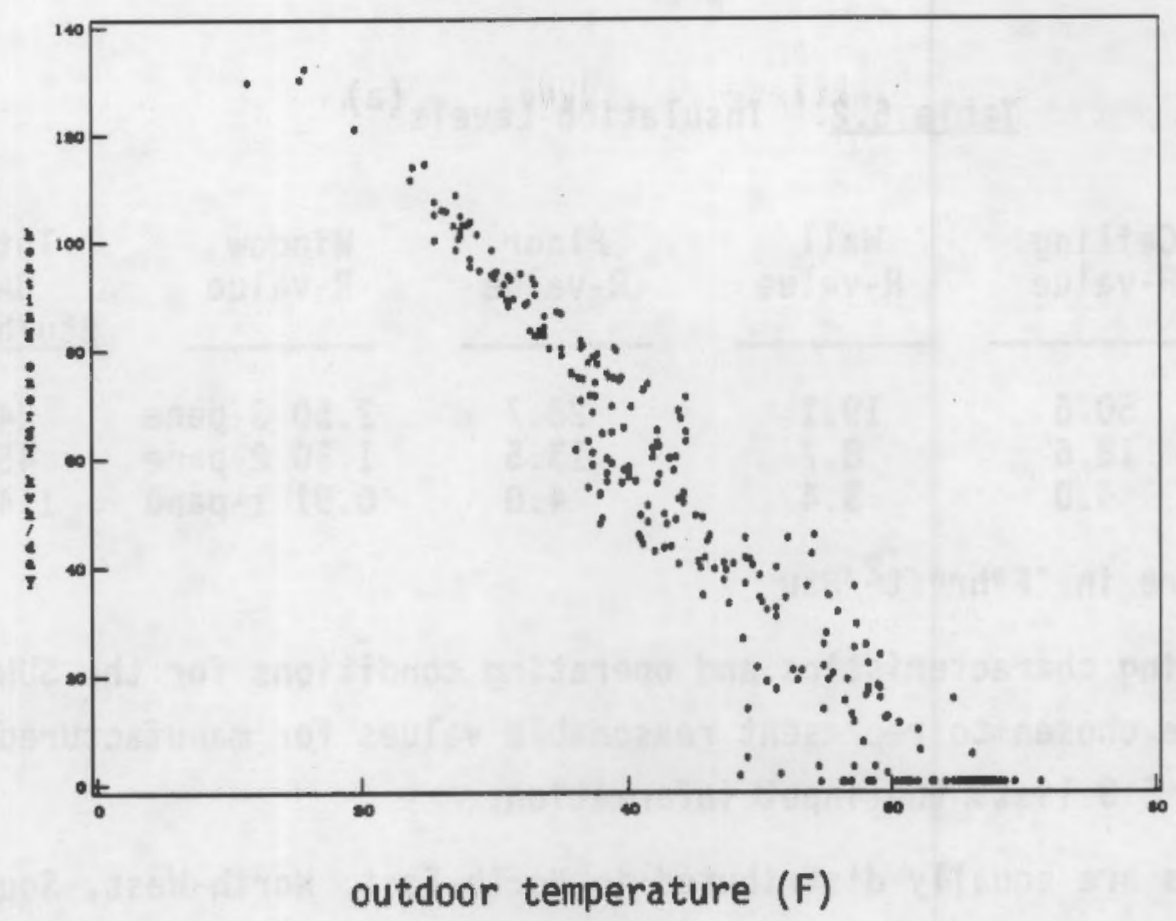

FIGURE 5.2. Heating Energy vs. outdoor Temp. - Hood River (real)

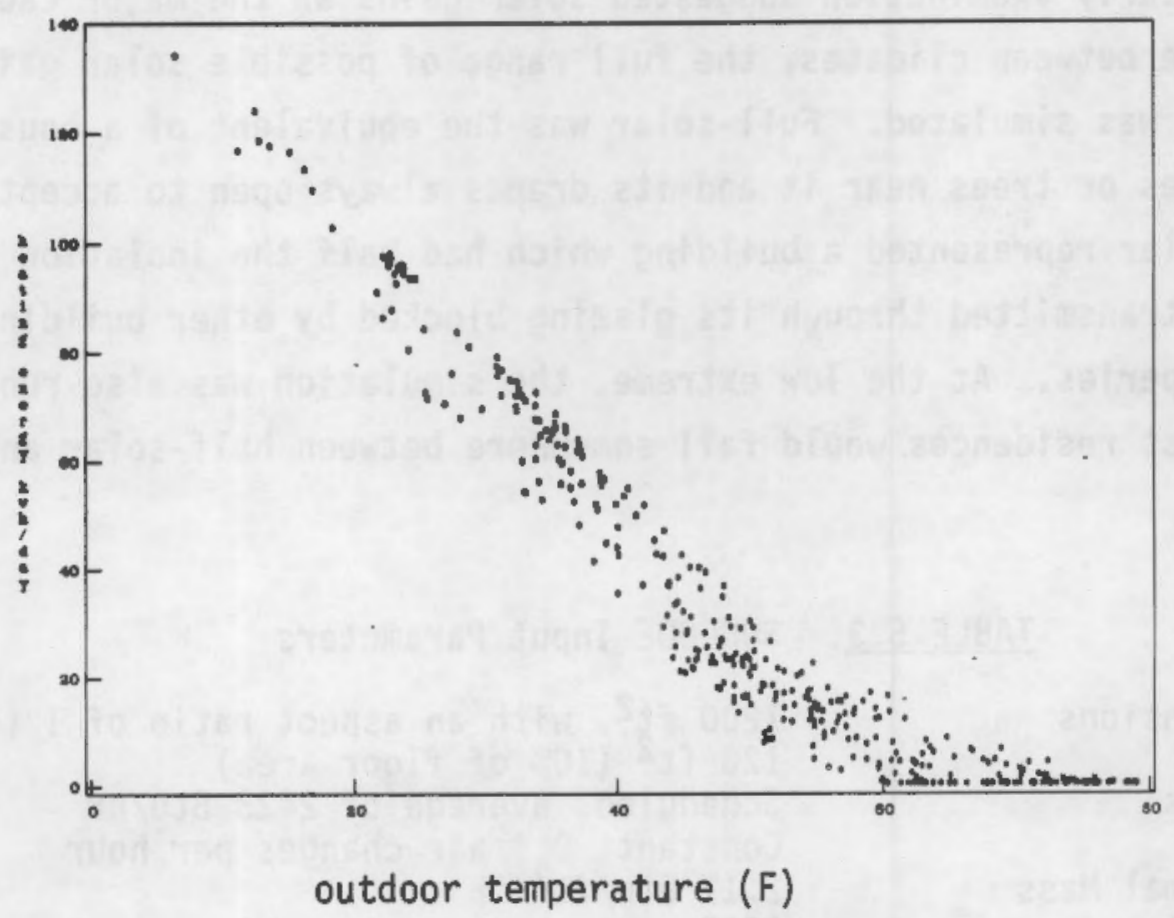

FIGURE 5.3. Heating Energy vs. Outdoor Temp. - Hood River (SUNCODE) 
Table 5.2. Insulation Levels ${ }^{(a)}$

\begin{tabular}{|c|c|c|c|c|c|}
\hline & $\begin{array}{l}\text { Ceiling } \\
\text { R-value }\end{array}$ & $\begin{array}{l}\text { Wall } \\
\text { R-value }\end{array}$ & $\begin{array}{c}\text { Floor } \\
\text { R-value }\end{array}$ & $\begin{array}{l}\text { Hindow } \\
\text { R-value }\end{array}$ & $\begin{array}{c}\text { Total } \\
U A \\
B \text { Btu/hr/ } /{ }^{\circ} \mathrm{F} \\
\end{array}$ \\
\hline $\begin{array}{l}\text { Low } \\
\text { Medium } \\
\text { High }\end{array}$ & $\begin{array}{r}50.6 \\
18.6 \\
4.0\end{array}$ & $\begin{array}{r}19.1 \\
8.7 \\
3.4\end{array}$ & $\begin{array}{r}28.7 \\
13.5 \\
4.0\end{array}$ & $\begin{array}{l}2.50 \text { 3-pane } \\
1.30 \text { 2-pane } \\
0.91 \text { 1-pane }\end{array}$ & $\begin{array}{r}244 \\
450 \\
1144\end{array}$ \\
\hline
\end{tabular}

(a) R-values are in ${ }^{\circ} * \mathrm{hr}^{\star} \mathrm{ft}^{2} /$ Btu

The other building characteristics and operating conditions for the SUNCODE simulations were chosen to represent reasonable values for manufactured housing. Table 5.3 lists the input information.

The windows are equally distributed in North-East, North-Hest, SouthEast, and South-Hest orientations. The building orientation, 45 degrees off North, was chosen to lessen the impact of the long building axis orientation on energy use.

Because early examination suggested solar gains as the major cause of the difference between climates, the full range of possible solar gains for this building was simulated. Full-solar was the equivalent of a house with no other houses or trees near it and its drapes always open to accept the sun. Half-solar represented a building which had half the inolation on its exterior and transmitted through its glazing blocked by other buildings, trees, or draperies. At the low extreme, the simulation was also run with no-solar. Most residences would fall somewhere between half-solar and fullsolar.

IABLE 5.3. SUNCODE Input Parameters

Building Dimensions

Window Area

Internal Gains

Infiltration

Internal Thermal Mass

Heating Setpoint

Setback Setpoint

Setback Schedule

Heating System

Exterior Solar Absorptivity
$1200 \mathrm{ft}^{2}$, with an aspect ratio of 1 to 2

$120 \mathrm{ft}^{2}$ (10\% of floor area)

Scheduled, average of $2423 \mathrm{Btu} / \mathrm{hr}$

Constant, 0,4 air changes per hour

$2.17 \mathrm{Btu} / \mathrm{ft}^{2 \star *} \mathrm{~F}$

$68^{\circ} \mathrm{F}$

$60^{\circ} \mathrm{F}$ (on set-back runs)

12 PM to 6 AM (on set-back runs)

Electric baseboard

.7 (a medium hue exterior) 
These simulations used a constant infiltration rate. In reality, the infiltration rate varies with wind speed and indoor-outdoor temperature difference; therefore, this study does not reflect the differing infiltration loads occurring in the different climates. Nor do these simulations reflect the error in climate adjustment resulting from the varying correlation of wind speed and temperature with the different climates.

Nine basic simulations were done in each location: the 3 UAs for the 3 insolation levels. In addition, four simulations were done in each location with night-time setbacks. These setback runs had low- and medium-UAs with both half- and full-solar.

\subsection{ERROR INTRODUCED BY HDD EXTRAPOLATION METHOD}

The first analysis done with the SUNCODE outputs examined how well a linear HDD model (such as PRISM) extrapolated heating energy consumption from one climate to another. He used an approach similar to PRISM to fit the SUNCODE monthly heating energy estimates for a base city and the resulting reference temperature and slope to extrapolate to other locations. This analysis differed from PRISM in that we worked only with heating energy, therefore excluding effects of other loads.

The error introduced by adjusting the heating load from one $\mathrm{climate}$ to a different climate using the heating degree-day correction factor has been quantified in Table 5.4. This table displays the percentage difference between the predicted target climate heating load, based on data from the base climate, and the "true" simulated loads for the target climate. The cities in the columns are the base climate locations; the cities in the rows are the target locations. For example, with half-solar and low-UA, the prediction of Seattle's load based on the regression developed for Spokane is 24\% lower than Seattle's true load.

A number of key points are readily apparent from an inspection of Table 5.4. First, the cross-climate predictions are quite accurate under the no- 
IABLE 5.4. Percent Difference Between HDD Based Predicted Load And True Load

Target

Climate

NO SOLAR

LOW UA

NO SOLAR

MEDIUM UA

Seattle

Hood River

Spokane

Missoula

Seattle

Hood River

Spokane

Missoula

NO SOLAR

HIGH UA

Seattle

Hood River

Spokane

Missoula

HALF SOLAR

LOW UA

Seattle

Hood River

Spokane

Missoula

HALF SOLAR

MEDIUM UA

Seattle

Hood River

Spokane

Missoula

HALF SOLAR

HIGH UA

Seattle

Hood River

Spokane

Missoula

FULL SOLAR

LOW UA

Seattle

Hood River

Spokane

Missoula

FULL SOLAR

MEDIUM UA

Seattle

Hood River

Spokane

Missoula

FULL SOLAR Seattle

HIGH UA
Hood River

Spokane

Missoula

Base Climate

Seattle Hood River Spokane Missoula

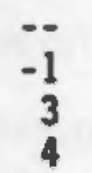

1
-2
6

$-4$

$-5$

$-5$

$-1$

$--$

-1
1
1

1

$-1$

$\because$

2

$-2$

$-1$

$-1$

$-\cdot$

--
-2
-1
0

2
-1
1

2
-1

1

$-1$

$\ddot{0}$

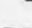

7

20

21

$\begin{array}{rrr}-4 & -24 & -21 \\ -- & -13 & -13 \\ 12 & -. & -1 \\ 12 & 2 & --\end{array}$

-
2
8

$\begin{array}{rrr}-3 & -12 & -9 \\ -- & -7 & -6 \\ 6 & -- & 0 \\ 6 & 0 & --\end{array}$

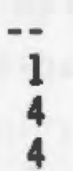

$-1$

$-5$

$-3$

$-6$

$-$

3

$-4$

$-1$

1

$-$

$-8$

$-40$

$-21$

12

34

35

19

19

$\begin{array}{ll}-- & -3 \\ 4 & --\end{array}$

$-4 \quad-23$

$-13$

$-. \quad-13$

12

$-9$

14

11

9

$--$

$-2$

-.

$\begin{array}{rrrr}-- & -3 & -12 & -10 \\ 2 & -- & -7 & -6 \\ 8 & 7 & -- & 0 \\ 7 & 6 & 0 & --\end{array}$


solar condition. The predictions become less and less accurate as solar increases. This shows that without solar energy inputs, the heating energy simplifies to being primarily a function of HDD for the SUNCODE model. Second, in terms of percentage error, the cross-climate extrapolations for low-UA houses tend to be much less accurate than extrapolations for the highUA houses. Third, the heating predictions from the warmer climates overestimate the colder climate loads and, conversely, the predictions from the colder climates underestimate the warmer climate loads. This is a systematic bias that will be present in PRISM results. The worst cases are Spokane's $42 \%$ underprediction of Seattle and Seațtle's $35 \%$ overprediction of Missoula, both for the full-solar, low-UA house. Note that projections between Spokane and Missoula tend to agree well with the simulated real data, as do projections between Hood River and Seattle. The results for the setback runs are not included in the table. Results for these simulations were very similar to the numbers obtained for the buildings with the same solar and UA levels but without the setback.

In summary, these results indicate that significant errors are likely to be introduced by using extrapolations based only on HDD. The errors are aggravated when solar gains differ substantially across climate zones. Dur results suggest that the errors can be as much as $40 \%$.

\subsection{GRAPHICAL ANALYSIS OF CLIMATE PARAMETERS}

This section presents a graphical analysis of key climate variables other than HOD that affect heating energy consumption. Solar and diurnal temperature swing will be the focus. Seattle and Missoula, the two most diverse locations in terms of climate, will be used as examples. All parameters will be compared with outdoor temperature, which is the driving variable in a heating degree-day based model.

Figures 5.4 and 5.5 show the SUNCODE estimated heating energy consumption versus outside temperature for Seattle and Missoula, respectively. These plots present the SUNCODE results that correspond to the hypothetical data presented. (The building simulated for these graphs and all remaining graphs is the medium-UA design with night-time setback.) The graphs appear similar, though Missoula is clearly a colder climate. However, 


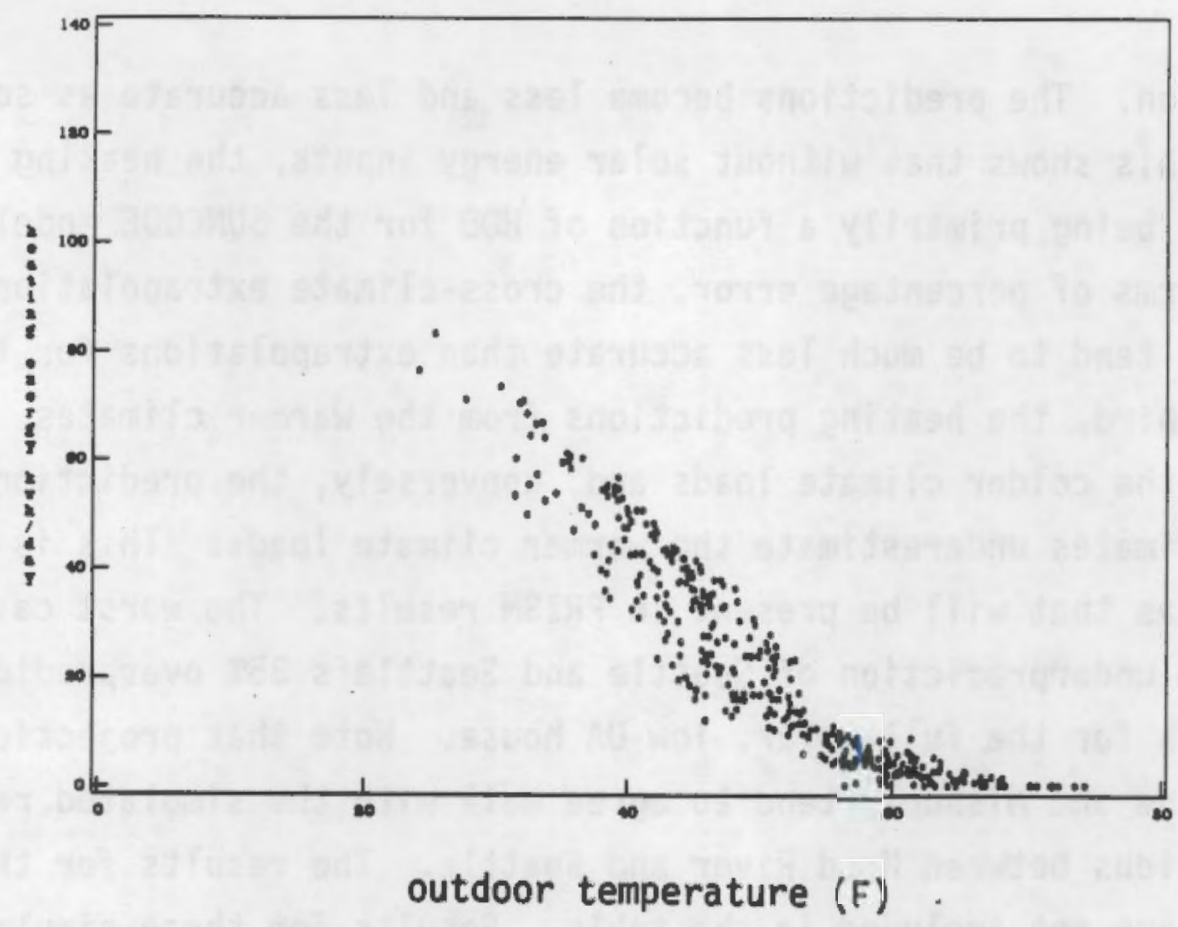

FIGURE 5.4. Heating Energy vs. Outdoor Temp. - Seattle

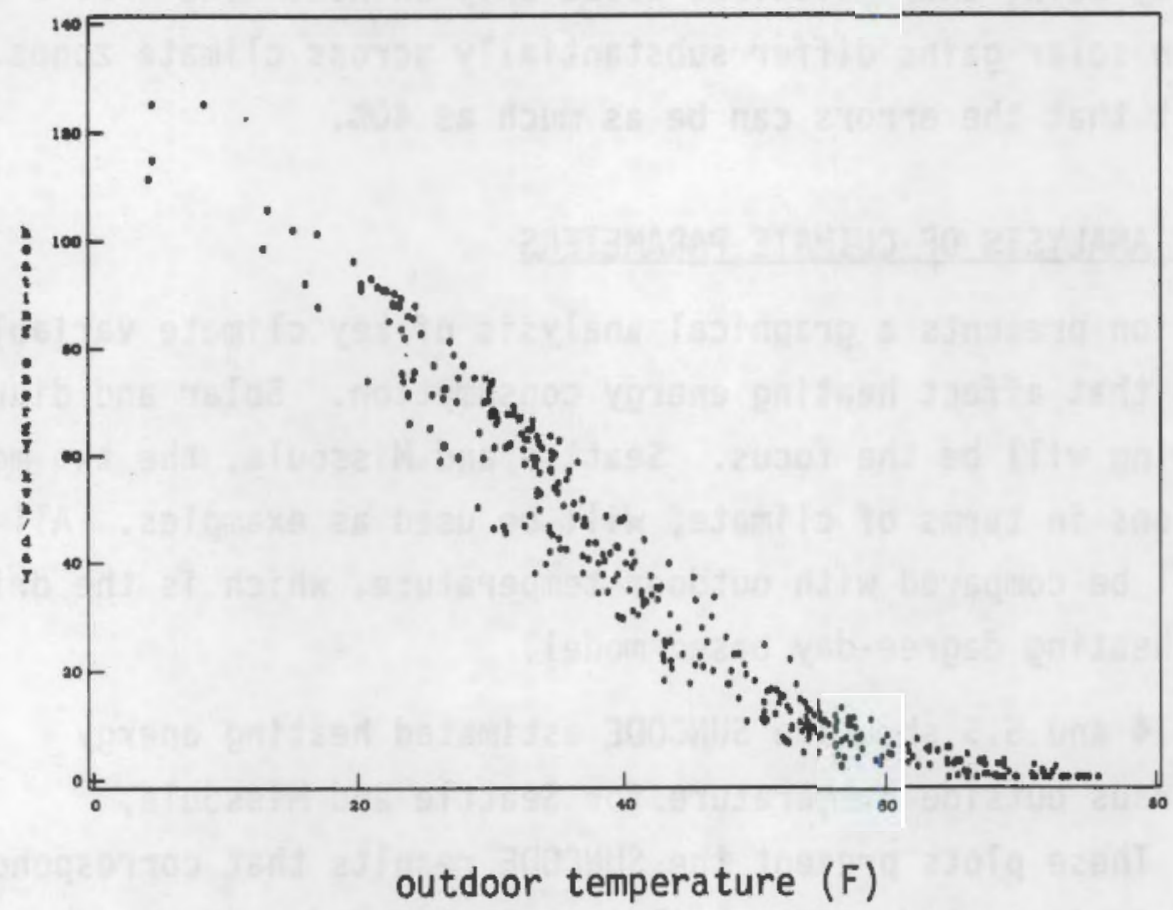

FIGURE 5.5. Heating Energy vs. Outdoor Temp. - Missoula 
a closer inspection reveals that for a particular temperature Seattle often has higher loads than Missoula, as was suggested in Figure 5.1.

Figure 5.6 is a plot similar to Figures 5.4 and 5.5, but without solar gains in the simulated building. Data for both Seattle and Missoula are plotted, and only every fifth day throughout the year is included to 1 imit the data points. Note that the Seattle and Missoula climates behave quite similarly when solar is excluded in the simulation. This implies that the main factor causing the heating degree-day method to err in cross-climate projections is the solar gain (assuming that the neglected infiltration effects are not significant).

The heating energy savings from solar gains in Missoula are plotted as a function of outside temperature in Figure 5.7. The savings are calculated by subtracting each day's energy use for the full-solar simulation from the same day's energy use for the no-solar simulation. This graph can be explained in sections by considering the regions marked with letters in the graph. At high temperatures (area $A$ ), heating savings from solar gains are low because the demand for heat is low. As the temperature decreases (area B) the energy savings from solar increase because the heating load becomes large enough to utilize much of the solar. From just under $40^{\circ} \mathrm{F}$ to about $55^{\circ} \mathrm{F}$ moderate to high solar energy savings are always present. These days occur at times of year when the days are always long enough to generate moderate amounts of solar and the outside temperatures are always low enough to allow full-use of the solar gains. At low temperatures (area C), all of the solar gains are used, and the quantity of solar available is now the limiting factor. Since the quantity of solar available at lower temperatures varies widely, the energy savings for each particular day also vary over a wide range. The lowest solar savings occur on short, cloudy winter days, while the high savings are from longer and sunnier early spring days.

The next graph (Figure 5.8) shows the utilizability of solar energy in Missoula as a function of temperature. The utilizability is defined as the fraction of the solar energy entering the building through the windows that is used to offset the heating load. Very little solar is utilized at high temperatures because of the low heating load. As the temperature goes down, 


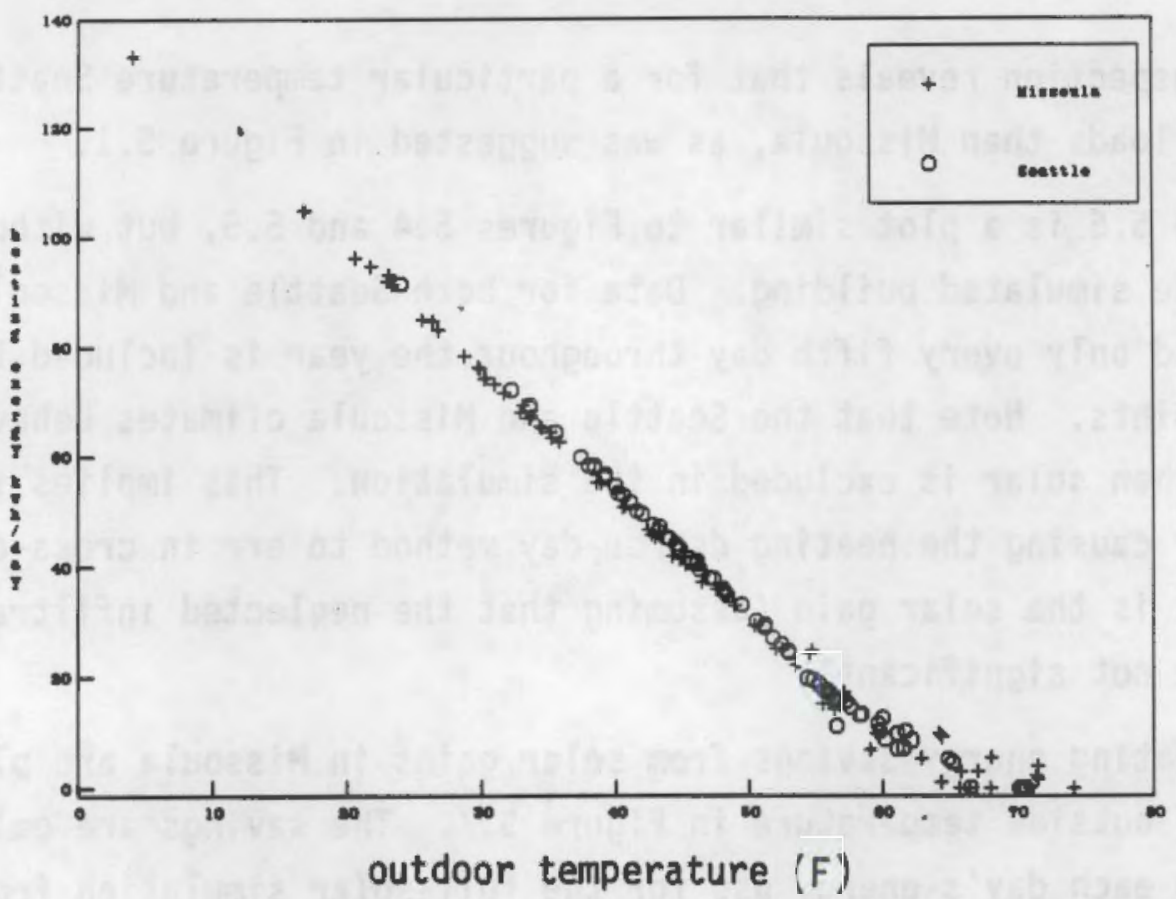

FIGURE 5.6. Heating Energy vs. Outdoor Temp. (no solar) - Seattle \& Missoula

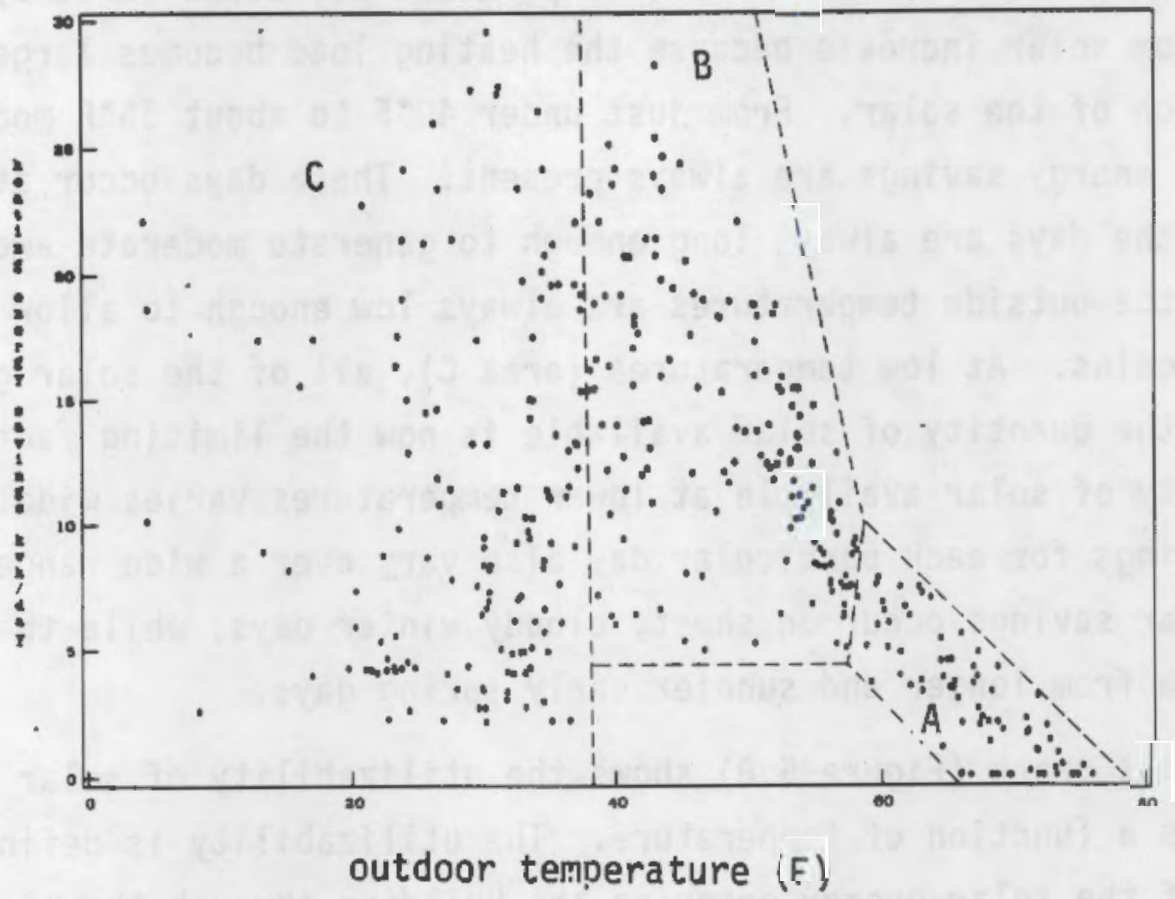

FIGURE 5.7. Heating Energy Savings from Solar vs. Temp. - Missoula 


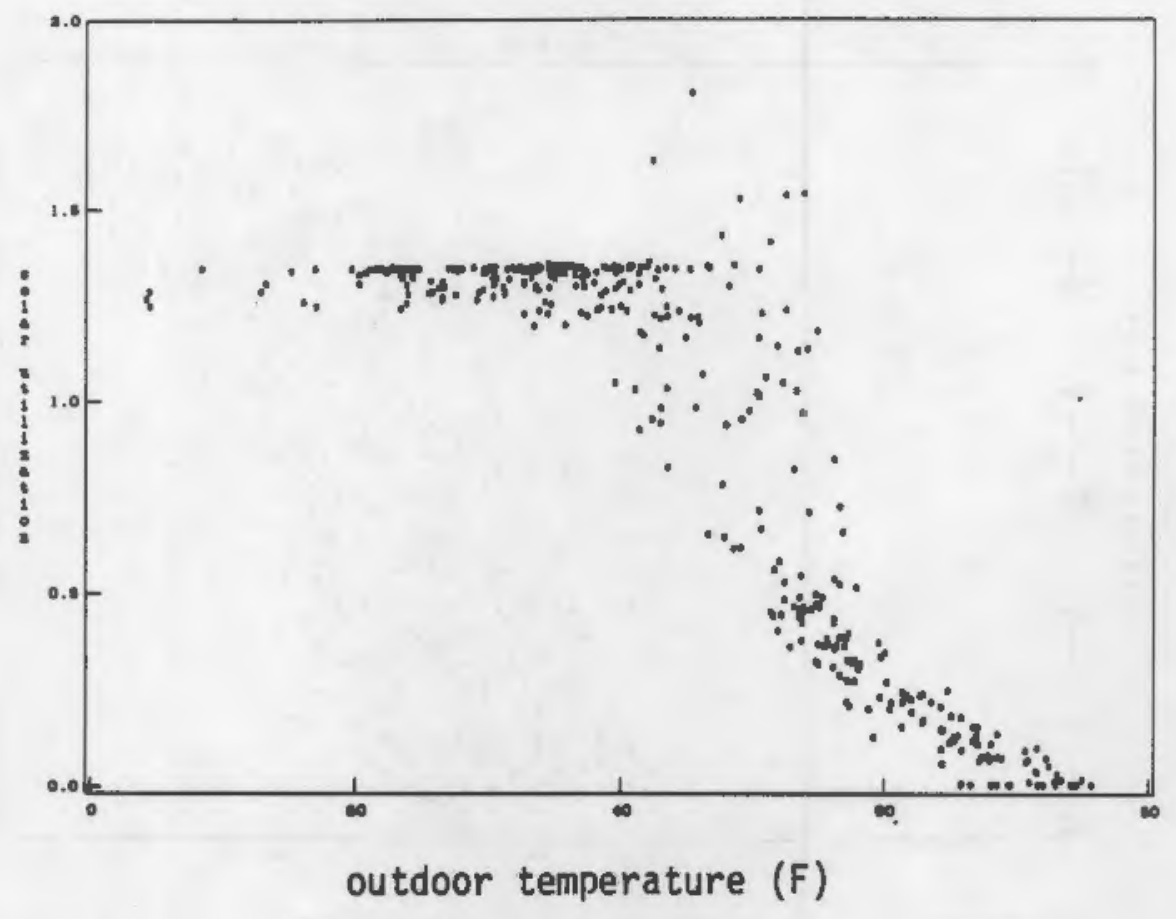

FIGURE 5.8. Solar Utilization vs. Temp. - Missoula

more and more solar is utilized. The utilization reaches a plateau of about 1.3 with a few higher points. If the energy savings were due only to solar gains through the windows the limit on the utilizability would be 1 . However, the energy savings from solar also include solar entering through the walls and the roof. The extra 0.3 represents savings from these components. The few values above 1.3 correspond to seasons when the sun is at its highest angle. On these days, the most solar energy input occurs when the sun is high, resulting in very little solar gains coming through the windows but relatively more coming through the roof.

The daily total solar gains during the year versus temperature are plotted in Figure $\mathbf{5 . 9}$ for Seattle and Figure $\mathbf{5 . 1 0}$ for Missoula. Figure $\mathbf{5 . 1 1}$ is a 1 ine fit through the 365 daily points for both Seattle and Missoula. At any particular temperature Missoula clearly has higher solar gains than Seattle. Seattle's gains drop off quickly as temperatures go below $60^{\circ} \mathrm{F}$, while Missoula's gains remain relatively high. This indicates Missoula has more solar gains at the low temperatures where they can be utilized. This systematic difference in the relationship between temperature and utilizable 


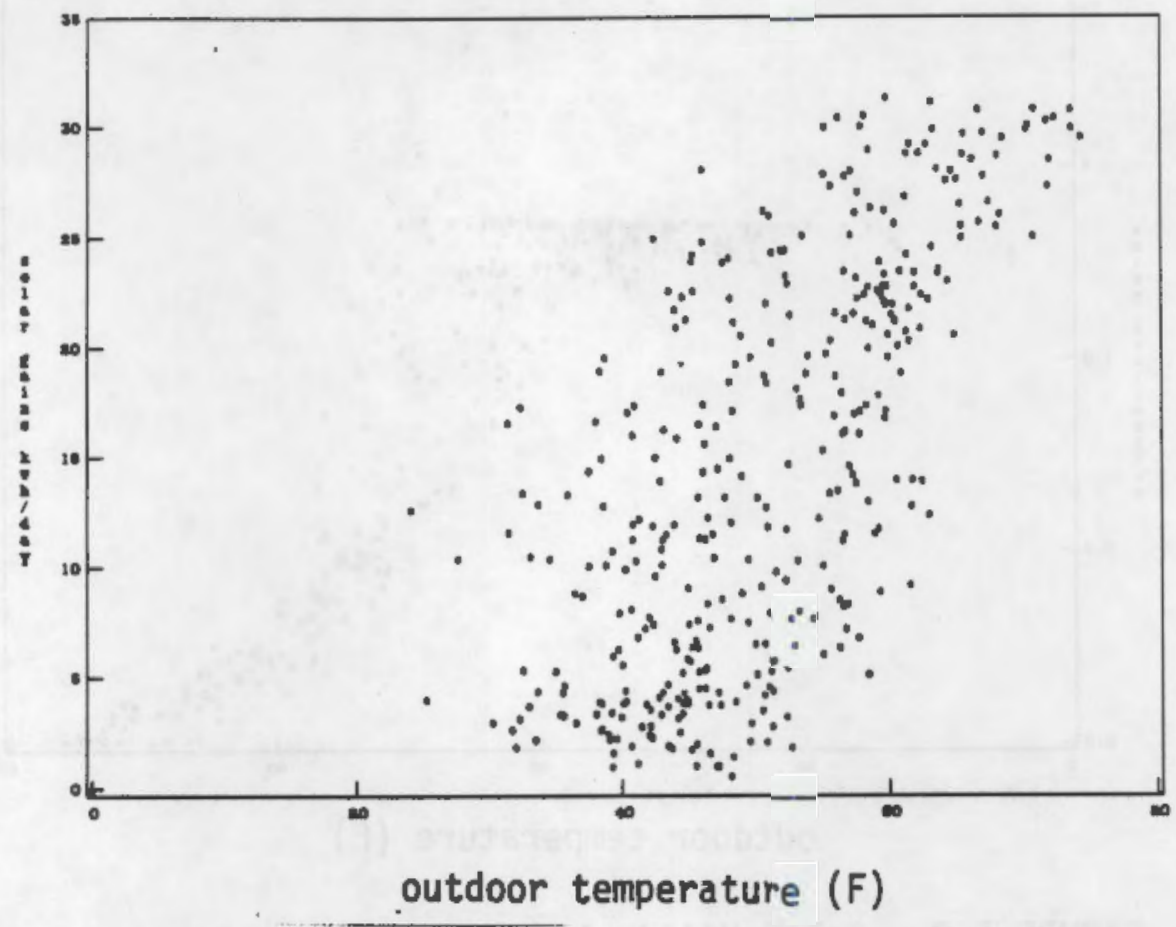

FIGURE 5.9. Solar Gains vs. Temp. - Seattle

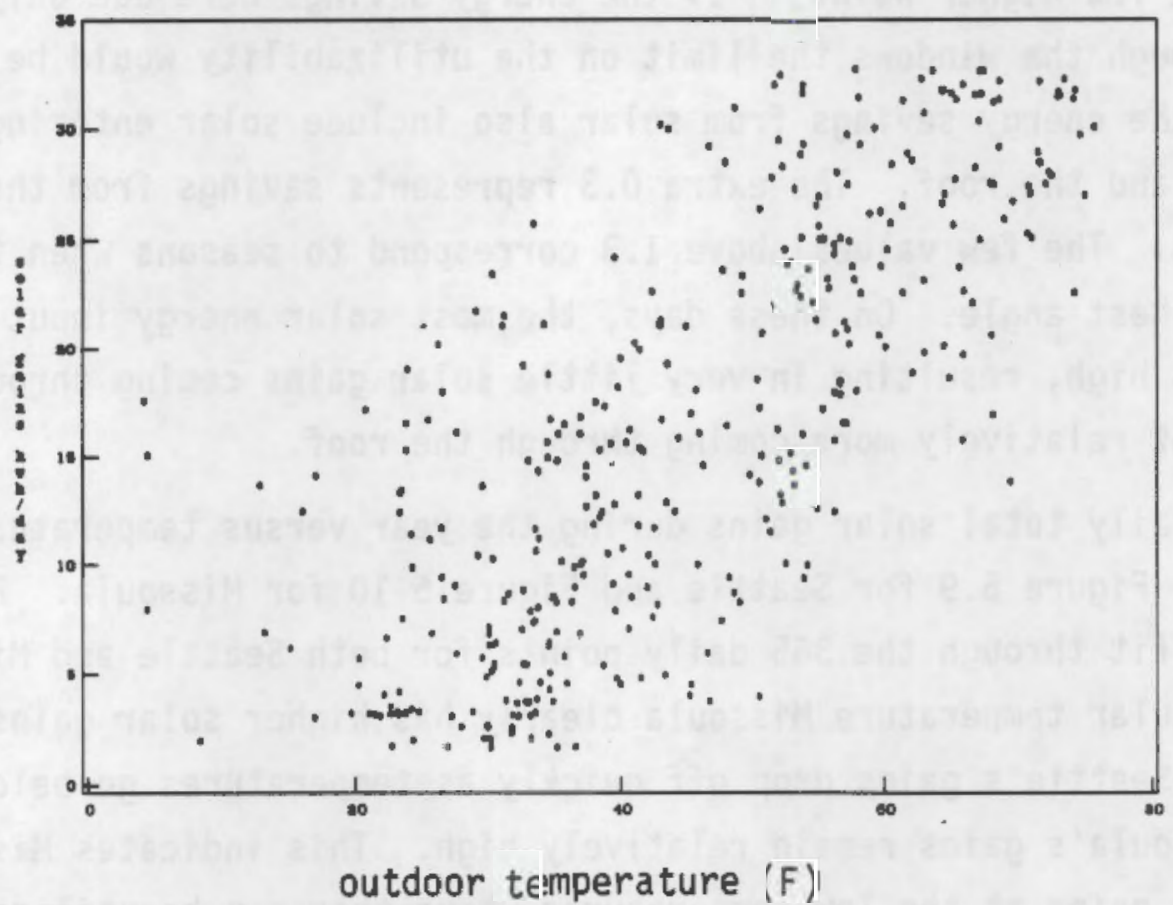

FIGURE 5.10. Solar Gains vs. Temp. - Missoula 


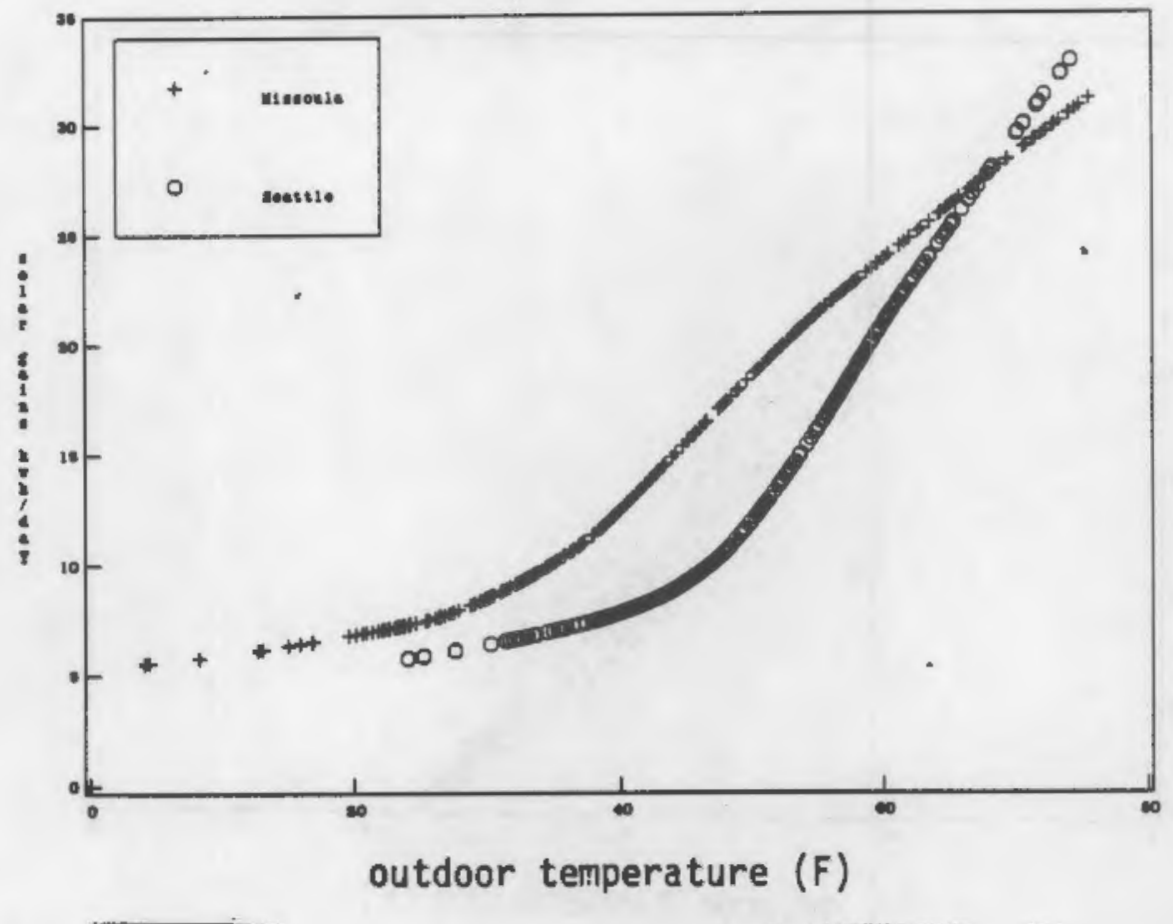

EIGURE 5.11. Lowess Curve Fit of Solar Gains vs. Temp. - Seattle \& Missoula solar gains explains Seattle's overprediction of Missoula's and Missoula's underprediction of Seattle's heating loads.

The final two graphs, Figures 5.12 and $\mathbf{5 . 1 3}$, examine diurnal temperature swing. The diurnal temperature swing is the difference between the highest and lowest temperatures for the day.

Figure 5.12 is similar to Figure 5.5. Both are plots of Missoula heating energy versus outdoor temperature for the same building. To compute values for Figure 5.12, however, we noted that the reference temperature was $55^{\circ} \mathrm{F}$ and excluded periods from the calculation of daily average temperature for hours when the outside temperature was greater than $55^{\circ} \mathrm{F}$. This produced an average temperature measure that was not affected by hourly outside temperatures that exceeded $55^{\circ} \mathrm{F}$. The "tail" visible at higher temperatures in Figure 5.5 has been eliminated and the plot is as linear in the lower energy portion as it is in the higher portion. This "tail" was caused by the small loads that occurred on days with average temperatures above the 


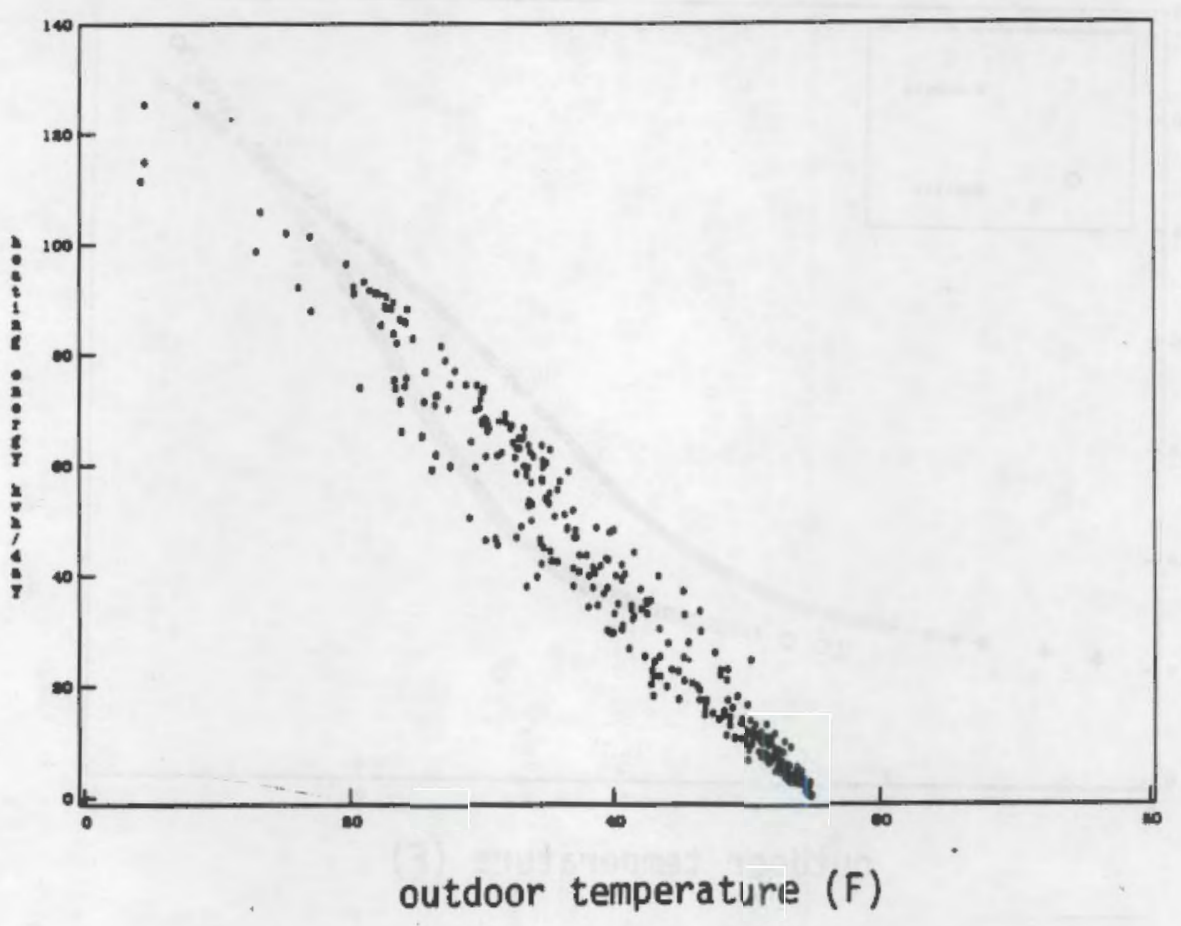

\section{FIGURE 5.12. Maximum Outdoor Temp. $=55$ - Missoula}

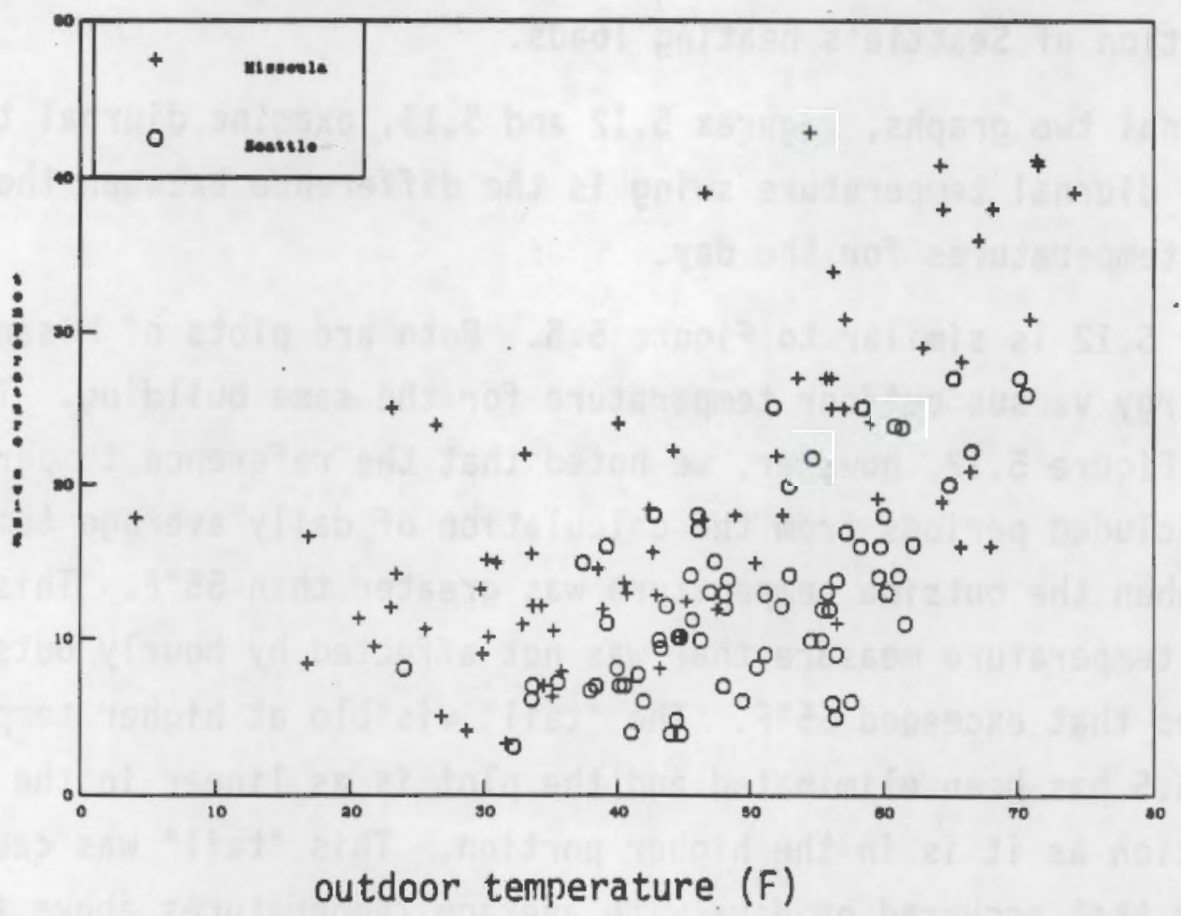

FIGURE 5.13. Daily Temp. Swing vs. Outdoor Temp. (F) - Seattle \& Missoula 
reference temperature, but night-time temperatures low enough to require some heating. The heating season daily temperature swing is clearly related to the magnitude of the heating energy consumed in the tail portion of the curve in Figure 5.5. The limited resolution inherent in the temperature data utilized by PRISM and other HDD-based methodologies would appear to introduce an error in their estimates that is related to the amount of temperature swing that occurs in a temperature range near the reference temperature.

The magnitude of the diurnal temperature swing and its correlation with the daily temperature varies from $\mathrm{cl}$ inate to $\mathrm{climate}$. Figure 5.13 shows the temperature swing on the $Y$-axis versus the daily outdoor temperature on the $X$-axis. Data for both Missoula and Seattle are plotted, with points linited to one out of every five days throughout the year for clarity. The data indicate that Missoula has higher temperature swings at all temperatures.

\subsection{ADJUSTMENI OF HEALUNG LOAD BASED ON REGRESSION ANALYSIS}

The information presented above partially demonstrates why, in many situations, heating loads cannot be accurately projected across climates with only HDD as a climate variable. This is particularly true with low-UA homes, like the MCS homes. The following discussion describes the development of a regression equation which allows more accurate cross-climate energy predictions.

The goal here was to develop a simple regression equation that would properly characterize the climate variables which affect the projections of energy use. A secondary goal was to use only data which were easily available to the PRISM user: billing data and climatic information specific to a city or small region. Though demographic and structural information was available for this report, to make the results more generally applicable we developed a method that did not require such data.

The climate adjustment methodology proposed is based only on locationspecific climate parameters and base location energy consumption data. In our analysis, we assume the heating/non-heating separation done by PRISM for the base location (Hood River) and the correction developed in Section 4 provide an accurate estimate of base location heating energy consumption. We 
assume that the location-specific climate parameters used are constant for any particular city or local region.

Table 5.5 summarizes the variables examined in the regression analysis for their effect on heating loads.

Because solar gains seened to be the most important parameter, the several measures of insolation shown were exanined. A1l solar terms were based on global horizontal radiation. The total solar is the total yearly radiation, the most commonly available solar data. The non-sumer solar is the total yearly radiation, except for the period of June 15 - September 15. This term represents solar for seasons in which some heating is likely. Winter solar is the total radiation for the winter, a period chosen as November 15 - February 15. Ninter to non-summer solar is the ratio of the last two terms described. This ratio indicates the sunniness of the winter relative to the entire heating season.

The swing is the average diurnal temperature swing for days with an average temperature between $50^{\circ} \mathrm{F}$ and $60^{\circ} \mathrm{F}$. PRISM uses HDD calculated from the average datly temperature, rather than from hourly data, and it was expected that some of the error would be related to this aggregation as suggested earlier. The range of $50^{\circ} \mathrm{F}$ to $60^{\circ} \mathrm{F}$ average daily temperature was selected to represent days with temperatures around the typical balance temperature. In this range, the daily average temperature may not capture the true relationship between heating and outside temperature.

\footnotetext{
IABLE 5.5. Climate Variables Analyzed

Total solar (annual global horizontal) Non-summer solar Winter solar Ratio of winter to non-summer solar Diurnal temperature swing Heating degree-days, base $55^{\circ} \mathrm{F}$ Heating degree-days, base $65^{\circ} \mathrm{F}$ Swing
}

HDD was expected to be the most significant single predictor of heating energy use. HDDs to base $55^{\circ} \mathrm{F}$ and $65^{\circ} \mathrm{F}$ were selected since these are commonly available. Most building balance temperatures are in this range. 
To be consistent with PRISM, the HDDs were calculated from average daily temperatures, not from hourly temperatures.

Given these variables, we performed several regression analyses to identify which terms were most significant and provided the best predictions. We regressed the difference between the heating energy consumption in the target location and the base location on the differences of the variables listed of Table 5.5. As expected, the HDD paraneter was by far the most significant term. Using only $H D D$ and the base climate heating energy (city 1), the difference in the heating energies between the locations could be regressed with an R-squared of .89 . As also expected, the no-solar runs were particularly well predicted by this term.

In most regresstons, alternative solar variables were somewhat interchangeable. The winter solar was generally the least significant. The other solar terms traded places as to which was most significant. In the final equation (discussed in the next sub-section), total solar is used as the solar parameter, but the other solar terms could be substituted (with some change in the coefficients), with only a small decrease in the R-squared value.

The differences of the diurnal temperature swing was surprisingly significant. In most of the regressions tried, the swing term was more significant, in terms of t-statistic, than any of the solar terms. The reason for the significance of the swing term is not completely clear. Initially, it was assumed to be a correction factor for the errors due to using average daily temperatures to calculate HDD; however, when the more accurate HDD determined from hourly data was substituted for daily HDD, the significance of the swing term went down only slightly. The diurnal swing is apparently capturing a secondary effect related to the climatic variables.

The regression equation presented here was developed based on the wide range of solar and UA parameters discussed earlier. The setback simulations were also included in the regressions. UAs from an uninsulated house up to the tightest MCS levels were covered. The levels of solar varied from zero to a completely unshaded building. Several of the variables were rejected because they were not statistically significant. The fact that the coefficient estimates for variables remaining in the resulting equation were 
developed with the widest possible range of variable values makes the equation suitable for application to manufactured homes with a broad range of characteristics.

It should be noted, however, that weather data for only one year were included in the simulations used to develop the cross-climate adjustment equation. The variation of weather from year to year could alter the cross-climate adjustment. It would be useful to test the cross-climate adjustment across years or against real data to validate the adjustment.

\subsection{REGRESSION RESULIS}

We developed a regression equation intended to make the cross-climate adjustment based on the heating load in the base climate. (a) The equation for predicting energy in one climate based on the measured heating energy from the base climate is:

$$
\begin{aligned}
& \text { Heating[city2]-heating[cityl] - } \\
& \begin{aligned}
& 0.000136 * \text { hdd * heating[cityl] } \\
- & 0.0000237 * \text { total solar * heating[cityl] } \\
+ & 123 * \text { swing }
\end{aligned}
\end{aligned}
$$

The following terms are the difference between the value for the target city (city 2) and the base city (city 1):

hdd = heating degree-day to base $55^{\circ} \mathrm{F}$

total solar = yearly global horizontal solar (klh/ $\mathrm{ft}^{2}$ )

swing = mean (daily maximum temperature - daily minimum temperature)

for days whose average temperature was between $50^{\circ}$ and $60^{\circ} \mathrm{F}$

Table 5.6 shows the values of the basic variables required in Eq. (5.1).

(a) We also estimated a relationship that corrects the results from an HDDbased method that have already been extrapolated across climates. It required additional, building-specific information and is not reported here. 
IABLE 5.6. Climate Parameters

\begin{tabular}{|c|c|c|c|}
\hline climate & $\begin{array}{l}\text { Total } \\
\text { Solar } \\
\text { kVh/h/m }\end{array}$ & $\begin{array}{c}\text { Temp. } \\
\text { Swing } \\
{ }^{*} \mathrm{~F} \\
\end{array}$ & 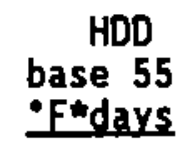 \\
\hline $\begin{array}{l}\text { Seattle } \\
\text { Hood River 1985-86 } \\
\text { Spokane } \\
\text { Missoula }\end{array}$ & $\begin{array}{l}12,774 \\
14,903 \\
15,344 \\
14,387\end{array}$ & $\begin{array}{l}13.67 \\
21.65 \\
21.62 \\
25.19\end{array}$ & $\begin{array}{l}2457 \\
3320 \\
4082 \\
4727\end{array}$ \\
\hline
\end{tabular}

The R-squared for Eq. $(5.1)$ is 0.983 . The t-statistics for the three terms are:

$\begin{array}{lr}\text { hdd"heating[cityl] } & 56 \\ \text { total solartheating (city } 1) & -12 \\ \text { swing } & 15\end{array}$

The t-statistics for the three climate variables show they are significant at above the $99 \%$ level.

The change in HDD is clearly the most important climate parameter in the regression equation. As expected, an increase in the HDD produces an increase in the heating load. The total solar has the opposite effect. Higher quantities of solar energy will cause a decrease in the heating load. Higher levels of the diurnal swing, like HDD, increase the heating load.

He applied this regression equation to the simulated data and present the results in Table 5.7. The table corrects the predictions presented in Table 5.4. The cross-climate heating adjustments using the regression equation developed here are clearly an improvement over adjustments based only on HDD. The average error for the regression equation results is only 2.7\% compared to $7.0 \%$ for the HDD-based results. Improvements of individual combinations of cities for different building designs vary greatly. Though the corrected average error for buildings without solar is actually higher for the regression-adjusted results (2.9\% versus $1.9 \%)$, a no-solar condition is not physically possible. For full-solar conditions, on the other hand, the regression method produces an average error of only $2.8 \%$ compared to 12.1\% for the HDD method. The column of interest for this report is Hood 
IABLE 5.7. Percent Difference Between Regression Predicted Load And True Load

Target

Climate

Base Climate

Seattle Hood River Spokane Missoula

NO SOLAR

Seattle Hood River

Spokane

Missoula

NO SOLAR

Seattle

MEDIUN UA

Hood River

Spokane

Missoula

NO SOLAR

HIGH UA

Seattle

Hood River

Spokane

Hissoula

$\begin{array}{ll}-- & -5 \\ 3 & -- \\ -2 & -3 \\ -2 & -1\end{array}$

-3
2

$-13$

$\begin{array}{rr}-2 & -4 \\ 3 & -- \\ 0 & -2 \\ -1 & -2\end{array}$

$\begin{array}{rr}-2 & -4 \\ 3 & -- \\ 0 & -2 \\ -1 & -2\end{array}$

$\begin{array}{rr}-2 & -4 \\ 3 & -- \\ 0 & -2 \\ -1 & -2\end{array}$

$\begin{array}{rr}-2 & -4 \\ 3 & -- \\ 0 & -2 \\ -1 & -2\end{array}$

$--$

$-5$

$\begin{array}{lll}-- & -5\end{array}$

$2 \quad-3$

0

$-2$

-3
--2
-2

$-4 \quad-9$

$1 \quad-2$

- $\quad-2$

Seattle

HALF SOLAR

Hood River

Spokane

Missoula

$\begin{array}{rr}-- & -3 \\ -3 & -- \\ -3 & -1 \\ -3 & 1\end{array}$

$-14$

LOW UA

Seattle

HALF SOLAR

Hood River

Spokane

Missoula

-

$-2$

$-4$

$\begin{array}{rr}-3 & -7 \\ 1 & -2 \\ - & -2 \\ 0 & --\end{array}$

Seattle

Hood River

Spokane

Missoula

FULL SOLAR

LOW UA

Seattle

Hood River

Spokane

Missoula

FULL SOLAR Seattle MEDIUM UA Hood River

Spokane

Missoula

FULL SOLAR

Seattle Hood River

Spokane

Missoula

-2
-2
-2

$\begin{array}{rr}-3 & -14 \\ 1 & -7 \\ -3 & -5 \\ - & --\end{array}$

$-1 \quad-2 \quad-6$

$\begin{array}{lll}-- & 0 & -3\end{array}$

$\begin{array}{lll}-1 & - & -1 \\ -2 & -1 & --\end{array}$

$\begin{array}{llll}- & -1 & -1 & -4\end{array}$

$\begin{array}{llll}0 & -- & 0 & -1\end{array}$

$-2 \quad-1$

$-10$

$-3-3 \quad-1$

$\begin{array}{llll}-. & -1 & -5 & -17 \\ -1 & -1 & -2 & -10\end{array}$

$-1$

$-2$

$-2$

$-2 \quad-10$

$--\quad-5$

3 -.

HIGH UA

$-2$

$-3$

$-6$

$-1 \quad-5$

$-2$

$-$

$-4$

$-1 \quad--$

$\begin{array}{rrrr}-- & 2 & 0 & -2 \\ -2 & -- & -1 & -2 \\ -3 & 0 & -- & 0 \\ -6 & -2 & -2 & --\end{array}$


River. The predictions based on Hood River are quite accurate, with an average error of only $1.8 \%$.

This correction methodology appears to provide a good basis for extrapolating the available data from Hood River homes to other climates. Section 6 applies this methodology to extrapolate energy savings for different conservation measures to cities representing the three MCS climate zones. 


\subsection{ESTIMATED ENERGY SAVINGS}

This section describes how we estimated heating energy savings for a range of energy conservation measures that can be applied to manufactured homes. The procedure relies principally on the PRISM estimates from the HRCP homes, before and after retrofit, and the adjustment processes described in Sections 4 and 5.

\subsection{INTRODUCTION}

In the past, most attempts to estimate energy savings from the installation of various energy conservation measures (ECMs), in both sitebuilt and manufactured homes, have relied on engineering or simulation mode1s. This study, on the other hand, takes an approach to estimate savings based on billing and end-use metered data in combination with ECM characteristics.

One direct way to characterize different ECMs is through their effect on design UA. This value is relatively easy to calculate for different ECMs and most engineering models implicitly utilize the design UA to estimate heat loss and heating energy requirements. The technique we used here linked estimated changes in design UA to measured changes in heating energy consumption, based primarily on HRCP data.

Since we had the objective of estimating potential energy savings throughout the Bonneville region, we applied the technique described in Section 5 to adjust the Hood River-based relationship between energy savings and design UA to estimate energy savings for locations other than Hood River.

\subsection{APPROACH USED TO ESTIMATE ENERGY SAVINGS}

Our methodology assumes that space heating energy consumption varies linearly with the design UA of a home. This assumption has a sound basis in conductive heat flow theory. Our approach merges the theoretical approach, based on heat flow theory, with empirical data. We estimate the slope that best fits heating energy consumption to the product of the whole-building design UA values and HDD and use that relationship to predict how heating 
energy consumption will decrease when ECMs are implemented that lower the building UA.

This approach implicitly assumes that within a given climate zone design UA and HDD are the dominant factors that drive heating energy consumption. For energy-efficient (low UA) homes, however, we would expect that internal and solar gains significantly affect the linearity between heating energy requirements and UA changes. In Section 6.4.2 we discuss one test for this interaction. Though our analysis appears to work well for the homes included in our sample, we would expect internal and solar gains to affect the relationship between UA and heating energy consumption, and this issue is addressed further at the end of this section.

\subsection{INITIAL WHOLE-HOUSE RESULTS}

We used the Hood River Conservation Project (HRCP) data to estimate the mean change in heating energy consumption as a function of building design UA. By restricting this first step in our analysis to Hood River data, we el iminated major effects of climate variables, other than heating degreedays (HDD), that were discussed in Section 5. This analysis included all HRCP homes for which billing data or metered data were available. Each home contributed one data point if data were available before retrofit and one data point if data were available after retrofit.(a) Where only billing data were available, the heating energy value used was the value calculated by applying the procedure in Section 4 to the PRISM heating component estimate. Where end-use data were available, we used the metered heating energy consumption instead.

This analysis set out to estimate the average effect of a change in design UA on heating energy consumption. It was not intended to fully characterize the relationship between heating energy consumption and other variables, such as those related to occupant behavior and solar gains, that affect the energy consumption of individual homes. We analyzed the data

(a) Note that the Hood River data from the pre- and post-retrofit periods were not adjusted to compensate for non-temperature differences between the two periods. The technique described in Section 6 could be applied to these data although the effects are likely to be relatively small. 
specifically to determine whether a linear fit was statistically reliable between 1) the product of the design UA and HDD (base $65^{\circ} \mathrm{F}$ ) and 2) the heating energy consumption.

To determine the relationship for the Hood River homes, we performed a 1 inear regression of heating energy on the value of UA*HDD. The UA values in the data covered a range from around 166 to $8008 \mathrm{tu} /\left(\mathrm{hr}-{ }^{\circ} \mathrm{F}\right)$ and the annual heating energy values ranged from about 2,000 to $22,000 \mathrm{kth}$. The regression produced the following relationship:

Heating energy consumption (kWh/yr)=

$$
0.00463 * \mathrm{UA}\left(\mathrm{Btu} /\left(\mathrm{hr} /{ }^{\circ} \mathrm{F}\right)\right) * \mathrm{HDD}\left({ }^{\circ} \mathrm{F} \text {-days }\right)
$$

The R-squared value was 0.93 and the t-statistic for the coefficent was 93 . These statistics indicated that a statistically significant linear relationship existed between the independent and dependent variables and the relationship provided a good predictor of heating energy consumption.

We repeated this procedure for the three cities used to characterize the three HCS climate zones: Seattle (zone 1), Spokane (zone 2), and Missoula (zone 3). To do so, we used the climate adjustment method presented in Section 5 to convert the Hood River energy data to estimates of energy use in each of the other locations. We then regressed these energy estimates on the value of HDD, for the standardized weather year in each location, times the design UA for each-home. The resulting coefficients, t-statistic, and regression $R$-squared for each location are shown below: (a)

\section{IABLE 6.1. Initial Coefficients}

\begin{tabular}{|c|c|c|c|}
\hline Location & Coefficient & t-statistic & R-squared \\
\hline Hood River & 0.00463 & 93 & .93 \\
\hline Seattle & 0.00431 & 69 & .90 \\
\hline Spokane & 0.00446 & 75 & .91 \\
\hline Missoula & 0.00443 & 75 & .91 \\
\hline
\end{tabular}

(a) If the heating energy consumption were exactly equal to the product of HDD and UA, the coefficients would have a value of 0.00703 across all climate zones. The coefficients we estimated are about $60 \%$ of this value. 


\subsection{ESTIMATES OF ENERGY SAVINGS BY ECM}

There are two methodological questions that we addressed before attempting to estimate the energy savings as a function of specific ECMs. One involves whether the same UA changes in different components produce equivalent energy savings. The second involves whether the relationship between design UA and heating energy is 1 inear over the relevant range of design UAs. He exanined these two issues and then developed a procedure for estimating energy savings from specific ECMs.

\subsubsection{Vartations in Eneray Savings Across Components}

Though analytically feasible, the scope of this effort did not allow us to use the available measured data to investigate whether variations occur in the relationship between design $U A$ and energy savings across different ECMs. Instead, we relied on a "data base" of energy consumption changes for different ECMs calculated by the DOE-2.1 simulation model (LBL 1983). (a) DOE-2.1 is a detailed, hourly simulation model that calculates the change in heating energy load for changes in component characteristics. DOE-2.1 was used to model the energy consumption of manufactured homes and the results have been tabulated for different insulation levels, window characteristics, and infiltration rates in DOE (1986).

We also applied Eq. (6.1) to estimate changes in energy consumption resulting from changes in the design UA. Since this relationship is linear, we could fix the value of HDO and estimate the effect of changes in the UA value by simply multiplying the UA change by HDD and the estimated coefficient. We compared the energy savings calculated by DOE-2.1 to our estimates based on measured data and we used the DOE-2.1 results to examine whether savings per unit change in the design UA value differ across measures.

Table 6.2 compares the changes in a prototypical manufactured home's energy consumption estimated by DOE 2.1 with the changes estimated here from

(a) The operating assumptions used in the DOE 2.1 runs are described in LBL (1983). Temperature setpoints for heating are $70^{\circ} \mathrm{F}$ except between midnight and $6 \mathrm{a} . \mathrm{m}$. When setback to $60^{\circ} \mathrm{F}$ occurs. Internal gains are about $2800 \mathrm{Btu} / \mathrm{hr}$. 

IABLE 6.2. Initial Comparison of Estimated Changes in Prototype Home
Energy Consumption, MBtu/yr

\begin{tabular}{|c|c|c|c|c|}
\hline \multirow[b]{2}{*}{ Component } & \multirow[b]{2}{*}{ ECM Change } & \multirow[b]{2}{*}{$\begin{array}{l}\text { UA Change } \\
\left(B+u^{\prime} /{ }^{\circ} / F\right)\end{array}$} & \multicolumn{2}{|c|}{ Energy Change } \\
\hline & & & $\begin{array}{l}\text { Based on } \\
\text { DOE 2.1 }\end{array}$ & $\begin{array}{c}\text { Based on } \\
\text { Emoirical Data }\end{array}$ \\
\hline Floor & $R-7$ to $R-28$ & -66.5 & -9.5 & -5.3 \\
\hline Celling & $R-7$ to $R-33$ & -50.1 & -5.8 & -4.0 \\
\hline Walls & $R-7$ to $R-19$ & -68.4 & -6.8 & -5.4 \\
\hline Windows & $\begin{array}{l}\text { 1-pane Al to } \\
\text { 3-pane Al (i" gap) }\end{array}$ & -70.8 & -5.0 & -5.9 \\
\hline
\end{tabular}

(a) The UA changes, are based on Taylor, Lucas, and Lee (1988) and the component areas in DOE (1986). The savings for Seattle based on measured data were estimated using the same HDD data used for the DOE2.1 simulations.

the actual data. The savings estimated based on empirical data were generated under the assumption that equivalent changes in the design UA for individual components produce the same change in energy consumption; i.e., the ratio of the change in energy savings to the change in design UA is equal to the average ratio calculated using the whole building UAs for the Hood River homes. The data tabulated are for Seattle and correspond to specific ECMs, such as an increase in the floor insulation level from R-14 to R-19.

The first fact that the table reveals is that our estimated savings based on empirical data typically are about $70 \%$ of those estimated by the DOE-2.1 mode1. For the measures shown in the table, the DOE-2.1 results agree quite closely with those from a model that assumes changes in heating energy equal the UA change times HOD (see footnote in Section 6.3). This result is consistent with the findings in Appendix $A$ and other studies referenced there that as-operated UAs are typically lower than design UAs. These prior findings suggested that buildings typically perform better than their design UA would suggest. As a result, heating energy savings associated with a given reduction in design UA would be less than those 
predicted strictly from the design UA change. This agrees with our observed results. (a)

The second key fact revealed by the table is that windows seem to behave differently than other components. Excluding windows, the average ratio of savings based on empirical data to savings estimated by DOE-2.1 equals 0.68 for the data presented here. The ratio for windows, on the other hand, is 1.18 .

To investigate this discrepancy further, we divided the DOE-2.1 estimated change in heating energy consumption by the change in UA for the ECMs shown in the table. Excluding windows, the average value of this ratio was 0.12 . For windows, the ratio was 0.071 . These results indicated that, for equivalent design UA changes, DOE-2.1 estimated that windows would have about half the effect on energy consumption that other components would have.

When it calculates changes in loads attributable to windows, DOE-2.1 includes the effects of solar gains and wind speed variations. The differences between our results and the DOE-2.1 results suggested that DOE-2.1's inclusion of these factors significantly affected the estimated energy consumption effects of windows in two ways.

First, window UA reductions typically occur through decreases in window area or improvements in the glazing thermal properties (lower U-values). Either approach, however, is likely to reduce solar gains (through smaller areas or lower shading coefficients). Reducing the solar gains means that less solar energy is avallable to offset the heating requirement. This compensating effect appears as a decrease in the apparent effect of the UA improvement. Section 5 pointed out the important role played by solar gains.

Second, the design UA values we have assigned to windows were based on extreme conditions, specifically, a wind speed of $15 \mathrm{mph}$ (ASHRAE 1985, BPA 1987). In the procedure followed by DOE-2.1, however, the effective UA

(a) He made a similar comparison to results generated by the SUNDAY simulation model (Eckman 1988a). For Seattle and internal gains of $3,000 \mathrm{Btu} / \mathrm{hr}$., we found that the change in energy consumption per unit change in design UA based on measured data was $78 \%$ of the change estimated by SUNDAY. This was consistent with the results from the comparison with DOE-2.1 estimates. 
varies depending on hourly wind speeds associated with the weather data. In effect, the equivalent glazing UA used in DOE-2.1 is based on an average wind speed that is likely to be less than $15 \mathrm{mph}$. This results in an effective UA change that is less than the value, based on $15 \mathrm{mph}$, that was assumed in Table 6.2.

The consequence of this finding for our analysis was that we could not assume that changing the design. UA of windows an anount equivalent to a change in another component would produce the same change in energy consumption. This does not strictly say that themal improvements to windows are less effective than improvements to other components. It says, instead, that 1) the design UA typically used for windows overstates the effect of window themal characteristics on energy consumption (consistent with ASHRAE 1985) and 2) the design UA affects how much solar energy is available to offset heating loads. The DOE-2.1 results provided an estimate of how much window UA changes affected energy consumption relative to other components.

To properly capture these effects, we developed two separate coefficients to estimate energy savings frow UA changes: one for windows and a second for all other components. He used the Hood River data to determine what proportion of the average building UA was due to windows and what proportion was due to other components. He combined these proportions with the DOE-2.1 data to split the coefficients presented in Section 6.3 into a coefficient for windows and a coefficient for other components. (a) The coefficients shown in Table 6.3 for four locations are multiplied by the change in design UA to estimate the change in heating energy consumption.

(a) We made the assumption that the ratio between the window UA effect and the other components' effect was uniform across climate zones. Strictly speaking, this would not be the case because the amount of insolation would vary across climate zones. The available data did not allow us to develop coefficients for each location that took this effect into account. 
IABLE 6.3. Coefficients for Estimating Changes in Heating Energy from Changes in Design UA

$\begin{array}{llcccc}\text { Component } & & \text { Seattle } & \text { Hood_River } & \text { Spokane } & \text { Missoula } \\ \text { Windows } & 0.00275 & 0.00295 & 0.00284 & 0.00283 \\ \text { Other } & 0.00470 & 0.00505 & 0.00486 & 0.00483\end{array}$

Based on these separate coefficients, we reconstructed the comparison between our estinates of energy savings and those from the DOE-2.1 model. Table 6.4 presents the revised values for comparison with Table 6.2.

The results for Seattle indicate that, across all components shown, the revised estimated savings based on empirical data are about $75 \%$ of those estimated by the DOE-2.1 mode1. This gives better agreenent with the simulation nodel, and the adjustment we made allows the calculated design UAs for all components to be used in the energy savings estimation procedure.

\subsubsection{Possible Non-Linear Effects of UA on Heating Energy Consumption}

We anticipated that at low UA values the relationship between UA and heating energy consumption might no longer be linear. This seemed probable because of anticipated changes in the utilizability of solar and internal gains as the building UA changes.

IABLE 6.4. Revised Comparison of Estimated Changes in Prototype Home Energy Consumption, MBtu/yr

\begin{tabular}{|c|c|c|c|c|}
\hline \multirow[b]{2}{*}{ Component } & \multirow[b]{2}{*}{ ECM Change } & \multirow[b]{2}{*}{$\begin{array}{l}\text { UA Change } \\
\left(B t w / h r /{ }^{\circ}\right)\end{array}$} & \multicolumn{2}{|c|}{ Energy Chanqe } \\
\hline & & & $\begin{array}{l}\text { Based on } \\
\text { DOE 2.I }\end{array}$ & $\begin{array}{c}\text { Based on } \\
\text { Empirical Data }\end{array}$ \\
\hline Floor & $R-7$ to $R-28$ & -66.5 & -9.5 & -6.0 \\
\hline $\begin{array}{l}\text { Ceiling } \\
\text { Halls }\end{array}$ & $\begin{array}{l}R-7 \text { to } R-33 \\
R-7 \text { to } R-19\end{array}$ & $\begin{array}{l}-50.1 \\
-68.4\end{array}$ & $\begin{array}{l}-5.8 \\
-6.8\end{array}$ & $\begin{array}{l}-4.5 \\
-6.2\end{array}$ \\
\hline Nindows & $\begin{array}{l}\text { 1-pane Al to } \\
\text { 3-pane Al }\end{array}$ & -70.8 & -5.0 & -3.8 \\
\hline
\end{tabular}


To test for this effect we defined new variables and tested for the significance of a quadratic term that would cause the relationship to become non-linear for low values of the UA. Me used the data for the subset of end. use metered Hood River homes combined with the Tulalip homes. (a) Me defined the new variables as differences. The dependent variable was the difference between the maximum heating energy consumption for all homes in the sample and the value for each home. The independent variables were 1) the difference between the maximum value of UA*HDO and the value for each home and 2) the square of this term. With these variables, the dependent variable would have large values for small values of the heating energy consumption and the independent variables would have large values for small values of UA.

We regressed the dependent variable on the two independent variables. If a non-linear relationship existed, we would expect a statistically significant, negative coefficient for the squared term. At low UAs (high values of the independent variables), the squared term would become more significant, partially offsetting the linear term and causing the estimated value of heating energy consumption to decrease less rapidly with the independent variables. When we ran this regression, the coefficient of the linear term was positive and significant, while the coefficient of the squared term was also positive but not statistically significant ( $t$ statistic $=0.08$ ). These results contradicted the hypothes is that there was a non-linear effect and we concluded that the linear relationship was applicable over the range of UAs considered in this study. (b)

\subsubsection{Estimation of ECM Energy Savings}

The results in Table 6.3 can be used to estimate how much heating energy individual ECMs save in manufactured homes. Over the wide range of building UAs covered by the Hood River homes (which overlaps the range of values for

\footnotetext{
(a) In a regression of heating energy consumption on design UA this subset of homes produced a slope that was quite close to the value for the entire set of Hood River homes. He used this subset for simplicity and for coverage of a wide range of UAs, since the Tulalip homes were designed to be energy efficient, i.e., low UA, homes.

(b) We would expect the non-1 inearity to appear if we extended this technique to a large sample of low-UA homes, for which utilizability of solar and internal gains would have a more marked effect.
} 
the Tulalip MCS homes) the linear relationship appears to hold. The results here suggest that one coefficient can be used to estimate the change in heating energy consumption resulting from the implementation of a specific ECM that affects components other than windows. A different coefficient is required for windows. Only the change in component design UA is required to estimate the average energy savings. The energy savings for different climates can be estimated by applying coefficients developed for the specific climates.

Our empirical results are significantly different from those produced by most simulation models. Typically, our empirical data indicate that, on the average, decreases in design UAs produce about 70-80\% of the heating energy savings that simulation nodels est fmate. Because this difference is significant and it is iaportant for planning and policy making purposes to estimate energy savings reliably, the causes of the discrepancy between the results produced by the two estimating approaches need to be understood better.

Several factors contribute to the observed differences. For example, modeling assumptions may not correspond well to actual operating conditions Measured data suggest that average indoor air temperatures are higher than those typically modeled. Also, internal and solar gains may differ from typical modeling assumptions. On the other hand, our estimation resulted in a linear fit between changes in design UA (given HDD based on a constant reference temperature) and changes in energy consumption that may not match the actual effect well for UA values at the extremes.

Though we tested for the existence of non-1 inear behavior as described in Section 6.4.2 and found no statistical evidence of such an effect, we believe the magnitude of the differences between our method and simulation results warrants further exploration of possible non-linearities. Specifically, we suggest that a technique, such as the lowess procedure (see Appendix A), that uses regression methods to provide a piecewise fit to data points, or regressions using non-linear functions that may capture expected curvature be applied to the data used in this study. As noted earlier, we expect the interaction between solar and internal gains and space heat requirements to vary with UA and a piecewise analysis of available data or 
non-linear functional relationship would allow us to quantify this variation. Using this kind of approach, our results could be modified to take into account an empirically-based variation in the effect of UA on heating energy consumption. 
. 


\subsection{LEVELIZED COST AND SUPPLY CURVE ANALYSES}

Bonneville uses a supply curve methodology to compare the cost and . supply of alternative resources, including energy conservation. In this study, we have considered improvements in the energy efficiency of new manufactured homes and estimated the levelized costs and magnitude of the potential conservation resource available. He also have estimated the

levelized cost of several retrofit measures based on Hood River project data, but have not developed corresponding retrofit supply curves.

The new manufactured housing supply curves have been generated using Bonneville's supply curve methodology (BPA 1986). The existing manufactured housing data used by Bonneville have been updated based on our study as described in the following sections.

\subsection{RETROFIT LEYELIZED COST}

Bonneville does not include manufactured homes in its weatherization program, but retrofit occurred on a large number of homes as part of the HRCP. The data from that program provide a reliable empirical basis with which to assess the cost-effectiveness of manufactured home retrofits.

This section discusses the methodology used to estimate the retrofit levelized costs for different components, based on data for the manufactured homes located in Hood River. It describes the methodology used to estimate the costs of installing component measures and the methodology used to estimate levelized costs from first costs and energy savings. Last, this initial section presents the results of the retrofit analysis.

\subsubsection{Retrofit Installation Cost Estimation}

The initial requirement for calculating the levelized cost was to find the per unit cost to the homeowner to upgrade individual components, for example, the cost per square foot to upgrade from single-pane to double-pane glass. An attractive feature of the Hood River data base was that information on actual billed costs at a component level was available. Therefore, the cost estimations were based on real bills, rather than on 
engineering cost estimates which might or might not be based on an appropriate set of assumptions.

In the HRCP data, cost information was itemized as total installed cost by retrofit component. The components included ceiling, wall, and floor insulation as well as window retrofits. Component retrofits, however, of ten consisted of several different retrofits. For example, a pre-retrofit building could have had four walls of 100 square feet each of which initially had R-14 insulation. The post-retrofit building could have had 2 walls at R22 , one at $R-14$, and one at $R-28$. Since we wanted to estimate costs on a basis that could be related to the estimated energy savings, we needed to develop per unit costs on a component basis.

Our approach was to develop a weighted R-value change. For each wall, celling, or floor section that changed $R$-value, the $R$-value change was calculated. The section-by-section differences were then multiplied by the area of the sections which changed. This approach resulted in a weighted R. value change for each component in each house. This measure was commensurate across the different houses in the sample.

A standard cost per unit change in R-value per square foot was estimated through a regression approach. Since the underlying cost data were all generated by the same auditing and contracting process, it seemed likely that the errors in each of the four regressions would be correlated. For example, the wall model might produce errors for individual homes that had about the same magnitude but a different sign compared to the errors for ceiling estimates. This situation calls for a regression technique known as seemingly unrelated regressions (SUR). Johnston (1972, Pp. 238-241) gives an exposition of this technique. The interpretation of the statistical results is identical to that of Ordinary Least Squares regressions.

He implemented the approach by regressing the invoice cost for each component that was retrofit (wall, floor, ceiling) onto a constant and the weighted $R$-value change. The resulting parameter estimate for the $R$-value change variable yielded the cost per square foot per change in $R$-value. This technique had two analytic benefits. One was that it allowed the notion of a fixed cost for each component retrofit to be examined. This was done by testing the constant term to see whether or not it was significant. Second. 
we anticipated that, because insulation would have to be installed between the floor joists as well as below them when the insulation reached certain levels, the floor invoice cost would reflect higher costs for certain Rvalues. This effect would vary with the year of construction since construction practices changed around 1976 when the HUD standards went into effect. This situation is unique to manufactured homes and the regression technique allowed us to control for this effect. Table 7.1 shows the regression results.

The floor insulation regression performs very well. Both the parameters of interest are significant and the R-squared is .96. The constant term, however, is not statistically significant, indicating that the fixed cost of installing the insulation was negligible. The cost of the insulation was estimated at 4.7 cents per square foot of $R$-value change. As can also be seen, the cost of additional work associated with higher R-values was about $\$ 92$ on those houses that needed it.

Table 7.1 also shows the regression results for the ceiling costs. Again, the regression performs well with the quantity parameter significant and the regression $R$-squared over .94 . The constant term was not statistically significant. The regression estimates the cost of ceiling insulation at 3.1 cents per square foot of change in R-value. Ceiling insulation is the least expensive of the three insulation approaches. This is probably because ceiling insulation could be blown in and the labor and materials are generally less costly for this type of insulation.

The final insulation retrofit regression results reported in Table 7.1 are for the wall insulation cost. As before, the wall cost regression performs well by conventional standards. The R-squared is over .95 and the parameter of interest is highly significant. The regression indicates that wall insulation is the most expensive to retrofit at a cost of nearly 16 cents per square foot per change in $R$-value. This result is consistent with expectations. Insulating walls involves the most work since there is no readily available access to the interior of the walls. One important point about the data on wall insulation is that it did not include any $R$-values beyond R-19 and that it appeared no insulated wall sheathing was installed. 
IABLE 7.1. Seemingly Unrelated Regression Results for Insulation Costs Dependent Variable: Invoice Amount

Yariable

Intercept

Insulation

Quantity

Floor Hork

Single to Double Glazing

Single to Triple Giazing

Single Storm

Double Storm

Mood Sash

T.I.M.

1/2" Pane

R-Squared

No. of

Observations
Parameter Estimates

Eloor Celling Hall Windows

\subsection{5}

(0.94)

4.151

$(0.87)$

1.238

$(0.33)$

7.835

$(.53)$

0.0314

(104.48)

\subsection{0}

(108.953)
0.97

0.0473
$(89.18)$

91.71

(5.347)

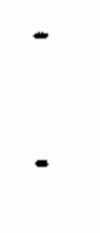

$-$

-

-

$-$

565
565
13.345

(34.36)

21.757

(20.54)

6.568

(25.26)

8.533

(35.98)

13.747

(2.78)

7.408

(12.33)

115.152

(4.32)

0.95

0.96

0.93

Therefore, this cost estimate does not include any retrofit modifications of that magnitude.

Window retrofit costs were estimated through a different method than the insulation costs. There did not seem to be a tractable way to aggregate or 
unify glazing, sash type, and air gap in the pre- and post-retrofit windows. The only form of aggregation which made sense was to examine the square footage of each type of window retrofit and treat each type separately. For exanple, a house could have two 6 by 4 foot windows retrofit from single- to double-pane and one 8 by 8 foot window retrofit to triple-pane. This house would have the window retrofits aggregated to 48 square feet of double-pane and 64 square feet of triple-pane. The resultant cost estimates would be dollars per square foot of a given window retrofit type.

Another issue with window retrofits was how to treat the differences in window sash and the air gap. This was particularly problematic because the sash type and air gap retrofits could be mixed. The ideal measure for sash type would have been linear feet of each sash used in the analysis. This was not available. Our compromise was to assume that each window was approximately square, and so the linear feet could be estimated from the area of the window. The two air gaps, one-fourth and one-half inch, were treated as dummy variables with a value of zero indicating the one-fourth inch gap and a value of one for the half-inch gap.

Table 7.1 also shows the window cost regression results. The regression has an R-squared of .90. Each of the coefficients, with the exception of the intercept, was significant and had the proper sign. As can be read from the table, relative to single-pane glazing the cost of double-pane windows was estimated to be $\$ 13.35$ per square foot. (The HRCP retrofit data base only contained retrofits that started with single-pane glazing.) Triple-pane windows were estimated to cost $\$ 21.76$ per square foot relative to single-pane windows. Relative to standard aluminum sashes, wood sashes cost $\$ 13.75$ per foot; thermally improved metal (T.I.M.) sashes were estimated to cost $\$ 7.41$ per foot. Unlike retrofits of other components, window retrofits required removing the existing component as well as installing the upgraded one. The regression appeared to capture the removal costs in the coefficients for each upgrade, rather than in the constant term. This suggested that the removal costs were related to the dimensions of the window replaced and the coefficients presented for most upgrades in the table should be interpreted as including removal, installation, and material costs. 


\subsubsection{Levelized Cost Methodology}

We used these retrofit installation cost estimating relationships to calculate levelized costs. Cost levelization is a technique that puts costs for different alternatives on a common basis. This allowed us to compare the cost of different retrofits, including window upgrades, on an equivalent basis. Calculating the levelized cost of a measure requires information about:

- lifetime of the measure

- cost of the itere

- energy savings

- changes in electric system line losses

- discount rate

The calculation of levelized cost is relatively easy in this case since several of the paraneters have been set by Bonneville. Equation 7.1 shows the formula for calculating the levelized cost of the retrofit measures.

Levelized cost (mills/kihh) =

$1000 *($ first cost $) *\left[(1+i)^{n} * 1\right] /\left[(1+i)^{n}-1\right] /(1$ ine

loss credit * annual energy savings)

Appendix A of BPA (1986) provides a complete derivation of the Bonneville levelized cost methodology used in this paper.

In this application the first costs are from the regressions reported in Table 7.1. Energy savings are in $k$ th/ $/ \mathbf{y r}$. The line loss credit accounts for reductions in electric transmission and distribution system line losses due to residential conservation savings and we use the Bonneville value of 1.1 (a $10 \%$ credit). Throughout the analysis the discount rate (i) was assumed to be 3\%. Me examined the effect of expected lifetimes, $n$, of both 10 years and 30 years on the levelized cost.

\subsubsection{Retrofit Analysis Results and Imolications}

The results of the retrofit analysis are given in Tables 7.2 and 7.3 . The results were calculated based on Hood River prototypical home and longterm average climate data. The prototype dimensions were $1,032 \mathrm{sq} . \mathrm{ft}$. of 
TABLE 7.2. Ceiling, Wall, and Floor Retrofit Costs and Savings

\begin{tabular}{|c|c|c|c|c|}
\hline $\begin{array}{l}\text { Energy } \\
\text { Conservation } \\
\text { Measure }\end{array}$ & $\begin{array}{l}\text { Measure } \\
\text { Cost, } 5\end{array}$ & $\begin{array}{c}\text { Measure } \\
\text { Savings } \\
\text { Kuh } \\
\end{array}$ & $\begin{array}{l}\text { Levelized } \mathrm{c} \\
\frac{30 \mathrm{yr} \text { Life }}{30}\end{array}$ & $\frac{\text { Cost, mill s/kwh }}{10 \text { yr Life }}$ \\
\hline $\begin{array}{l}\text { Cet1ing } \\
\text { R-14 to } R-19 \\
R-19 \text { to } R-22 \\
R-22 \text { to } R-30 \\
R-30 \text { to } R-38\end{array}$ & $\begin{array}{l}167 \\
102 \\
264 \\
264\end{array}$ & $\begin{array}{l}455 \\
182 \\
320 \\
192\end{array}$ & $\begin{array}{l}17 \\
26 \\
38 \\
64\end{array}$ & $\begin{array}{r}39 \\
59 \\
88 \\
146\end{array}$ \\
\hline $\begin{array}{l}\text { Hall } R-11 \text { to } R-19\end{array}$ & 1124 & 569 & 92 & 211 \\
\hline $\begin{array}{l}\text { Floor } \\
\text { Pre-1976 homes } \\
R-11 \text { to } R-14 \\
R-14 \text { to } R-22 \\
R-22 \text { to } R-25 \\
R-25 \text { to } R-28 \\
R-28 \text { to } R-33 \\
\text { Post-1976 homes } \\
R-11 \text { to } R-14 \\
R-14 \text { to } R-22 \\
R-22 \text { to } R-25 \\
R-25 \text { to } R-28 \\
R-28 \text { to } R-33\end{array}$ & $\begin{array}{l}153 \\
397 \\
243 \\
243 \\
341 \\
153 \\
397 \\
153 \\
153 \\
250\end{array}$ & $\begin{array}{r}157 \\
294 \\
150 \\
123 \\
152 \\
181 \\
306 \\
103 \\
61 \\
44\end{array}$ & $\begin{array}{r}45 \\
63 \\
75 \\
92 \\
104 \\
39 \\
61 \\
68 \\
117 \\
262\end{array}$ & $\begin{array}{r}103 \\
144 \\
172 \\
210 \\
238 \\
90 \\
138 \\
157 \\
269 \\
606\end{array}$ \\
\hline
\end{tabular}

floor and ceiling area, $866 \mathrm{sq}$. $\mathrm{ft}$. of wall area, $146 \mathrm{sq} . \mathrm{ft}$. of window area, and $35 \mathrm{sq}$. $\mathrm{ft}$. of door area, based on the means of the values observed for the HRCP homes. Energy savings have been estimated using the method described earlier.

The two different measure lifetimes, 10 and 30 years, can be associated with the remaining life of the home since retrofit would occur on homes that have been occupied already for some period of time. As can be seen the Tevelized costs vary dramatically between the 30- and 10-year lifetime assumptions. This is to be expected since all the costs of retrofit are incurred today and the benefits accrue over the lifetime of the measure. The levelized costs are about 2-1/2 times as high for the 10-year lifetime assumption . 
Table 7.2 shows that the most cost-effective way to save energy was to insulate the ceiling. Going from R-14 to R-19 in the ceiling cost 17 mills per kWh for a 30-year lifetime. If the home had an expected lifetime of 10 years the levelized cost was $39 \mathrm{mills}$. The range of levelized costs varied greatly depending on the pre-retrofit level of insulation. As would be expected from the relationship between R-value and energy savings, the levelized costs associated with a given change in $R$-value were higher for higher pre-retrofit insulation levels. Thus, the most cost-effective insulation retrofits would be for cases where initial insulation levels were the lowest.

Table 7.3 shows the savings and levelized costs assoctated with several window retrofit options. The retrofit costs were based on 62.7 square feet of glass and 45.6 feet of sash being replaced. This glass area was the average amount retrofit in the Hood River project. As noted before, all window retrofits started from a base of single glazing in these manufactured homes.

As can be seen, the levelized costs of window retrofits were considerably higher than those of insulation retrofits. As noted earlier, window retrofits performed on the HRCP manufactured homes involved window removal as well as replacement. Consequently, the levelized costs would be higher than the costs based on materials and installation alone. The 30-year 
IABLE 7.3. Window Retrofit Costs and Savings

\begin{tabular}{ccc}
$\begin{array}{c}\text { Measure } \\
\text { Cost } \\
5\end{array}$ & $\begin{array}{c}\text { Measure } \\
\text { Savings } \\
\text { kth }\end{array}$ & $\begin{array}{c}\text { Levelized Cost, } \\
\text { mills/kl.h }\end{array}$ \\
\hline
\end{tabular}

Metal Sash to T.I.M.

Single to 1/4" Double

Single to $1 / 4^{\prime \prime}$ Double + Storm

Single to $1 / 2$ ' Double

$1182 \quad 397$

$1594 \quad 631$

138.17

117.19

317.48

1297

509

Single to $1 / 2^{*}$ Double + Storm

1709

672

118.26

269.27

$118.04 \cdot 271.22$

Metal Sash to Metal Sash

Single to $1 / 4^{\circ}$ Double

Single to 1/4" Double + Storm

$845 \quad 315$

$1257 \quad 539$

Single to $1 / 2 "$ Double

960

Single to $1 / 2$ - Double + Storm

1372

427

590

$124.17 \quad 285.31$

$108.04 \quad 248.26$

$104.14 \quad 239.30$

$107.78 \quad 247.60$

Metal Sash to Hood Sash

Single to $1 / 4^{\prime \prime}$ Double

Single to 1/4" Double + Storm

Single to $1 / 2^{\prime \prime}$ Double

single to $1 / 2^{n}$ Double + Storm

Metal Sash to Hood Sash

Single to 1/4: Triple

Single to 1/4" Triple + Storm

Single to 1/2" Triple

Single to 1/2" Triple + Storm

\section{$1471 \quad 488$}

1883

1587

1998

1999

2534

2114

2649
723

580

753

682

804

763

845
$139.71 \quad 321.03$

$120.89 \quad 277.78$

$126.86 \quad 291.50$

$123.08 \quad 282.82$

135.97

146.19

128.46

145.46
312.43

335.90

295.18

334.24 
lifetime levelized cost of retrofitting metal sash single-pane to a better thermal performer would range from about 100 mills to 150 mills depending on the retrofit sash type and number of panes, and whether or not a storm would be added. In most cases except for upgrades involving triple-pane glazing, the addition of storm windows lowered levelized costs, suggesting that the addition of a storm was more cost-effective than the other measures. In general, window retrofits appeared to be an expensive way to reduce energy consumption. The levelized costs covered a fairly narrow band of values. This suggested that the ratio of additional energy savings to additional costs was fairly constant over the avallable measures. This differed from the cases involving insulation measures in whtch increnental costs increased considerably faster than increnental energy savings as higher insulation levels were installed.

\subsubsection{Discussion of Retrofit Results}

Our retrofit analysis indicates that some retrofit conservation measures are cost-effective in Hood River. Certainly insulation retrofits that can be purchased in the 17-40 mill range are worth considering. The results also indicate, however, that other retrofit efforts will not be cost-effective, particularly those involving glazing changes.

We have not attempted to develop a retrofit supply curve because it was beyond the study scope. These preliminary results suggest, however, which retrofits might be cost-effective. Our results were derived for Hood River, which has a relatively mild climate, so the cost-effectiveness would improve in other, more severe climates. The expected lifetime is the major assumption affecting the cost-effectiveness. Ceiling and possibly some floor insulation upgrades might be cost-effective on a substantial share of newer homes expected to last thirty years or more, particularly in colder climates An analysis of the resource potential and development of a retrofit supply curve would require collection of data on the number of existing manufactured homes in the Bonneville region and information about their age distribution.

The remainder of this section addresses conservation measures applied to new housing. It provides both information on levelized costs and supply curves for conservation upgrades. 


\subsection{NEY HOME LEYELIZED COSTS AMD SUPPLY CURVES}

This section presents the levelized cost and supply curve analyses and results for new manufactured homes in the Bonneville service territory. The results presented were generated using several assumptions provided by Bonneville in conjunction with the data obtained during this study.

\subsubsection{Methodology and Assumptions}

The methodology used relies on the calculation of levelized costs for a range of ECHs. The levelized costs reflect the 30 -year levelized investment costs for individual conservation measures, in typical single-wide or doublewide manufactured homes, divided by the electrical energy savings due to reduced heating requirements. The measure costs are based on 1987 data collected from manufacturers for actual conservation upgrades and on other data sources (noted in the text) for upgrades not currently offered. (a) The energy savings have been estimated based on the mathodology and design UAs calculated as described in previous sections.

Application of the methodology requires several input assumptions. We have adopted Bonneville's existing supply curve assumptions (James 1987) where we have not acquired new data. Bonneville's assumptions are the following:

- low, base, and high scenario estimates of the number of new manufactured homes sited in the Bonneville region between 1987 and 2006 are $247,800,345,400$, and 350,700 , respectively

- low, base, and high scenario estimates of the proportion of manufactured homes in public utility service territories are 0.38 , 0.39 , and 0.38 , respectively

- line loss credit equals 1.1

- discount rate equals $3 \%$

(a) The cost estimates for upgrades not commonly available are based on data from construction demonstration projects, involving small numbers of homes, or engineering cost estimates. In either case, these cost estimates are likely to be higher than actual costs that would be observed in the factory due to quantity material discounts and learning curve effects. 
- denolition factor equals $\mathbf{0 . 9 7 9}$

\subsubsection{Energy Conservation Measures and First Costs}

This section delineates the ECMs which we have included in the supply curve for the region. It then presents the techniques used to estimate first costs and the estimated costs.

The cost and supply curve analyses are based on the incremental effects of the ECMs considered. Specifically, all first costs have been calculated as incremental costs for an ECM level compared to the next less stringent level. The "current practice" building component values constitute the starting point for each measure. He have used manufacturer estimates of insulation levels in their most-comionly sold units as the basis for current practice estimates developed in the first stage of this study (Harkreader et al. 1987) and auganented them with information from the Northwest Power Planning Council (NPPC 87). The current practice values used are shown in the following table. Current practice insulation values are means based on manufacturer data. We have used the new assumptions shown in Table 7.4 based on the sources indicated.

The major ECMs analyzed are those assoctated with improvements to the thermal performance of the envelope. Measures include floor, wall, and ceiling insulation, and window and door types. He also include the option of reducing infiltration rate. The ECMs considered are listed in Table 7.6. 
IABLE 7.4 New Assumptions in Studya

\begin{tabular}{|c|c|c|}
\hline Parameter & Value & Source \\
\hline $\begin{array}{l}\text { New Homes } \\
\text { Electrically- } \\
\text { Heated }\end{array}$ & $\begin{array}{l}\text { Low }=70 \% \\
\text { Base }=83 \% \\
\text { High }=93 \%\end{array}$ & $\begin{array}{l}\text { Harkreader et a7. } 1987 \text {. Low value } \\
\text { is based on } 1975 \text { data; high is based } \\
\text { on 1987; base is mean of } 1975,1982 \text {, } \\
1987 \text { data. }\end{array}$ \\
\hline $\begin{array}{l}\text { New Home Distri- } \\
\text { bution by MCS } \\
\text { Clinate Zone (CZ) }\end{array}$ & $\begin{array}{l}C Z 1=64 \% \\
C Z 2=25 \% \\
C Z 3=11 \%\end{array}$ & $\begin{array}{l}\text { Harkreader et al. } 1987 \text {. } \\
\text { Manufacturer estimates of siting. }\end{array}$ \\
\hline $\begin{array}{l}\text { Floor Area-- } \\
\text { Single-wide } \\
\text { Double-wide }\end{array}$ & $\begin{array}{l}899 \text { sq.ft. } \\
1484 \text { sq.ft. }\end{array}$ & $\begin{array}{l}\text { Harkreader et al. } 1987 \text {. } \\
\text { Manufacturer estimates of average } \\
\text { floor area. }\end{array}$ \\
\hline Glazing Area & $\begin{array}{l}10 \% \text { of } \\
\text { floor area }\end{array}$ & $\begin{array}{l}\text { Harkreader et al. } 1987 . \\
\text { HUD Compl iance Certificates. }\end{array}$ \\
\hline $\begin{array}{l}\text { Hew Hone Shares-- } \\
\text { Single-wide } \\
\text { Double-wide }\end{array}$ & $\begin{array}{l}19 \% \\
81 \%\end{array}$ & HUD 1986 siting statistics \\
\hline
\end{tabular}

(a) He assume that the mix of single-wide and double-wide homes does not vary across climate zones since manufacturing data show a fairly consistent production mix across climate zones.

\section{IABLE 7.5 Current Practice Values}

\begin{tabular}{l|c|c} 
Measure & Single-wide & Double-wide \\
\hline Floor Insulation & $R-9.8$ & $R-9.7$ \\
Ceiling Insulation & $R-16.7$ & $R-17.8$ \\
Hall Insulation & $R-11.3$ & $R-12.4$ \\
(2"x4" construction) & & \\
Glazing & \\
$\quad$ (2 pane, 1/4", meta1) & $U-0.75$ & $U-0.75$ \\
Door & & \\
Infiltration & $U-0.40$ & $U-0.40$ \\
& $0.35 \mathrm{ACH}^{(a)}$ & $0.35 \mathrm{ACH}(a)$
\end{tabular}

(a) ${ }^{-A}$ ir $^{-}$changes per hour. Rate is based on BPA (1987). 
IABLE 7.6. ECM Levels Included in Supply Curve Analys is

\begin{tabular}{l|l} 
ECM & Levels Included \\
\hline Floor Insulation & $R-14$ \\
& $R-19$ \\
& $R-22$ \\
$R-25$ \\
$R-28$ \\
& $R-33$ \\
\hline Ceiling & $R-19$ \\
Insulation & $R-22$ \\
& $R-30$ \\
& $R-38$ \\
\hline Wall Insulation & $R-18$ (2x4 construction) \\
& $R-19$ (2x6 construction) \\
& $R-22$ \\
\hline Windows & $R-26$ \\
\hline Doors & 2 Pane, Aluminum with Storm \\
& 2 Pane, Alum./Therm Break with Storm \\
\hline Infiltratjon & Storm Doors (U = 0.29) \\
Control & 0.1 ACH + AAHX=0.2 ACH (thermal) \\
\hline
\end{tabular}

(a) $A C A^{-}$Tñdzates air changes per hour. AAHX indicates use of ar. air-to-air heat exchanger that brings the total exchange rate up to $0.35 \mathrm{ACH}$ with $60 \%$ thermal efficiency.

We developed estimated incremental costs for each of these measures. For most, the previous study of current practice (Harkreader et al. 1987) provided the required costs. For measures that regional manufacturers do not currently offer as options, we used nationally based data collected through a U.S. Department of Energy study or a HUD-sponsored study, or we relied on the limited empirical data from previous Bonneville-sponsored demonstration projects. Table 7.7 sumarizes the retail first costs and the data sources for single-wide homes and Table 7.8 sumarizes the data for double-wide homes. 
IABLE 7.7. Single-Hide ECM Cost Data(a)

\begin{tabular}{|c|c|c|c|}
\hline Component & $\begin{array}{c}\text { Measure Leve } 1 \\
\text { or Type }\end{array}$ & $\begin{array}{l}\text { Consumer Incrementa] } \\
\text { Cost, } \$ \text { /Unit }\end{array}$ & Data Source \\
\hline Floor & $R-7$ to $R-30$ & $0.0257 / R$-value/sq. ft. & $\begin{array}{l}\text { Harkreader } \\
\text { et a1 } \quad 1987\end{array}$ \\
\hline Ceiling. & $R-11$ to $R-38$ & 0.0269/R-value/sq.ft. & $\begin{array}{l}\text { Harkreader } \\
\text { et al.1987 } \\
\end{array}$ \\
\hline $\begin{array}{l}{ }^{\text {Nalls }} \\
2 \times 6\end{array}$ & $\begin{array}{l}R-7 \text { to } R-13 \\
R-13 \text { to } R-19 \\
R-13 \text { to } R-19 \\
R-19 \text { to } R-30\end{array}$ & $\begin{array}{l}0.0269 / R-v a l u e / s q . f t . \\
0.0724 / R-v a l u e / s q . f t . \\
0.4072 / \text { sq.ft. }+ \\
0.0269 / R-v a l u e / s q . f t . \\
0.0724 / R-v a l u e / s q . f t .\end{array}$ & $\begin{array}{l}\text { Harkreader } \\
\text { et a } 1.1987 \\
\text { DOE } 1986 \\
\text { Levy } 1986 \\
\\
\text { Harkreader } \\
\text { et al. } 1987 \\
\text { DOE } 1986 \\
\text { Levy } 1986\end{array}$ \\
\hline Windows & $\begin{array}{l}\text { Addition of } \\
\text { Storm } \\
\text { Addition of } \\
\text { Thermal Break }\end{array}$ & $\begin{array}{l}1.68 / \mathrm{sq} . \mathrm{ft} . \\
8.72 / \mathrm{sq} . \mathrm{ft} .\end{array}$ & $\begin{array}{l}\text { DOE 1986, HUD } \\
1987 \text {, Levy } \\
1986 \\
\text { DOE 1986, HUD } \\
1987 \text {, Levy } \\
1986 \\
\end{array}$ \\
\hline Doors & $\begin{array}{l}\text { Add Storm } \\
\text { Door }\end{array}$ & $186 /$ door & HUD 1987 \\
\hline Infiltration & $0.1 \underset{\text { AAHX }}{\mathrm{ACH}}+$ & $\begin{array}{l}1.43 / \mathrm{sq} . \mathrm{ft} \text {. gross } \\
\text { walt area }\end{array}$ & $\begin{array}{l}\text { Levy } 1986 \text { and } \\
\text { DOE } 1986\end{array}$ \\
\hline
\end{tabular}

(a) The incremental costs were developed from actual data. The data indicated changes in structural requirements for these measures had no identifiable effect on costs to consumers except for the alternative wall ECMs based on $2 \times 4$ or $2 \times 6$ construction. 
IABLE 7.8. Double-Wide ECM Cost Data(a)

\begin{tabular}{|c|c|c|c|}
\hline Component & $\begin{array}{c}\text { Measure Leve1 } \\
\text { or Type }\end{array}$ & $\begin{array}{c}\text { Consumer Incremental } \\
\text { Cost, S/Unit }\end{array}$ & Data Source \\
\hline Floor & $R-7$ to $R-30$ & 0.0252/R-value/sq.ft. & $\begin{array}{l}\text { Harkreader } \\
\text { et al. } 1987\end{array}$ \\
\hline Ceiling & $R-11$ to $R-38$ & $0.0241 / R-v a l u e / s q . f t$ & $\begin{array}{l}\text { Harkreader } \\
\text { et a1. } 1987\end{array}$ \\
\hline 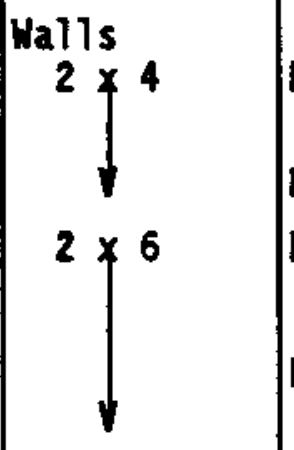 & $\begin{array}{l}R-7 \text { to } R-13 \\
R-13 \text { to } R-19 \\
R-13 \text { to } R-19 \\
R-19 \text { to } R-30\end{array}$ & $\begin{array}{l}0.0241 / R-v a l u e / s q . f t . \\
0.0724 / R-v a l u e / s q . f t . \\
0.2976 / \text { sq.ft. }+ \\
0.0241 / R-v a l u e / s q . f t . \\
0.0724 / R-v a l u e / s q . f t .\end{array}$ & $\begin{array}{l}\text { Harkreader } \\
\text { et al. } 1987 \\
\text { DOE } 1986 \\
\text { Harkreader } \\
\text { et al. } 1987 \\
\text { DOE } 1986 \\
\text { Levy } 1986\end{array}$ \\
\hline Windows & $\begin{array}{l}\text { Addition of } \\
\text { Storm } \\
\text { Addition of } \\
\text { Thermal Break }\end{array}$ & $\begin{array}{l}1.68 / \mathrm{sq} . \mathrm{ft} \\
8.72 / \mathrm{sq} . \mathrm{ft}\end{array}$ & $\begin{array}{l}\text { DOE 1986, HUD } \\
1987 \text {, Levy } \\
1986 \\
\text { DOE 1986, HUD } \\
1987 \text {, Levy } \\
1986\end{array}$ \\
\hline Doors & $\begin{array}{l}\text { Add Storm } \\
\text { Door }\end{array}$ & $186 /$ door & HUD 1987 \\
\hline Infiltration & $\int_{\text {AAHX }}^{\text {ACH }}+$ & $\begin{array}{l}1.45 / \mathrm{sq} . \mathrm{ft} . \text { gross } \\
\text { wall area }\end{array}$ & $\begin{array}{l}\text { Levy } 1986 \text { and } \\
\text { DOE } 1986\end{array}$ \\
\hline
\end{tabular}

(a) The incremental costs were developed from actual data. The data indicated changes in structural requirements for these measures had no identifiable effect on costs to consumers except for the alternative wall ECMs based on $2 \times 4$ or $2 \times 6$ construction.

\subsubsection{Levelized Costs and Supoly Curve}

Levelized costs were calculated for prototypical single-wide and doublewide homes. The prototypes were based on the characteristics presented in Table 7.4. The levelized costs were calculated on an incremental basis; i.e., each measure was considered relative to the next less stringent measure. Energy savings, therefore, were calculated as the incremental change in energy consumption relative to the next less stringent measure. 
The first costs were calculated using the data in Tables 7.7 and 7.8 . For measures with costs based on the R-value, we determined the appropriate consumer incremental cost from these tables and multiplied by the incremental $R$-value. If the incremental cost in the table were per square foot, we calculated the number of square feet required and multiplied by the approprlate value.

The incremental energy savings for each envelope ECM were estimated by first calculating the change in design UA based on U-values from BPA (1987). He multiplied the U-value change by the appropriate component area. For infiltration UA effects, we used the methodology described in Section 3. The UA change was then multiplied by the appropriate coefficient from Section 6 , based on climate zone and the HDD, to estinate the incremental energy savings. He used 5389 HDD for Seattle, 6732 HDD for Spokane, and 7658 HDD for Missoula, based on TAY data.

The first cost and energy savings were combined using the procedure discussed in Section 7.1 to calculate incremental levelized cost for each relevant ECM. The increnental costs are shown in Table 7.9 for each measure, applied to both prototypical single-wide and double-wide homes. The table also shows the corresponding incremental design UA change.

Several construction assumptions are reflected in the cost and UA estimates. The two major assumptions are the following. First, the floor construction is assumed to be based on the use of $2 \times 6$ lumber for all Rvalues. The calculations assume that insulation up to $R-19$ is installed between the joists. For floor insulation above $R-19$, we assumed that the additional R-value would be achieved by installing blanket insulation below the floor joists. These assumptions are consistent with those described in Section 3 .

Second, since the current practice wall insulation level is below R-13, we assume current practice is based on the use of $2 \times 4$ framing in the wal1. (a) The R-18 wall is based on R-13 batt insulation plus R-5 insulated sheathing. Wall insulation levels of R-19 and above are achieved with $2 \times 6$ framing, an R-19 batt, and insulated sheathing. The table indicates that the

(a) This assumption is consistent with manufacturer survey data and compliance certificate data as described in Harkreader et al. (1987). 
R-19 wall costs more than the R-18 wall and has a higher UA. The higher costs result from the cost of going from $2 \times 4$ framing to $2 \times 6$ framing. The increase in UA for the R-19 wall results primarily from the fact that insulated sheathing in the R-18 wall covers the framing members and, therefore, reduces the U-value where the framing is present as well as between framing members where the batt insulation is placed. There are two consequences of this effect. The first is that, starting with $2 \times 4$ construction, it is more cost-effective to add insulated sheathing to

IABLE 7.9. Incremental costs and Design UAs for ECMs

\begin{tabular}{|c|c|c|c|c|c|}
\hline ECH & Leve1 & sing & $\begin{array}{l}\text { le-Wide } \\
\text { UA Decrease }\end{array}$ & $\begin{array}{l}\text { Dou } \\
\text { s }\end{array}$ & $\begin{array}{l}\text { ble-Wide } \\
\text { |UA Decrease }\end{array}$ \\
\hline Floor Insulation & $\begin{array}{l}R-14 \\
R-19 \\
R-22 \\
R-25 \\
R-28 \\
R-33(a)\end{array}$ & $\begin{array}{r}97 \\
116 \\
69 \\
69 \\
69 \\
116 \\
\end{array}$ & $\begin{array}{l}8.5 \\
6.7 \\
4.1 \\
3.2 \\
1.9 \\
1.4 \\
\end{array}$ & $\begin{array}{l}161 \\
187 \\
112 \\
112 \\
112 \\
187 \\
\end{array}$ & $\begin{array}{r}14.4 \\
11.0 \\
6.8 \\
5.3 \\
3.1 \\
2.4 \\
\end{array}$ \\
\hline $\begin{array}{l}\text { Celling } \\
\text { Insulation }\end{array}$ & $\begin{array}{l}R-19 \\
R-22 \\
R-30 \\
R-38\end{array}$ & $\begin{array}{r}56 \\
73 \\
193 \\
193 \\
\end{array}$ & $\begin{array}{l}5.4 \\
5.4 \\
9.0 \\
5.4\end{array}$ & $\begin{array}{r}43 \\
107 \\
286 \\
286 \\
\end{array}$ & $\begin{array}{r}4.2 \\
8.9 \\
14.8 \\
8.9 \\
\end{array}$ \\
\hline Wall Insulation & $\begin{array}{l}R-18(2 \times 4) \\
R-19(2 \times 6) \\
R-22 \\
R-26\end{array}$ & $\begin{array}{l}439 \\
222 \\
234 \\
312\end{array}$ & $\begin{array}{r}35.5 \\
-3.2 \\
9.7 \\
8.6\end{array}$ & $\begin{array}{l}243 \\
236 \\
227 \\
303\end{array}$ & $\begin{array}{r}29.3 \\
-3.1 \\
9.4 \\
8.4\end{array}$ \\
\hline \multirow[t]{2}{*}{ Hindows } & $\begin{array}{l}2 \text { Pane, A1. } \\
+ \text { Storm }\end{array}$ & 151 & 19.8 & 249 & 32.7 \\
\hline & $\begin{array}{l}2 \text { Pane, T.I.M. } \\
+ \text { Storm }\end{array}$ & 784 & 8.1 & 1294 & 13.4 \\
\hline Doors & Storm Doors & 372 & 3.9 & 372 & 3.9 \\
\hline $\begin{array}{l}\text { Infiltratjon } \\
\text { Control }\end{array}$ & $\begin{array}{l}0.1 \mathrm{ACH}+\text { AAHX }= \\
0.25 \mathrm{ACH} \text { (thermal) }\end{array}$ & 1719 & 18.0 & 1784 & 30.0 \\
\hline
\end{tabular}

(a) “ Cösts̄ hàve been extrapolated slightly beyond the maximum R-value (R-30) for which data were available.

(b) ACH indicates air changes per hour. AAHX indicates use of an air-toair heat exchanger that brings the natural exchange rate up to $0.35 \mathrm{ACH}$ with $60 \%$ thermal efficiency. 
achieve the R-18 wall than to switch to $2 \times 6$ construction and use R-19 insulation. The second consequence is that the cost-effective step up from the $R-18$ wall is to an R-19 wall with sheathing (e.g., the R-22 wall) rather than to the R-19 wall itself. For this reason, the R-19 wall has been deleted from our supply curve analysis.(a)

Table 7.10 and Table 7.11 respectively present the single-wide and double-wide levelized cost estimates for cities representing the three MCS climate zones. The results for each component option are presented based on the marginal cost and energy savings relative to the less efficient option it would replace. Note that the options considered for both single-wide and double-wide homes were identical except for the exclusion of R-38 ceiling in the single-wide due to significant compression of the insulation. The options are arranged by component, starting with ceilings and moving through the other components to the infiltration control option presented earlier. Note also that we found the levelized costs to increase and then decrease for wall insulation levels between R-18 and R-26 (because of the averaging of the $2 \times 6$ cost). Both tables, therefore, report only the values for R-26 walls. We observed a similar phenomenon in the floor insulation in which levelized costs of R-22 (R-19 between the joists and an R-3 blanket below the joists) were lower than the incremental levelized cost of R-19 alone. Consequently, the tables do not report the values for $R-19$ floor insulation.

To get a sense of the relative costs of these conservation measures, we compared the levelized costs to estimated levelized costs for new coal generating plants. Current estimates of regional coal plant levelized costs are in the range of 37 to $45 \mathrm{mills} / \mathrm{kWh}$ (NPPC 1986). For comparison purposes, we used a figure of $40 \mathrm{mills}$ here.

(a) This issue deserves further review. While insulated sheathing is used by a few manufacturers nationally, the manufactured housing industry in the Northwest has indicated $1 \mathrm{ittle}$ interest in this type of construction because of concerns about cost, structural integrity, and consumer reaction. Nevertheless, our data from limited applications of insulated sheathing have shown this measure to be cost-effective from a regional perspective. Data from Bonneville's Residential Construction Demonstration Program may shed some light on the validity of including this measure in the supply curve. The regional cost-effectiveness of this approach suggests Bonneville should work with the industry to share information on the use of insulated sheathing and examine cost-effective ways to apply this construction technique. 
IABLE 7,10. Incremental Levelized costs of Single-Wide ECMs in New Manufactured Homes

\begin{tabular}{|c|c|c|c|c|}
\hline Location & $\begin{array}{l}\text { Energy } \\
\text { Conservation } \\
\text { Measure }\end{array}$ & $\begin{array}{c}\text { Measure } \\
\text { Costs, } \\
5 \\
\end{array}$ & $\begin{array}{l}\text { Measure } \\
\text { Savings } \\
\text { (kwh/yr.) }\end{array}$ & $\begin{array}{l}\text { Levelized } \\
\text { Cost, } \\
\text { mills/kwh }\end{array}$ \\
\hline \multirow[t]{2}{*}{$\begin{array}{c}\text { Seattle, } \\
\text { Zone I }\end{array}$} & $\begin{array}{l}\text { R-19 Ceiling } \\
\text { R-22 Ceiling } \\
\text { R-30 Ceiling } \\
\text { R-18 Hall (2X4) } \\
\text { R-26 Nall (2X6) } \\
\text { R-14 Floor } \\
\text { R-22 Floor } \\
\text { R-25 Floor } \\
\text { R-28 Floor } \\
\text { R-33 Floor } \\
\text { Storm Hindow } \\
\text { T.I.M. Hindow } \\
\text { Storm Doors } \\
\text { Infiltration }\end{array}$ & $\begin{array}{r}56 \\
73 \\
193 \\
439 \\
768 \\
97 \\
185 \\
69 \\
69 \\
116 \\
151 \\
784 \\
372\end{array}$ & $\begin{array}{r}136 \\
136 \\
228 \\
899 \\
382 \\
215 \\
273 \\
81 \\
48 \\
35 \\
293 \\
120 \\
99\end{array}$ & $\begin{array}{r}19.1 \\
24.9 \\
39.3 \\
22.6 \\
93.2 \\
20.9 \\
31.4 \\
39.5 \\
66.7 \\
153.7 \\
23.9 \\
303.0 \\
174.3\end{array}$ \\
\hline & Control & 1719 & 456 & 230.4 \\
\hline \multirow[t]{2}{*}{$\begin{array}{l}\text { Spokane, } \\
\text { Zone } 2\end{array}$} & $\begin{array}{l}\text { R-19 Celiling } \\
\text { R-22 Celiling } \\
\text { R-30 Ceiling } \\
\text { R-18 Hal1 }(2 \times 4) \\
\text { R-26 Wall }(2 \times 6) \\
R-14 \text { Floor } \\
\text { R-22 Floor } \\
\text { R-25 Floor } \\
\text { R-28 Floor } \\
\text { R-33 Floor } \\
\text { Storm Window } \\
\text { T.I.M. Windows } \\
\text { Storm Doors } \\
\text { Infiltration }\end{array}$ & $\begin{array}{r}56 \\
73 \\
193 \\
439 \\
768 \\
97 \\
185 \\
69 \\
69 \\
116 \\
151 \\
784 \\
372\end{array}$ & $\begin{array}{r}177 \\
177 \\
294 \\
1161 \\
494 \\
278 \\
353 \\
105 \\
62 \\
46 \\
379 \\
155 \\
128\end{array}$ & $\begin{array}{r}14.7 \\
19.1 \\
30.4 \\
17.5 \\
72.1 \\
16.2 \\
24.3 \\
30.5 \\
51.6 \\
117.0 \\
18.5 \\
234.6 \\
134.8\end{array}$ \\
\hline & Control & 1719 & 589 & 178.3 \\
\hline \multirow[t]{2}{*}{$\begin{array}{l}\text { Missoula, } \\
\text { Zone } 3\end{array}$} & $\begin{array}{l}\text { R-19 Celling } \\
\text { R-22 Ceiling } \\
\text { R-30 Ceiling } \\
\text { R-18 Wall (2X4) } \\
\text { R-26 Wall }(2 \times 6) \\
\text { R-14 Floor } \\
\text { R-22 Floor } \\
\text { R-25 Floor } \\
\text { R-28 Floor } \\
\text { R-33 Floor } \\
\text { Storm Window } \\
\text { T.I.M. Windows } \\
\text { storm Doors }\end{array}$ & $\begin{array}{r}56 \\
73 \\
193 \\
439 \\
768 \\
97 \\
185 \\
69 \\
69 \\
116 \\
151 \\
784 \\
372\end{array}$ & $\begin{array}{r}198 \\
198 \\
333 \\
1313 \\
559 \\
314 \\
399 \\
118 \\
70 \\
52 \\
429 \\
176 \\
144\end{array}$ & $\begin{array}{r}13.1 \\
17.1 \\
26.9 \\
15.5 \\
63.7 \\
14.3 \\
21.5 \\
27.1 \\
45.7 \\
103.5 \\
16.3 \\
206.6 \\
119.8\end{array}$ \\
\hline & Control & 1719 & 666 & 157.7 \\
\hline
\end{tabular}


IABLE 7.11. Incremental Levelized Costs of Double-Wide ECMs in New Manufactured Homes

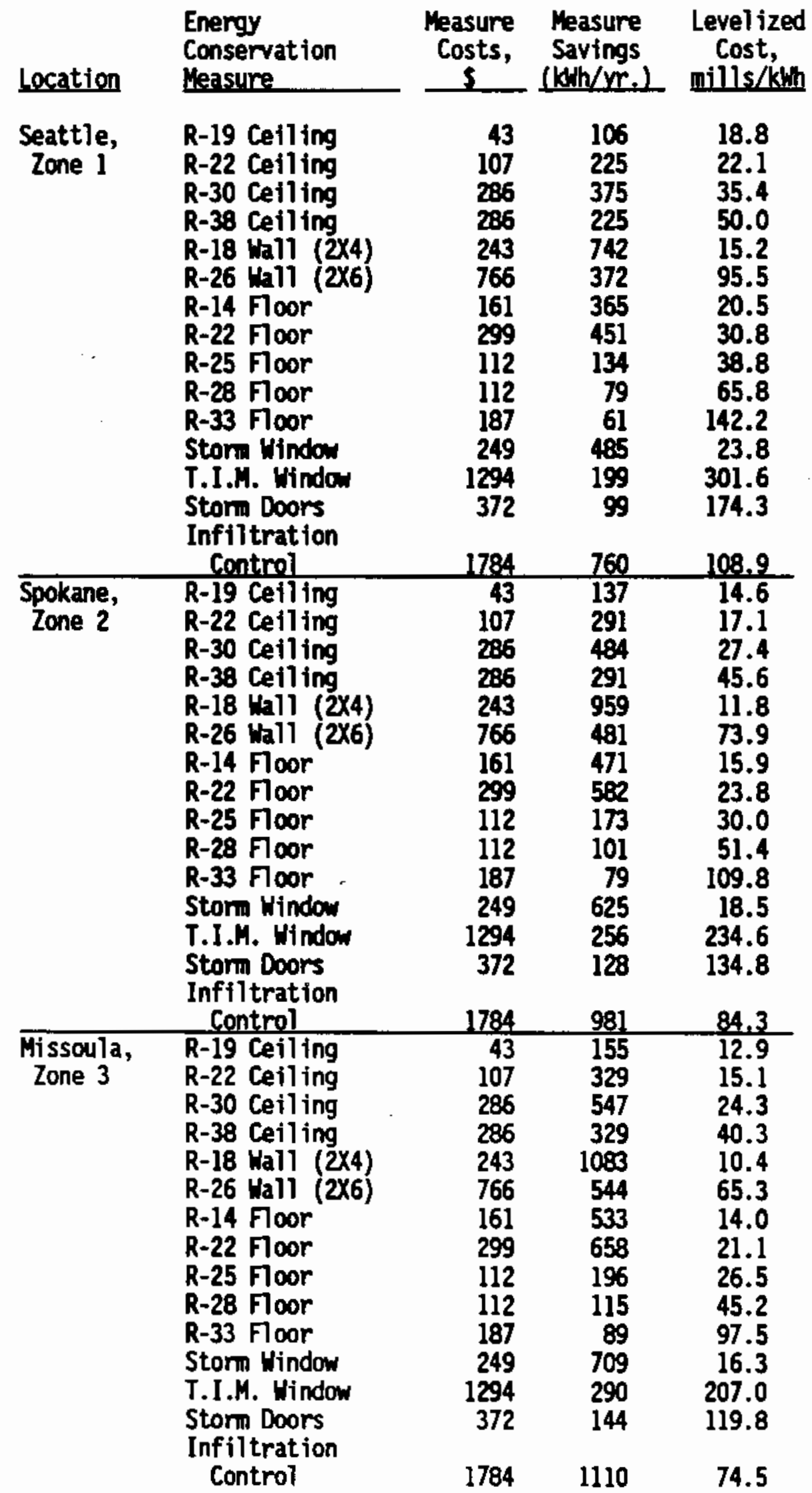


Typically, the levelized costs are lower in the double-wide homes and each option has a lower levelized cost in the colder climate zones. The most cost-effective option for single-wide homes is the installation of R-19 ceiling insulation. Starting at the current practice average level of about $R-17$, the ceiling insulation can be increased to $R-19$ for as little as 13 to $19 \mathrm{mills} / \mathrm{klh}$ of savings across the climate zones. In double-wide homes the comparable levelized costs are even lower. Using the $40 \mathrm{mills} / \mathrm{kWh}$ threshold, up to R-30 in the celling is cost-effective in all climate zones for both single-wide and double-wide homes. R-38 ceiling insulation is cost-effective under this criterion only in double-wides in climate zone 3 . The savings per dollar invested decrease substantially over the range from $R-19$ to $R-30$ with it costing nearly twice as much per kWh saved to go from $R-22$ to $R-30$ as it does from current practtce to R-19.

Probably the most surprising result is the cost-effectiveness of increasing current practice insulation levels in walls to $R-18$ ( $2 \times 4$ walls with R-13 batts plus R-5 insulated sheathing). The levelized cost of this option ranges from about 10 to $23 \mathrm{mills} / \mathrm{kWh}$. (a) These estimates are based on assumed current construction practice of $2 \times 4$ walls with about R-11 insulation. Industry data indicate that this is the most typical construction, yet manufacturers in the Northwest currently do not offer a $2 X$ 4 wall with insulated sheathing as an option and have indicated their preference to market homes with $2 \times 6$ walls and conventional R-19 insulation instead. Our results, however, suggest that the insulated sheathing approach is far more cost-effective from the regional perspective. The costeffectiveness results from two factors. First, the insulated sheathing covers the extension of the wall studs thus preventing them from acting as a thermal bridge. Second, the change to $2 \times 6$ framing adds about $\$ 300$ to the retail price of a home based on data collected from manufacturers. A few

(a) R-19 wall insulation with $2 \times 6$ construction also meets the costeffectiveness test for both single- and double-wide homes in all 3 climate zones. For single-wide homes the levelized costs range from 26 $\mathrm{mills} / \mathrm{kWh}$ in zone 3 to $38 \mathrm{mill} \mathrm{s} / \mathrm{kWh}$ in zone 1 . For double-wides, the costs range from 23 to $33 \mathrm{mills} / \mathrm{kWh}$. Because $\mathrm{R}-1 \mathrm{~g}$ walls are also costeffective, the findings in this report based on the R-18 wall construction are comparable to the findings that would apply if we considered conventional R-19 walls instead. 
manufacturers have gained experience using insulated sheathing and its apparent cost-effectiveness warrants further discussions between Bonneville and the industry on its potential applicability.

The floor insulation upgrades appear cost-effective up to about R-25. The cost per unit energy savings is approximately twice as much for insulation increases between R-22 and R-25 as it is for increases from current practice (about R-10) to R-14.

The storn window option has relatively low levelized costs (less than 24 mills) in all cases, but changing to the thermally improved metal (T.I.M.) window added levelized costs of about 200-300 mills. The storm door costs also were very high, up to $174 \mathrm{mills}$. The infiltration control package (including an AAHX) exceeded 40 mills by a significant amount, and was at its lowest for the double-wide home in clinate zone 3 (about 75 mills).

Table 7.12 presents the combined supply curve results for single-wide and double-wide homes. The values indicate the average megawatts of capacity that investments in efficiency improvements in new manufactured homes could displace. The amount displaced is shown for different levelized costs of the investments in efficiency improvements. The results are average in the year 2007 within only the Bonneville customers' service area. The major assumption underlying these results is that $50 \%$ of all manufactured homes built between 1987 and 2007 would contain the measures at each levelized cost level. The three scenarios are based on the low, base, and high parameter values presented earlier. Because they are larger and they constitute a large proportion of the new manufactured housing stock, double-wides make up about $90 \%$ of the total potential savings.

For the base scenario, manufactured housing efficiency improvements costing $40 \mathrm{mill} / \mathrm{s} / \mathrm{kWh}$ or less could contribute about 78 average $M$ in the year 2007. The average cost of these measures would be about $22 \mathrm{mills} / \mathrm{kWh}$. Using simflar assumptions, the Northwest Power Planning Council estimated achievable conservation savings of 45 average $M$ in 2005 (NPPC 1986). The Council's estimate discounts savings as ours does based on an assumed saturation limit of $50 \%$. 


\section{TABLE.7.12. Cumulative Energy Savings at Different Levelized Costs, Average M}

\begin{tabular}{crrr} 
& \multicolumn{3}{c}{ Scenario } \\
\cline { 2 - 4 } Hils/kWh Low & Base & High \\
\cline { 2 - 4 }$<10$ & 0.0 & 0.0 & 0.0 \\
$<20$ & 25.7 & 42.4 & 48.3 \\
$<30$ & 41.5 & 68.5 & 78.0 \\
$<40$ & 47.2 & 78.0 & 88.8 \\
$<50$ & 49.9 & 82.5 & 93.9 \\
$<60$ & 51.4 & 84.9 & 96.5 \\
$<70$ & 53.8 & 89.0 & 101.2 \\
$<80$ & 60.1 & 99.4 & 113.2 \\
$<90$ & 63.8 & 105.5 & 120.0 \\
$<100$ & 67.8 & 112.1 & 127.5
\end{tabular}

\subsection{COMPARISON OF RETROEIT AND MEH HOME UPGRADE RESULTS}

We were able to compare the levelized costs of efficiency improvements through retrofit with those made during the production of new homes. For all the insulation measures, per unit costs were higher to implement through retrofit as would be expected. Retrofit costs were higher by from $50 \%$ to $100 \%$, with the largest differences occurring in walls. The window retrofits were more difficult to compare since new homes started with double glazing, whereas retrofits were based on homes with single glazing only. The application of storm windows to new homes appeared significantly less expensive than to existing hones. This probably resulted from the additional labor required to size and install windows in the field.

The retrofit levelized costs were consistently higher than levelized costs associated with new homes. This result followed from the higher first costs. 


\subsection{STUDY FINDINGS AND RESEARCH RECOMMENDATIONS}

This study has addressed the three goals of 1) estimating levelized costs for retrofitting existing manufactured homes, 2) estimating levelized costs for upgrading new manufactured homes, and 3 ) developing a supply curve for efficiency improvements in new manufactured homes. We utilized measured energy consumption data from Hood River homes and the Tulalip MCS homes to estimate changes in energy consumption that result from efficiency improvements. Data from the Hood River Conservation Project permitted us to estimate the costs of efficiency retrofits. A survey of the industry and the collection of manufacturers' compliance form data provided comprehensive information on current construction practices, trends, and new home ECM costs (Harkreader et al. 1987). Together, these data allowed us to estimate retrofit costs and energy savings, estimate new hore ECM costs and energy savings, and develop a supply curve showing expected electricity savings for a range of conservation measures.

The analyses required the development of several new tools and approaches that were specifically needed because of the research goals and diversity of data sources. These tools augnent existing analytic tools for the study of manufactured homes in the region, but may have applications to other housing types and regions as well.

This study rasies policy and planning issues because it assesses costeffectiveness through an empirically-based approach. Bonneville and the Northwest Power Planning Council typically utilize models to estimate conservation energy savings for policy and planning purposes. The modeling approach has the virtue of allowing the analyst to vary assumptions about occupant behavior, trends, and other factors that directly affect forecast energy savings. Our approach, on the other hand, accounts for factors as they are reflected in the empirical energy consumption data. The empirical approach has the benefit of taking these factors into account, but has the limitation of being based on only a snapshot in time. Our analysis also is tied to households in a single geographic area whose representativeness for the Northwest is uncertain. 
Though the energy savings required considerable analysis to estimate, they are based on empirtcal data and a relatively simple and physically reasonable model of space heating energy consumption. The large amount of data underlying the estimates and the generally good fits to the data are solit evidence that the approach is reliable for the situations analyzed. The observed difference between as-operated UAs (see Appendix A) and design UAs is consistent with several other studies. The PRISM adjustments, both for the heating load and clinate zone extrapolations, represent a significant improvement over using billing data and HDD-based extrapolations alone. Nevertheless, the information available did not permit us to fully verify the extrapolations to other cl taate zones and provided no insights about the effect of internal and solar gains or other factors.

This study constitutes a step toward integrating analysis of empirical data with the planning and policy-making process. He recomnend, however, due to the limitations of either the modeling or empirical approaches alone, that an analytic approach based on both techniques be pursued in the future to address questions related to the cost-effectiveness of conservation measures.

This section highlights the key research findings and closes with a discussion of methodological issues.

\subsection{RESEARCH FINDINGS AND CONCLUSIONS}

This study produced several types of findings and conclusions that are important for program evaluation, planning, and implementation, and future analyses in support of these activities. He present here two types: 1) the levelized cost and supply curve products of the analysis and 2) intermediate analytical findings that are important by themselves.

\subsubsection{Levelized Costs and Conservation Supply Curve}

In existing homes in Hood River (MCS climate zone 1), numerous component insulation and window retrofit upgrades appear technically feasible. Installation costs are too high given the resulting energy savings to make the highest $R$-values and most window retrofits cost-effective. Selected retrofits, on the other hand, are cost-effective. 
- Assuming 30-year measure lifetimes and Hood River weather, ceiling upgrades to R-30 and floor upgrades to R-14 can be accomplished for about $40 \mathrm{mills} / \mathrm{kWh}$ or less.

- In colder climate zones, such as MCS zone 3, ceiling insulation up to R-38 and floor insulation up to R-22 may be cost-effective.

- The number of years a manufactured home is expected to last after being retrofit plays a dominant role in determining the costeffectiveness of retrofit measures. If the remaining lifetime is 10 years rather than 30 years, levelized costs are higher by a factor of about 2.5.

In new manufactured homes, a wide-range of ECMs appears both technically and economically feasible. We examined floor insulation levels up to R-33, ceiling insulation up to $R-38$ (R-30 in single-wide homes), wall insulation up to $R-26$, storm windows and thermally improved metal (T.I.M.) windows, storm doors, and infiltration control with an air-to-air heat exchanger (AAHX).

- The levelized costs of the measures examined were typically lower in double-wide homes, both because of the larger size of doublewide homes and lower prices (per unit area) at the retail level.

- As a result of the more severe weather conditions, levelized costs in MCS climate zone 2 were about 25\% less than those in climate zone 1 , and costs in climate zone 3 were about $33 \%$ lower than in climate zone 1 .

- Based on avatlable cost data, $2^{1} \times 4^{\prime \prime}$ wall construction with both conventional insulation and insulated sheathing appears to be more cost-effective than $2^{\prime \prime} \times 6^{\prime \prime}$ construction with conventional insulation alone. This option merits further investigation because it has not been widely accepted by the industry, but may be quite costeffective.

- Using the levelized cost of a new coal plant as the test of costeffectiveness, $R-30$ ceiling insulation and $R-18$ wall insulation using insulated sheathing (or conventional R-19 insulation) are cost-effective on an incremental basis (i.e., based on cost and savings relative to the next less efficient ECM level) throughout 
the region. Storm windows are also cost-effective throughout the region, but the levelized costs of T.I.M. windows, storm doors, and tight infiltration packages are well above the coal plant levelized cost.

- Using the $40 \mathrm{mills} / \mathrm{k}$ th criterion and the average levelized cost (based on the total cost and savings to go from current practice to a given ECM level), rather than the incremental levelized cost, several additional ECMs are cost-effective. In double-wide homes, R-38 cefling insulation is cost-effective in all climate zones. $R$ 26 wall insulation using insulated sheathing is nearly costeffective (average levelized cost is less than $43 \mathrm{mill} / \mathrm{s} / \mathrm{k} / \mathrm{h}$ ) and R30 floor insulation is cost-effective in all climate zones. The thermally-improved metal window plus storm, however, is still not cost-effective by itself.

The levelized costs provide the basis for developing a new manufactured housing supply curve. Double-wide homes dominate the savings at each levelized cost level because of the large proportion of new homes in this category.

- Me estimate savings of about 78 average $M$ in the year 2007 for a levelized cost of $40 \mathrm{mill} / \mathrm{s} / \mathrm{kth}$ or less.

\subsubsection{Other Analytic Results and Findings}

We have developed other valuable information and identified several other important findings in the course of estimating the levelized costs and supply curve. While most of these findings are intermediate analytical results, some are methodological in nature and should provide valuable insights for other studies.

He developed software to calculate the design UA for the Hood River manufactured homes. This was necessary because available software had been designed for site-built homes and many calculations had to be tailored to construction assumptions consistent with manufactured homes.

- Software is now available to calculate the design UA of Hood River manufactured homes and could be modified for use with other data sets of manufactured homes. 
The Hood River data set provided both manufactured home end-use data and billing data that we used to compare performance before and after retrofit. These data provided two pieces of information for comparison with other studies.

- Both PRISM and the lowess and linear fit methodologies (see Appendix A) Indicated average heating energy savings of about $10 \%$ after retrofit. These results are consistent with previous studies.

- Measured temperature data indicated no statistically significant evidence that occupants "take back" part of their energy savings through higher temperatures.

We analyzed two sets of homes built to the MCS. The 34 Tulalip homes were analyzed with PRISM and the results were compared with measured heating energy data. Three other homes built to the MCS under a Bonneville program were metered with end-use metering equipment. These data were analyzed with the lowess and linear fit methodologies.

- Both sets of MCS homes consumed considerably more energy for space heating than their design estimates, due at least in part to inconsistencies between assumed and actual operating conditions.

- Both sets of MCS homes, however, consumed about one-third to onehalf less than comparable current practice homes.

Use of the lowess and linear fit techniques described in Appendix $A$ was significantly hampered by a lack of data. Application of this methodology, however, revealed two key insights about building performance.

- As-operated UAs, calculated using a linear model, are lower than design UAs. This observation is most likely due to the effect of internal and solar gains in heating requirements.

- Average inside air temperatures appear to be considerably above $65^{\circ} \mathrm{F}$, which is often assumed in simulation analyses. The higher air temperatures contribute significantly to the difference between heating energy estimates based on simulations and those based on measured energy data. 
The use of PRISH in our analyses permitted examination of the accuracy of the space heating estimates derived from this methodology. Me made several consistent observations across the data sets analyzed and were able to develop a new technique for correcting the PRISM estimates.

- PRISM tends to overestimate space heating energy consumption, in part, because seasonal and temperature-dependent loads other than space heating are apparently included in the estimat of the heating component.

- PRISH overestimates space heating more for homes, such as energyefficient homes, that use a relatively saall share of their total electrical energy for space heating, and may underestimate space heticularly for homes that consume relatively little energy for heating. This methodology requires limited information, primarily weather data and the PRISM estimates.

Since we were limited to data in MCS climate zone 1 , we examined the issue of climate zone extrapolations very closely. Heating degree-day (HDD) based methods, such as PRISH, are unable to correct for climate variables other than average temperature differences. He examined several other climate variables and developed a methoticularly for homes that consume relatively little energy for heating. This methodology requires 1 imited information, primarily weather data and the PRISH estimates.

Since we were 1 imited to data in MCS climate zone 1 , we examined the issue of climate zone extrapolations very closely. Heating degree-day (HDO) based methods, such as PRISH, are unable to correct for climate vartables other than average temperature differences. He examined several other climate variables and developed a methodology for extrapolating heating energy consumption data to other climates. He used results from a simulation model to generate data that captured solar and other effects that we felt were important in climate extrapolations. 
o We found that extrapolations based strictly on HDD tended to underestimate consumption when going from colder to warmer climates, and conversely.

o For the Bonneville region, we found that insolation was the major factor that would improve climate extrapolations that were based strictly on HDD. Temperature swing also had a significant effect on the accuracy of the extrapolations.

- The solar effect is related directly to utilizability of solar gains.

o The adjustment in going from one climate zone to another is 1) positively related to the product of the heating load in the first clinate and the change in HDO, 2) positively related to the change in temperature swing, and 3 ) negatively related to the change in insolation.

We used the large set of Hood River data to derive a relationship between changes in heating energy consumption and design UA. The PRISM estimates for Hood River homes were adjusted using the PRISM heating and nonheating load split correction and climate extrapolation procedure. The results provided the basis for estimating a relationship between design UA and changes in heating energy consumption for the three HCS climate zones.

- A linear fit between heating energy consumption and design UA fit the available measured energy data well.

- The change in heating energy consumption associated with a change in design UA is about 70-80\% of the amount predicted by a simple linear model based on HDD or generated by simuiation models.

- A change in the window design UAs appears to have about half the effect of a change in the design UA of other components. This probably results from 1) the fact that window UA improvements typically decrease solar gains and 2) window design UAs do not capture the average effect of wind speed. 


\subsection{RESEARCH ISSUES AND RECOMHENDATIONS}

This study permits some 1 tmited comparisons of different energy analys is methods. Since this study was not designed specifically with these comparisons in mind, these comparisons are not systematic. Nevertheless, the comparisons identify research issues that.merit further attention because most research relies on a single methodology whose results are not systematically qualified based on the 1 imitations or biases inherent in the methodology.

Our linited comparison of the results from the PNL linear and lowess fit methodologies and the Equivalent Thermal Parameter (ETP) methodology demonstrates significant differences in the estimates of as-operated UAs (see Appendix A). The ETP methodology relies on hourly data, whereas the RSDP methodology relies on daily average data. In addition, the ETP methodology explicitly separates effects of solar gains. In situations where hourly enduse data are available, further comparisons of these methodologies should be pursued to establish the reasons for their different results.

The observed differences between calculated as-operated UAs and design UAs, though frequently noted, are not fully understood or predictable. Occupant behavior, internal gains, and solar gains undoubtedly have a major effect on the differences, yet the exact effects have not been established. Further research should examine what factors contribute to the differences between as-operated UAs and design UAs.

Consistent with prior studies, our results show that using the PRISM heating component as an estimate of space heating energy use can lead to significant errors. We have developed a methodology that improves the PRISM estimates, especially for energy-efficient homes. This methodology, however, was developed using a small data set and should be tested using other data. The corrected results are biased toward overestimating heating energy consumption, as are PRISM results. It is unknown whether the remaining error could be further reduced using additional data readily available (e.g., PRISM parameter estimates or weather data) or whether other variables not considered here, and more difficult to obtain, could be incorporated into the correction methodology and significantly reduce the error. This methodology should be explored further with the extensive end-use data collected on site- 
built homes in both the Hood River Conservation Project and the End-Use Load and Consumer Assessment Program (ELCAP).

The retrofit analysis results suggest that further analysis of the costeffectiveness and supply curve associated with manufactured housing retrofits might be productive. An estimate of the number of existing manufactured homes in the region and their ages would provide information that, in conjunction with existing data, could be used to assess the costs and beneftts of manufactured housing retrofits.

Our analyses went part of the way toward assessing the effects of individual conservation measures, but to a major extent assumed that energy savings for all measures, except glazing, had the same dependence on UA changes. The Hood River data and other data developed by Bonneville could be used to examine whether design UA changes for different components have consistent effects on heating energy use.

Our climate adjustment procedure neglects two major factors that may play a role in climate extrapolations. First, infiltration rates are climate-dependent and loads resulting from infiltration constitute 10-20\% or more of total heating load. Incorporating estimates of infiltration loads in our methodology would improve the adjustment procedure. Second, variations of internal loads with climate variables (such as lighting loads that depend on insolation) have an effect on climate extrapolations. The methodology developed here could be tested by using data from two different parts of the heating season in a single location or data from two or more climate zones, and additional correction terms could be investigated.

Finally, we expect the relationship between energy consumption and UA to vary because of the effects of internal and solar gains. Additional analyses should be performed to determine if the effect of internal and solar gains on the relationship between heating energy consumption and design UA can be estimated. This effect may be especially important for energy-efficient homes, such as manufactured homes built to meet the MCS. 
,

.

,

\author{
.
}

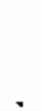

.

-

$\infty$ 


\subsection{REFERENCES}

ASHRAE. 1985. Fundamentals Handbook Inch-Pound Edition. American Society of Heating, Refrigerating, and Air-conditioning Engineers, Atlanta, Georgia.

Becker, R. A. and J. M. Chambers. 1984. An Interactive Environment for Data Analysis and Graphics. Bell Laboratories, New Jersey.

Bonneville Power Administration (BPA). 1986. 1985 Conservation Supply Document. DOE/BP-626, Portland, Oregon.

Bonneville Power Administration (BPA). 1987. Super Good Cents Technical Specifications for Manufactured Homes. Port land, Oregon.

Bronfman, B. H., H. J. Horowitz, and D. I. Lerman. 1987. Energy Use in Homes Built to Model Conservation Standards: Outcomes Evaluation of the Iacoma Early Adopter Program. IEAL/PO-13. International Energy Associates Limited, Portland, Oregon.

Collette, C. 1987. "The Hobile Hone Cones of Age", Northwest Energy News. August/September, Volume 6, Number 5, p.15. Northwest Power Planning Council, Portland, Oregon.

Conner, Craig. 1987. "Heat Loss Characteristics of the ELCAP Residential Sample." Draft PNL report. Pacific Northwest Laboratory, Richland, Washington.

Drost, K. et al. 1986. Analysis of Thermal Performance Data Taken Under the Residential Standards Demonstration Program, PNL-6021, Pacific Northwest Laboratory, Richland, Washington.

Ek, C. 1987. "Air Leakage Data by Brand." Bonneville Power Administration, Portland, Oregon.

Eckman, T. 1988a. "Cost-Effectiveness Analysis for Mobile Homes." Northwest Power Planning Counci1, Portland, Oregon.

Eckman, T. 1988b. "Equivalent MCS Requirements." (personal communication) Northwest Power Planning Council, Portland, Oregon.

Fels, M. F. 1986. "PRISM: An Introduction." Energy and Buildings, Vo1. 9, pp. 5-18. Berkeley, California.

Fels, M. F., J. Rachl in, and R. Socolow. 1986. "Seasonality of Non-Heating Consumption and Its Effect on PRISM Results." Eneray and Buildings, Vol 9, pp. 139-148. Berkeley, California.

Goldberg, M. L. 1982. A Geometrical Aporoach to Nondifferentiable Regression Models as Related to Methods for Assessing Residential Energy 
Conservation. Ph.D. Dissertation, Princeton University, Princeton, New Jersey.

Harkreader, S. A., A. D. Lee, and M. P. Sherman. 1987. Current Construction Practice in Pacific Northwest Manufactured Homes and Uograde Possibilities. Pacific Northwest Laboratory, Richland, Hashington.

Hendrickson, P. L., B. L. Mohler, Z. T. Taylor, A. D. Lee, and S. A. Onisko. 1987. Marketing Eneray Conservation Options to Northwest Manufactured Home Buyers. PNL-5496 Rev. 1, Pacific Northwest Laboratory, Richland, Hashington.

Hirst, E. and R. Goeltz. 1986. Electrictity Use for Residential Soace Heating: Comparison of the Princeton Scorekeeping Method with End-Use Load Data. ORNL/CON-203. Oak Ridge National Laboratory, Oak Ridge, Tennessee.

Hirst, Eric. 1987. "Cooperation and Comanity Conservation." DOE/BP:11287-18. Oak Ridge Mational Laboratory, Oak Ridge, Tennessee.

Janes, Ruth Ann. "Supply Curve Horksheet." Bonneville Power Administration, Portland, Oregon.

Knight, P. A. and L. Rangelov. 1986. Mobile Home Retrofit Handbook. Energy Resources Center, University of Illinots, Chicago, Illinois.

Lawrence Berkeley Laboratory (LBL). 1983. Affordable Housing through Energy Conservation. A Guide to Designing and Constructing Energy Efficient HomesIechnical Supdort Docunent. DOE/SF/00098-1. Berkeley, Cali fornia.

Lee, A. D., Z. T. Taylor, G. B. Parker, G. L. Nilfert, J. W. Callaway, and S. A. Onisko. November 1986. "Energy and Indoor Air Qual ity Measurements from Five Energy Conserving Manufactured Homes." Pacific Northwest Laboratory, Richland, Washington.

Levy Partnership in Association with Glen River Industries. 1986. Final Report--Energy Efficient Manufactured Housing Demonstration Project. Prepared for Bonneville Power Administration. New York, New York.

Miller, Nancy. 1987. "Thermal Analysis of the ELCAP Base Case Residential Sample: Sumary of Initłal Results." Draft PNL Report. Pacific Northwest Laboratory, Richland, Washington.

Miller, Nancy. 1988. "Therma1 Performance of Hood River End-Use Metered Homes." Pacific Northwest Laboratory, Richland, Washington.

National Conference of States on Building Codes and Standards, Inc. (NCSBCS) 1987. "Mobile Home Program Statistics." Herndon, Virginia.

National Oceanic and Atmospheric Administration (NOAA). 1979. "Hourly Solar Radiation-Surface Meteorological Observations." Solmet. Volume 2, Final Report. TD-9724. Ashville, North Carolina. 
Nesse, R. J., J. H. Callaway, R. F. Darwin, A. D. Lee, and S. A. Harkreader. 1988. Analysis of Alternative Manufactured Housing Energy Standards. Oraft Report. Pacific Northwest Laboratory, Richland, Washington.

Northwest Power Planning Council (NPPC). 1983. Northwest Conservation and Electric Power Plan. Volume 2. Northwest Power Planning Council, Portland, Oregon.

Northwest Power Planning Counctl (NPPC). 1986a. (Revised Feb. 1986) Model Conservation Standards Equivalent Code, pp. 56-58. Portland, Oregon.

Northwest Power Planning Council (NPPC). 1986b. Northwest Conservation and Electric Power Plan. Vol. 2, pp. 5-13. Portland, Oregon.

Northwest Power Planning Council (NPPC). 1987. "Energy Efficiency and Manufactured Housing in the Rorthwest." Staff presentation to the Council, June 10, 1987, Ashland, Oregon.

Onisko, S. A. 1986. "The Cost of Energy Efficiency in Hud-Code Manufactured Homes." Bonneville Power Administration, Portland, Oregon.

Onisko, S. A. 1987. "Simulation Model Estimates for Manufactured Homes." Bonnevile Power Administration, Portland, Oregon.

Palmiter, L. and D. Straub. 1984. SUNDAY 2.0. Ecotope, Inc., Seattle, Washington.

Palmiter, L. and T. Wheeling. 1984. SUNCODE: A Program User's Manual. Ecotope Inc., Seattle, Washington.

Palmiter, L. and M. Toney. 1987. "The Effect of Solar Gains on Degree-Day Regression Results." 12th Mational Passive Solar Conference, Anerican Solar Energy Society. Ecotope Inc. ACEEE. Seattle, Mashington.

Pearson, E. H., G. H. Stokes, and R. S. Crowder, October 1985. "Data Verification in End-Use Metering." Presented at the Electric Power Research Institute's Conmercial End Use Metering Workshop. Pacific Northwest Laboratory, Richland, Washington.

Sonderegger, R. C. January 1985. Dynamic Models of House Heating 8ased on Equivalent Thermal Parameters. Ph.D. Dissertation. Princeton University, Princeton, New Jersey.

Sonderegger, R. C. 1977/78. "Movers and Stayers: The Resident's Contribution to Variation Across Houses in Energy Consumption for Space Heating". Energy and Buildings 1, pp.311-324. El sevier Science Publishers, New York, New York.

Stovall, T. K. 1987. "Hood River Conservation Project Load Analysis." DOE/BP:11287-17. Oak Ridge National Laboratory, Oak Ridge, Tennessee. 
Taylor, Z. T., R. G. Lucas, and A. D. Lee. 1988. Impacts of Alternative Residential Energy Standards-Rural Housing Amendments Study. Phase l. Rev. 1. Pacific Northwest Laboratory, Richland, Mashington.

Tomich, S. D. and G. J. Schuster. 1985. Descriotion of Field Data Acauistion Systen for Building Energy Monitoring. Pacific Northwest Laboratory, Richland, Washington.

U.S. Department of Energy (DOE). 1986. Iechnical Support Document in Support of Proposed Interin Energy Conservation Standards for New Federal Residential Butldings. Hashington, D.C.

Mestman, E. D. and W. H. Monroe. 1986. Performance of the Princeton Scorekeeping Method for Estimating Annual End-Use Energy Shares as Measured with Metered End-Use Data." ACEEE Sumber Study. Santa Cruz, California. 


\section{APPENDIX A}

ANALYSIS OF ELCAP AND HOOD RIYER END-USE DATA 
APPENDIX A

\section{ANALYSIS OF ELCAP AND HOOD RIVER END-USE DATA}

This appendix contains a description of the analytic technique used on the end-use metered data and the results from applying this technique to 1) the HRCP end-use metered homes, 2) the ELCAP base case manufactured homes, and 3) the ELCAP new manufactured homes designed to meet the MCS. The analytic technique is one previously developed by PNL for Bonneville to analyze ELCAP-metered homes built under the Residential Standards Demonstration Project (RSDP). The methodology is referred to herein as the "PNL RSDP methodology."

This appendix provides initial results fron applying the PNL RSDP methodology to the end-use metered homes in this study, and identifies research issues that deserve further attention. The energy consumption and thermal performance estimates presented in this appendix have not been used in the derivations presented in Sections 5, 6, and 7 for two reasons: 1) the ELCAP manufactured home sample consists of too few homes and 2) the Hood River homes analyzed here were those for which end-use heating energy data were available. We elected to use the Hood River homes' metered heating energy consumption data rather than estimates derived from the techniques described in this appendix.

\section{MEIHODOLOGY}

The methodology used in this analysis has been applied in several other thermal performance analyses. In the analysis of ELCAP-monitored RSOP homes, the PNL RSDP methodology was used to characterize and compare the therma? performance of new MCS homes with that of both new "control" homes and ELCAP base case homes built after 1978 (Drost et a1. 1986). In a later work, similar characterizations were made for a large portion of the ELCAP residential base sample of homes as well as the previous RSDP work (Miller 1987). In an analytic effort currently underway the methodology is being applied to the whole sample of HRCP homes and the work reported here is being integrated with that effort (Miller 1988). 
Description of Thermal Performance Characterization with PNL RSDP Methodology

The PNL RSDP methodology actually consists of two closely related analytic techniques. One is based on a linear fit to energy consumption data and the other relies on a smooth curve-fitting technique. Our thermal performance characterization is based on an analys is of hourly exterior temperature, interior temperature, and electrical space-heat consumption data aggregated to the dally level. In homes where wood stove use is monitored, we exclude days with diagnosed wood stove use from the analysis. A scatterplot of heater consumption versus the difference between inside and outside temperatures (delta temperature) is made from the daily data points. As noted above, these points are fit using two different procedures--a robust 1 inear fit and a robust smooth curve. Robust techniques are used to calculate all parameters. These techniques are resistant to the effect of outlier points.

The linear fit provides two measures of thermal performance, a balance point and slope for the structure. The balance point of a structure is the instde-outside teaperature difference at which heating equipment will begin operating. While we use differences between the inside and outside temperature data to derive the parameters in our linear model, many empirical analyses of residential thermal performance data are based on fitting a linear relationship between heating energy consumption and outside temperature. Fitting such a model provides a slope, which is related to the conductive UA (total load coefficient, including infiltration load) divided by the efficiency of the heating system, and an estimate of an effective reference temperature, or outside temperature above which space heating is usually not required. The linear model we use is essentially the same, but the heating data are fit to the inside-outside temperature differences. While the slope parameter retains the same meaning as in the model based on outside temperature alone, our model provides an estimate of the balance point, rather than an estimate of the reference temperature itself.

The slope is a measure of the amount by which the output of the heating equipment must increase to meet the increased load imposed by a fixed decrease in outside temperature. The slope estimate may be used as a measure A. 2 
of thermal integrity of the structure; as such, it may be viewed as an "asoperated" or "apparent" UA for the structure.

The second procedure, the smooth curve fit, provides a functional relationship between heater consunption and a series of inside-outside temperature differences. This procedure essentially breaks the data into small subsets that can be fit individually to provide a composite curve that fits the data better than a single straight line. A smooth curve is fit to the data points using the "lowess" robust regression procedure (Becker 1984), where lowess means locally weighted regression scatter plot smoothing. This smooth curve fit more accurately fits the energy consumption associated with small delta temperature values. If a nonlinear region exists at high values for the temperature difference, then the lowess fit also models this region more accurately than would the linear model. All data points with zero energy consumption are excluded from the lowess curve fit. (a) Results from the two methods as applied to HRCP data are presented later in Linear Fit Results.

Both methods are subject to stmilar caveats. Implicitly included in these methods are the levels of internal and solar gains actually observed in the load data. Estimated slopes, or "as-operated" UAs, reflect the effects of these loads so the estimated UAs are not based purely on a building's thermal characteristics. Both methods ignore possible correlations between inside and outside temperatures. Assuming that inside air temperature, internal gains, and solar gains are not highly correlated with outside air temperature, the procedures described in the paragraphs to follow provide powerful tools for comparing the performance of groups of structures.

(a) The practice of excluding points that represent zero heating energy has been established as a means to increase consistency across homes analyzed when the analysis is directed at characterizing primarily the thermal characteristics of a home. Exclusion of such points reduces the weight given to days when occupants are away from home for extended periods and to variations in occupant behavior. It can be argued, on the other hand, that exclusion of these points may lead to an overestimate of heating energy use for an individual home. 


\section{Estimation of Annual Space Heating Consumption}

Either the linear or lowess curve fit results can be used to estimate annual heating energy consumption. Although PNL relies on the lowess technique to estimate annual energy consumption, in principle the parameters estimated from the linear fit could be used to produce an alternative estimate (see Linear Fit Results). The results from applying either technique can be combined with appropriate weather data (daily temperatures) to estimate annual heating energy consumption. In the case of the linear model, the slope is a constant that relates heating energy consumption to the datly inside-outside temperature difference. Suming over all heating days provides an estimate of annual heating energy consumption.

Using results from the lowess snooth curve-fit, heating energy consunption is estimated using the nonlinear relationship between heating load and temperature difference throughout its entire range. The first step, as with the linear technique, is to select an internal temperature by using 1) the mean value of the measured internal temperature over the heating season or 2) a fixed internal temperature of $65^{\circ} \mathrm{F}$. Next, the annual outside temperature distribution is divided into temperature bins of 1 to 2 degrees per bin, and the inside-outside temperature differences are calculated for each heating day. The annual space-heating energy consumption is then estimated; this is done by suming over the temperature bins the product of the number of days during the heating season at a given outside temperature and the lowess estimate for energy used at that particular value of insideoutside temperature difference.

To make valid comparisons across homes for which we had data, it was important to apply a normalization procedure to adfust for climate differences, both between years and between $\mathrm{climate}$ zones. The procedure used in this work to normalize for weather consists of selecting a comparison site with known outdoor temperature data and then using the procedure (described in the next paragraph) to predict the annual space-heating requirements of a particular structure at that site. For the ELCAP homes located in climate zone 1--Seattle and Portland--typical meteorological year (TMY) data were used for the estimate of heating requirements. ELCAP homes 
located in climate zones 2 and 3 have estimates based on Spokane and Missoula TMY weather data, respectively.

For the Hood River homes, no comparable standardized climate data were available so we used several actual weather years that covered the range of weather conditions observed in Hood River. The years selected and the associated heating degree-days (HOD, to base $65^{\circ} \mathrm{F}$ ) are shown below:

1978-79 6134 HDD (coldest)

1976-77 5502 HDD (typical)

1980-81 5142 HDD (warmest)

These years represent the coldest, most typical, and warmest weather years for the cominunity of Hood River over the last 10 years. The summaries for the Hood River hones found in the section below refer to the "most typical" 1976-77 weather year.

We note again that the climate normalization methods used here (and in the analysis reported in Section 4) assume that values of HDD adequately characterize weather effects on heating energy consumption. Section 5 specifically addresses that assumption.

\section{HOOD RIVER MANUFACTURED HOME RESULTS}

This section of Appendix A first presents energy consumption estimates of the HRCP manufactured homes based on the PNL RSDP lowess technique. Next, it presents results from the linear model, examines the effect of UA and balance temperature changes on energy consumption, and compares the results to the lowess model's results. This is followed by a comparison of the design UAs with the as-operated UAs estimated here. The last section presents results from other analyses of pre- and post-retrofit energy consumption in HRCP manufactured homes.

\section{Lowess Analysis Results}

Estimates of annual space-heating consumption, based on the lowess technique, are shown in Table A.1 for the subset of HRCP homes that we were able to characterize in both the pre- and post-retrofit periods. The estimates are based on each home's mean inside temperature, and results are displayed for several different weather years. 
IABLE A.l Mean Estimated Annual Electrical Space Heat

Consumption (kWh/ft $\mathrm{f}^{2} /$ year) for HRCP Manufactured Homes

\begin{tabular}{|c|c|c|c|c|}
\hline $\begin{array}{l}\text { Neather } \\
\text { Data }\end{array}$ & $\begin{array}{c}\text { Pre- } \\
\text { Retrofit }\end{array}$ & $\begin{array}{c}\text { Post- } \\
\text { Retrofit }\end{array}$ & Change & $\begin{array}{l}\text { Percent } \\
\text { Change }\end{array}$ \\
\hline $\begin{array}{l}\text { Hood River 1978-79 } \\
6134 \text { HDD }\end{array}$ & 13.17 & 11.78 & -1.39 & -10.5 \\
\hline $\begin{array}{l}\text { Hood River 1976-77 } \\
5502 \text { HDD }\end{array}$ & 11.66 & 10.38 & -1.28 & -11.0 \\
\hline $\begin{array}{l}\text { Hood River } 1980-81 \\
5142 \text { HDD }\end{array}$ & 10.51 & 9.34 & -1.17 & -11.1 \\
\hline Seattle TIY & 10.7 & 9.51 & -1.19 & -11.1 \\
\hline Portl and TMY & 9.24 & 8.21 & -1.03 & -11.2 \\
\hline Sample size & $n=24$ & $n=24$ & & \\
\hline
\end{tabular}

The subset of Hood River homes used to generate the results in the table meet several tests required to characterize the data using the PNL RSDP methodology. Where wood heat sensors were installed, we removed days in which wood heat was used. After removal of wood-heating days, we excluded homes for which the range of inside-outside temperature deltas was inadequate to characterize thermal performance. The table reports data for only those 24 homes which met these tests both before and after retrofit. These homes constitute about half of the end-use metered homes.

For all weather data, estimates of heating requirements decrease after retrofit. The decrease is about $11 \%$, with very little variation for different climate adjustments. Figure A.1 displays the comparison between pre- and post-retrofit consumption estimates for these 24 sites based on the typical Hood River weather year. Note that, for a few homes estimated, consumption did not change, and for four homes the consumption estimate increased slightly. For 17 homes, however, the consumption estimates decreased, as much as 33\%. 


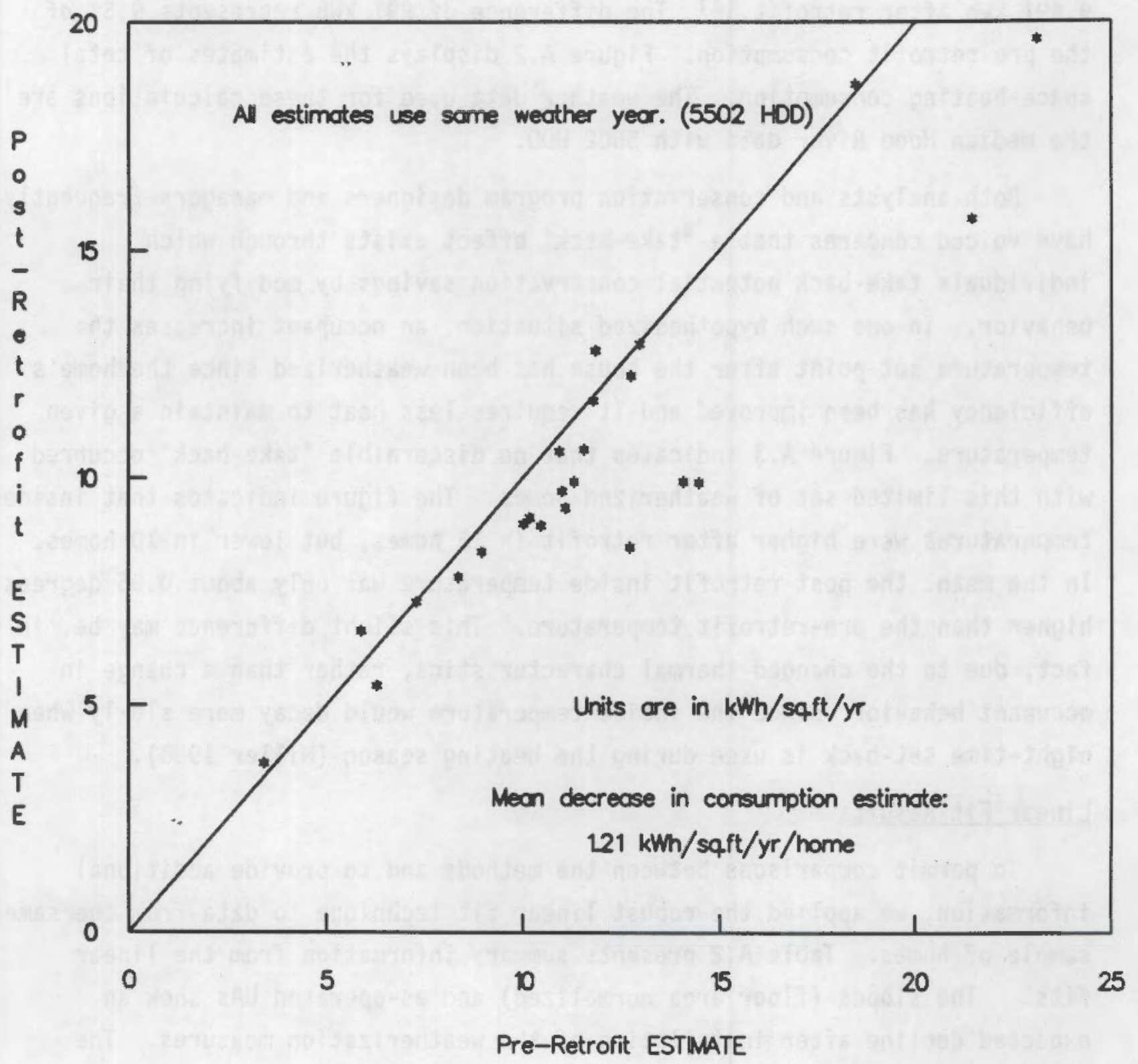

Figure A.1. Comparison of Space Heating Estimates for 24 Hood River End-Use Metered Manufactured Homes 
The consumptions reported in Table A.l are the space heating energy per square foot of floor area. Removing the floor area normalization yields a mean estimate of 10,482 $\mathrm{kWh}$ for annual space-heating before retrofit and $9,491 \mathrm{kWh}$ after retrofit. (a) The difference of $991 \mathrm{kWh}$ represents $9.5 \%$ of the pre-retrofit consumption. Figure A.2 displays the estimates of total space-heating consumption. The weather data used for these calculations are the median Hood River data with 5502 HDD.

Both analysts and conservation program designers and managers frequently have voiced concerns that a "take-back" effect exists through which individuals take-back potential conservation savings by modifying their behavior. In one such hypothesized situation, an occupant increases the temperature set-point after the house has been weatherized since the home's efficiency has been improved and it requires less heat to maintain a given temperature. Figure A.3 indicates that no discernible "take-back" occurred with this limited set of weatherized homes. The figure indicates that inside temperatures were higher after retrofit in 13 homes, but lower in 10 homes. In the mean, the post-retrofit inside temperature was only about 0.05 degrees higher than the pre-retrofit temperature. This slight difference may be, in fact, due to the changed thermal characteristics, rather than a change in occupant behavior, since the inside temperature would decay more slowly when night-time set-back is used during the heating season (Miller 1988).

\section{Linear Fit Results}

To permit comparisons between the methods and to provide additional information, we applied the robust linear fit technique to data from the same sample of homes. Table A.2 presents summary information from the linear fits. The slopes (floor area normalized) and as-operated UAs show an expected decline after installation of the weatherization measures. The

(a) We compared the lowess estimates to the actual consumption for a subset of homes. Using the weather data for the year upon which the lowess estimates were based resulted in agreement between the lowess estimates and measured data within $2 \%$ on the average. Though the agreement is quite good, it is possible (as Section 6.0 discusses) that extrapolations to other weather conditions may be less reliable. 


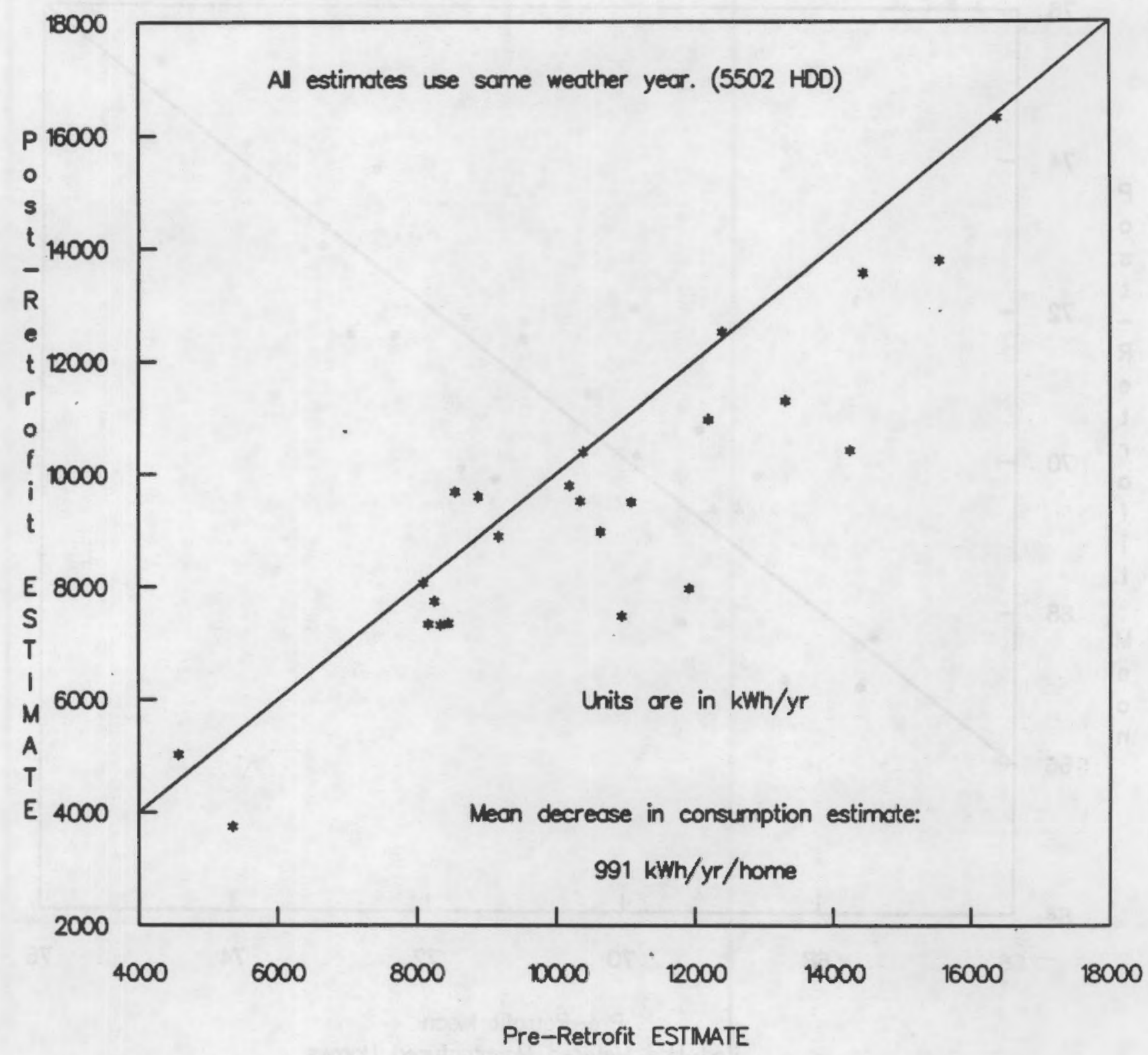

Figure A.2. Comparison of Space Heating Estimates for 24 Hood River End-Use Metered Manufactured Homes 


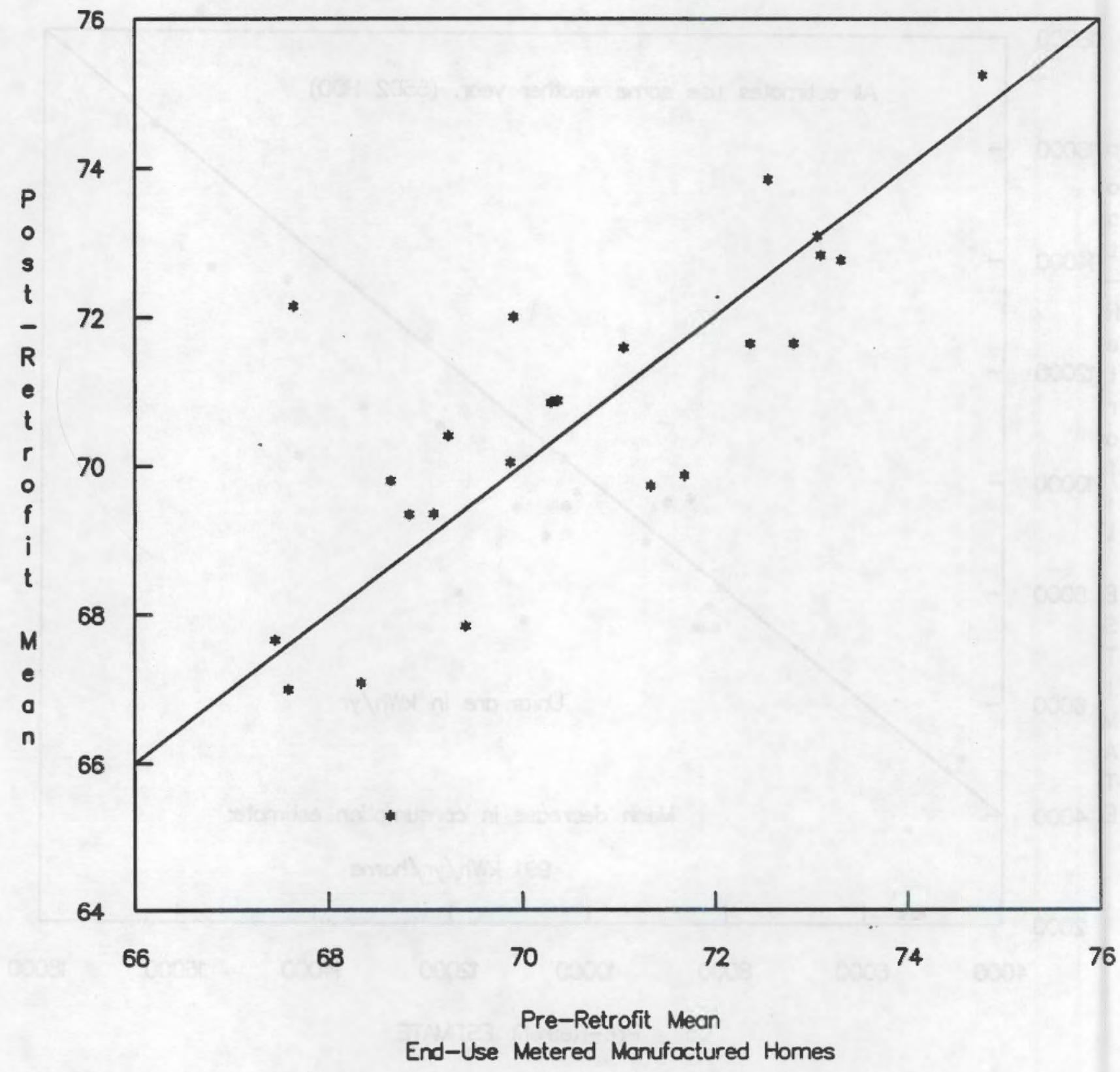

Figure A.3. Average Inside Air Temperature Over The Heating Season in Degrees $F$ 
IABLE A.2. Summary of Mean Statistics From the Robust Linear Fits for Hood River Manufactured Homes

\begin{tabular}{|c|c|c|c|c|}
\hline & $\begin{array}{c}\text { Pre- } \\
\text { Retrofit }\end{array}$ & $\begin{array}{c}\text { Post- } \\
\text { Retrofit }\end{array}$ & Change & $\begin{array}{l}\text { Percent } \\
\text { Change }\end{array}$ \\
\hline $\begin{array}{l}\text { Slope } \\
\text { kWh/ft }{ }^{2} / \text { day/F }\end{array}$ & 0.00303 & 0.00269 & -0.00034 & -11.1 \\
\hline $\begin{array}{l}\text { Balance Point } \\
-F\end{array}$ & 11.53 & 11.61 & +0.08 & +0.8 \\
\hline $\begin{array}{l}\text { As-Operated UA, } \\
\text { Btu/hr/ } /{ }^{\circ} \mathrm{F}\end{array}$ & 389 & 350 & -38 & -9.9 \\
\hline $\begin{array}{l}\text { Inside Air } \\
\text { Temperature, } \\
\text { •F }\end{array}$ & 70.47 & 70.51 & 0.05 & +.07 \\
\hline $\begin{array}{l}\text { Conditioned Floor } \\
\text { Area, } \mathrm{ft}^{2}\end{array}$ & 988 & 988 & & \\
\hline Number of Homes & 24 & 24 & & \\
\hline
\end{tabular}

balance points show an increase of about $1 \%$, which is small but consistent in direction with shell tightening measures.

We can compare the heating energy estimates from the linear fit to those from the lowess procedure. He calculated the mean HDD for these homes before and after retrofit, based on the mean balance point and inside air temperature. This gave an average pre-retrofit HDD of 3,800 and a postretrofit $H D D$ of 3,775 . The linear model assumes that the heating energy is equal to the product of UA and HDD. Using the mean estimated as-operated UAs from Table A.2 and the estimated mean HDD values, we calculated an average heating energy consumption of 10,395 kWh prior to retrofit and 9,288 after retrofit. These values are within $2 \%$ of the estimates from the lowess analysis. Since the lowess results agreed well with actual data, the linear model also appeared to fit the measured data well. As with the lowess results, however, we note that extrapolations to other weather conditions could reduce the accuracy of the linear model estimates. 


\section{Comparison of UA Estimates}

Models that estimate residential heating energy consumption typically rely on engineering heat flow principles which relate energy consumption to the building load coefficient, UA. This coefficient provides a measure of the rate of heat flow as a function of inside-outside temperature differences. The existence of a strong relationship between indoor-outdoor temperature differences and heating energy consumption has been well demonstrated. The analyses in this study also rely on this conceptual model. Because of the widespread acceptance of $U A$ as an indicator of thermal performance, we have used the results frow our study to compare design UAs (based on physical properties) and "as-operated" UAs inferred from empirical data.

For 22 of the 24 Hood River manufactured homes summarized in the pre- . retrofit column of Table A.2, we have calculated design UAs from structural information (see Section 3.1 for details). The mean design UA for these homes, prior to installation of weatherization measures, is $456 \mathrm{Btu} / \mathrm{hr} /{ }^{\circ} \mathrm{F}$. For the same homes after retrofit, the mean design $U_{A}$ is $366 \mathrm{Btu} / \mathrm{hr} /{ }^{\circ} \mathrm{F}$. The percent decrease in design UA for the two samples is $19.7 \%$ of the preretrofit level. The mean as-operated UAs (calculated from the linear model) for the same 22 homes are 391 and $356 \mathrm{Btu} / \mathrm{hr} /{ }^{\circ} \mathrm{F}$, respectively. The mean asoperated UAs show a decrease of $9 \%$ and, consistent with results from prior work (Miller 1987), the as-operated UAs are less than the design values.

- The mean of the as-operated UAs is less than the design UAs in both preand post-retrofit periods. The mean pre-retrofit, as-operated UA is $14 \%$ less than the design value, and the post-retrofit estimate is $3 \%$ less than the design value. For this sample of Hood River manufactured homes, the homes appear to be performing better than the structural characteristics data would indicate, particularly prior to installation of weatherization measures. Similar observations have been made in other comparisons between design and as-operated UAs that were limited to site-built homes (Miller 1987). The reasons for these differences are uncertain but may be due to correlations between internal and solar gains and outside temperatures. This issue is the topic of further analysis at PNL. 


\section{Results Reported in Other Studies}

Other studies have compared the pre- and post-retrofit heating energy consumption in HRCP manufactured homes. Using the PRISH methodology (see discussion in Section 4.0) with billing data and a much larger sample of Hood River homes (138 homes), the percent reduction in electric space heating requirements for manufactured homes has been calculated to be around $9 \%$ (Hirst 1987). In a related work, using the load data for the majority of end-use metered Hood River manufactured homes ( 55 homes), the percent reduction in space-heating requirements was found to be $8 \%$ (Stovall 1987). The percent reduction in space-heating requirements of $9.5 \%$ reported in this analysis are derived from an analysis of 24 homes. Given the differences between the methodologies used in this analysis and those of Hirst and Stovall, as well as the differences in sample size and composition, the various results are in close agreement.

\section{ELCAP BASE CASE MANUFACTURED HOMES RESULTS}

Only 10 manufactured homes are in the ELCAP base case set of homes. Primarlly because of extensive wood heat use in seven of the homes, we have

been able to analyze data for only three. All three homes have forced air heating systems and are located in climate zone 1. All the homes are relatively small, around 900 square feet. The design UAs for these homes, excluding the infiltration component, are 225 to 290, and all three were bullt between 1960 and 1978 .

Table A.3 summarizes the derived paraneters from the robust linear fit. The mean as-operated UA for these homes is 315 , which is lower than the comparable value for both pre- and post-retrofit HRCP homes summarized in Table A.2. Though part of this difference may be because of the small size of the three ELCAP homes, the average slope is also lower than for the HRCP homes, indicating that the ELCAP homes are more efficient on a floor area normalized basis. The balance point, however, indicates the ELCAP homes are unable to maintain as large a temperature differential as the HRCP homes, suggesting possible internal load or solar gain differences.

We also estimated electrical space-heating requirements for these homes using Seattle TMY data; results are shown in Table A.4. Two estimates are 
given. The first was calculated using the mean inside air temperature over the heating season (listed in Table A.4); the second estimate used an inside air temperature of $65^{\circ} \mathrm{F}$.

IABLEA.3. Sunmary of Derived Parameters from the Linear Fit for the ELCAP Base Case Manufactured Homes (1986-87)

\begin{tabular}{|c|c|c|c|}
\hline Site & $\begin{array}{c}\text { Slopes } \\
\text { kih/ft?-day-OF }\end{array}$ & $\begin{array}{l}\text { As - op UA } \\
\text { Btu/hr- } \mathrm{F}\end{array}$ & $\begin{array}{c}\text { Bal Point } \\
\text {-F }\end{array}$ \\
\hline $\begin{array}{l}217 \\
364\end{array}$ & $\begin{array}{l}0.00203 \\
0.00286 \\
0.00251\end{array}$ & $\begin{array}{l}275 \\
353 \\
317\end{array}$ & $\begin{array}{l}8.2 \\
8.1 \\
7.9\end{array}$ \\
\hline
\end{tabular}

IABLEA.4. Sumary of Estimated Electrical Space-Heating Requirements for ELCAP Base Case Manufactured Homes Using Alternative Inside Air Temperatüres and Seattle TMY Data, 1986-87, kth $/ \mathrm{ft}^{2} / \mathrm{yr}$.

\begin{tabular}{|c|c|c|}
\hline \\
\hline Site & Meas. & $I A T=65^{\circ} \mathrm{F}$ \\
\hline $\begin{array}{l}17 \\
54\end{array}$ & $\begin{array}{r}8.50 \\
10.40 \\
9.88\end{array}$ & $\begin{array}{l}6.20 \\
8.33 \\
7.21\end{array}$ \\
\hline
\end{tabular}

Note: "IAT" denotes indoor air temperature.
"Meas" refers to the measured IAT.

The table illustrates the sensitivity of the results to assumptions about indoor air temperature (IAT). The first column of results shows the estimated consumption based on the measured IAT, and the next column shows the results assuming an IAT of $65^{\circ} \mathrm{F}$. The final column shows the actual mean IAT for the heating season. As expected, the difference between energy consumption estimates depends directly on the difference between the measured and assumed temperature values. The estimated consumptions for these examples of the existing stock of manufactured homes are relatively high, averaging $9.6 \mathrm{kth} / \mathrm{sq} \mathrm{ft} / \mathrm{yr}$ based on measured IAT. This is quite close, 
however, to the Northwest Power Planning Council's estimate of $9.7 \mathrm{kWh} / \mathrm{sq}$ $\mathrm{ft} / \mathrm{yr}$ for new manufactured homes in climate zone 1 (NPPC 1986, p.5-13).

\section{ELCAP MCS MANUFACTURED HOMES}

In a previous Bonneville project, five new manufactured homes were designed and built to meet the MCS requirements for the three climate zones. PNL tested these homes, while unoccupied, during the spring of 1986, and the results have been reported previously (Lee et al. 1986). In the current study, we have analyzed data from the unoccupied test period and from the period after the homes were occupied. This section of Appendix A reports these results.

\section{Ouality of Data}

The analyses reported here were severely constrained by a lack of adequate, reliable data. For several reasons, we caution the reader when interpreting and generalizing the results. First of all, the results are limited to only three hones, a clearly inadequate sample size. The results are of great interest because the homes were designed to meet the MCS, yet the sample size is too small to generate statistically reliable conclusions. Second, the data collected during the unoccupied phase were generated under atypical operating conditions. Because the unoccupied phase occurred during the spring, the thermostat was set well above normal values to generate an adequate inside-outside temperature difference. Third, the data collected during the occupied phase represented only a small portion of the heating season (late-winter through spring), and resulted in a temperature swing much smaller than data for a complete heating season would produce. Such small temperature swings add considerable uncertainty to the parameter estimates. Additionally, since the spring is a swing season, mean daily temperatures may be fairly high, yet heating may be required at night and in the morning. The PNL RSDP methodology assumes that heating load increases as average daily temperatures decrease, and this relationship is least reliable during swing seasons. Fourth, two of these homes were located in an area with a mild climate, which compounded the other problems noted here.

We present the results to give preliminary indications of how these MCS homes performed and to allow initial comparisons across the different 
methodologies. We stress that the results should be interpreted only as relative indicators and not quantitative measures of performance or energy consumption. Additional data are being collected on these homes through ELCAP and will permit a more reliable analysis in the future.

\section{Comparison of Estimated UAs}

During the unoccupied test period, the thermostat was turned up to the mid- $80^{\circ} \mathrm{s}$ to maxinize the temperature difference across the shell. Additionally, the air-to-air heat exchanger was operated only part of the time to allow comparison of structural characterizations both with and without the air-to-air heat exchanger. In a prior study, load data collected from each home were analyzed using a model based on RC (resistancecapacitance) circuit analogs (Sonderegger 1985) that utilized hourly energy data and accounted separately for solar gain effects. This model is referred to here as the Equivalent Thermal Paraneter, ETP, nodel. Using load data from the homes after they were occupied, we applied the linear fit technique to analyze performance when occupied. Table A.5 compares UA estimates resulting from these different data sets and analytic techniques, and al so presents the calculated design UAs. Though five homes were tested, data gaps caused by wood heat use and other factors allowed us to analyze results for only three homes when they were both unoccupied and occupied.

Because of the extremely small sample size, we can draw only limited conclusions and inferences from these results. Given that these homes were designed to meet MCS requirements, the UAs estimated during the occupied period were, as expected, typically lower than comparable values for the HRCP homes shown in Table A.2. Comparisons of the UAs in Table A.5 show that the unoccupied UAs estimated with the ETP model are close to the design values. The as-operated, occupied UAs based on the linear model are consistently lower than the design values and, in 2 of 3 cases, the unoccupied ETP estimates. As noted earlier, previous studies and the results reported here for HRCP homes (see Comparison of UA Estimates) typically have shown the asoperated UA to be less than the design value. 
IABLE A.5. Comparison of As-Operated and Design UAs, Btu/hr./ ${ }^{\circ}$

$\begin{array}{lccc}\text { ID } & \begin{array}{c}\text { Design } \\ \text { Yalue }^{\mathrm{a}}\end{array} & \begin{array}{c}\text { ETP Model } \\ \text { Unoccupieds }\end{array} & \begin{array}{c}\text { Linear Mode1 } \\ \text { Occupted }\end{array} \\ 101 & 209 & 184 & 206 \\ 203 & 226 & 258 & 208 \\ 211^{\mathrm{b}} & 337 & 371 & 246\end{array}$

(a) Lee et al. (1986) based on conditions with the air-to-air heat exchanger (AAHX) operating. He used estimates based on the $A$ AHX operating since we assumed it would be operated when occupied. Values reported here include infiltration UA.

(b) Data limitations for this home were significant and reduce the reliability of the estimates.

\section{Comparison of Heating Energy Consumption Estimates}

We also applied the lowess technique to estimate heating energy consumption in these homes under different assumptions. Space heating estinates (see Table A.6) were calculated for both unoccupied and occupied periods. The metered data from the unoccupied homes included periods of time with the air-to-air heat exchanger both on and off. All estimates used Seattle TrY weather data. The second colum of Table A.6 displays the energy budget (annual $\mathrm{kWh} / \mathrm{ft}^{2}$ ) that the MCS homes were designed to meet in 1983. (Note that site 203 was designed for climate zone 3 and the MCS budget given is for that Zone, but the other values in the table were based on Seattle weather data.) The third column gives the lowess-based space heating estimate assuming an inside temperature of $65^{\circ} \mathrm{F}$. These values were calculated from metered data taken during the unoccupied period. The fourth and fifth columns display the lowess-based electrical space heating estimates using metered data from occupied homes during the 1986-87 heating season. The fourth column presents the lowess-based estimate using an average heating season temperature of $65^{\circ} \mathrm{F}$. Column 5 provides the lowess-based estimate using the mean inside air temperature over the heating season. The last 
IABLEA.6. Estimated Annual Space-Heat Requirements for 3 MCS Homes Using Seattle TMY Data $\left(\mathrm{kWh} / \mathrm{ft}^{2} / \mathrm{yr}\right)$

\begin{tabular}{llllll}
$\begin{array}{l}\text { MCSa } \\
\text { Budget }\end{array}$ & $\begin{array}{l}\text { Vacant } \\
\text { Lowess } \\
65^{\circ} \mathrm{F}\end{array}$ & $\begin{array}{l}\text { Occupied } \\
\text { Lowess } \\
65^{\circ} \mathrm{F}\end{array}$ & $\begin{array}{l}\text { Occupied } \\
\text { Lowess }\end{array}$ & $\begin{array}{l}\text { Occupied } \\
\text { IAT }\end{array}$ & IAT( F) \\
\hline 101 & 2.0 & 2.2 & 2.1 & 5.3 & 75.2 \\
$203^{\mathrm{a}}$ & 3.2 & 2.5 & 2.7 & 4.4 & 71.1 \\
$211^{\mathrm{b}}$ & 2.0 & 3.2 & 5.1 & 6.8 & 70.0
\end{tabular}

(a) The MCS budget for home 203 is based on climate zone 3 data, whereas the requirenents were estimated using Seattle weather data. Converting to climate zone 3 weather data would increase. the estimated requirenents. The budgets are from NPPC (1983).

(b) The estimates for home 211 are considered unrelfable due to data inadequactes.

column displays that mean inside air temperature for the 1986-87 heating season.

The small sample size again makes it impossible to draw statistically defenstble conclusions from these results. For home 101, the heating energy consumption based on $65^{\circ} \mathrm{F}$ agrees well with the MCS budget. (Data limitations make it impossible to make the same comparisons for the other two homes.) A comparison with Table A.1 shows that the estimated heating energy requirements, based on measured inside air temperatures, are about one-half to two-thirds the values estimated for the HRCP homes. These MCS homes appeared to be performing much better than the typical HRCP manufactured homes. The most significant information from this table is how much the heating energy estimates increased when measured, average inside air temperatures were used to calculate the heating requirements. In all cases, the IAT was considerably higher than $65^{\circ} \mathrm{F}$, which was the basis for the MCS budget estimates. These higher temperatures overwhelm the observed UA effect (as-operated UA less than design UA), and result in energy requirements higher than the design estimates.

\section{OBSERVAIIONS BASED ON ANALYSES AND RESULTS}

The analyses presented in this appendix have been hampered by limitations in the available data. In both the original samples of HRCP and 
ELCAP homes, numerous homes relied extensively on wood heat and were therefore deleted from our analysis to eliminate the confounding effects of wood heat use. The small size of the original sample of ELCAP homes, both typical homes and MCS homes, severely restricted our ability to develop results that can be generalized.

The larger sample of HRCP metered homes, however, did permit analyses that could be compared with other findings. For example, our estimates of about $10 \%$ total energy savings resulting from conservation retrofits were consistent with estinates made in other studies. Comparisons between estimated as-operated UAs and design UAs showed that manufactured homes tended to perfora better than their design UA would indicate, consistent with results for site-built homes.

Though the sample of ELCAP homes was too small to provide statistically valid results, it did permit preliminary identification of methodological and performance issues. The results showed potential differences between UA values calculated using the ETP technique based on hourly data and the linear fit technique based on average daily data. Though only three homes were compared, these results suggested that the two methods merit further comparison. The results derived from the PNL RSDP analysis of the occupied MCS homes suggested that their thermal performance is substantially below that profected from design data and engineering analyses. This finding was consistent with results reported in Section 4 for the Tulalip MCS homes. Though the results here must be considered in the light of several caveats, they suggested that the relationship between UAs and heating energy consumption in occupied homes differs from theoretical predictions and occupants maintained relatively high indoor temperatures that offset the improvements in thermal performance that could be expected from the UA effect alone.

Neither the linear nor lowess model explicitly deals with possible correlations between outdoor temperature and either internal or solar gains. As a result, their extrapolations across climate zones suffer from the effects discussed in Section 5 . 
APPENDIX B

PRISM HEATING COMPONENT AD.JUSTMENT UITHIN CLIMATE ZONE 
APPENDIX B

\section{PRISM HEATING COMPONENT ADJUSTMENT HITHIN CLIMATE ZONE}

This appendix presents the details of the methodology developed to adjust PRISM's estimates of heating consumption based on measured data. It relies on metered space heating data from the HRCP and Tulalip homes, but has been developed so it can then be applied to the entire sample of Hood River homes.

As the results in Section 4 indicated, PRISH-based estinates of the heating component can differ substantially from the metered heating energy consumption. For individual homes in our sample, the errors ranged from $-42 \%$ to $+102 \%$ and the mean value of the errors tended to obscure the large variance in the differences. The positive and larger errors for the energyefficient homes were particularly troubling since our focus was on estimating the performance of energy-efficient homes.

Given the sample of homes available, we examined the relationship between the PRISM-based heating component and the measured heating consumption. He ran a simple regression analysis using the actual heating consumption as the dependent variable and the PRISM-based estimate as the independent variable. Table B.1 shows that a significant relationship exists, with the actual average heating consumption about $96 \%$ of the PRISMbased estimate. The $R$-squared was 0.68 , which indicated a reasonable correlation between the variables. The predictive power of the PRISM-based heating component was not particularly good, though, as the results in Section 4 confirmed, particularly for the Tulalip, energy-efficient homes. 
IABLE B.1. Initial Regression Results

Dependent Variable: Actual heating energy consumption

Independent

Yariable

PRISM-based space-

heating estimate

Number of Observations

R-squared
Estimated

Coefficient

0.96

26.4

Because of the demonstrated inability of the PRISM-based heating component to provide an adequately accurate estimate of the actual spaceheating consumption, we developed a methodology to adfust the PRISM-based estimates of heating consumption and utilized the measured data available in our study. The technique was developed to increase the utility of information from PRISM in estimating heating loads within a given climate zone.

One principle observed in developing the adjustment methodology was to restrict the required information to two kinds of data. One kind is provided by PRISM itself, such as the PRISM-based reference temperature (T-ref). The second kind consists of data readily obtained for specific homes being analyzed with PRISM, such as weather data or the design UA.

\section{BACKGROUND}

The PRISM-based heating component consists of the product of the PRISM heating slope and the PRISM heating degree-days (HDD), which are based on outside daily average temperatures and the PRISM T-ref. The heating component can be represented through the following equation:

PRISM-based heating component = PRISM slope $\mathrm{HDO}_{\mathrm{p}}$

where $H_{p D}$ is the PRISM estimate of HDD, based on PRISM T-ref. HDD is the sumation of the difference between PRISM T-ref and the average daily outside temperature for those days when PRISM T-ref exceeds the average outside temperature. The PRISM reference temperature is estimated by PRISM and is 
intended to indicate the daily-average outside temperature at which heating begins.

Next, we assume that a true, but unobserved, linear relationship with a form similar to the form of PRISH's heating term exists for predicting heating energy consumption. This is essentially a degree-day formulation for estimating space-heating load. We write this relationship as

$$
\text { Actual heating = actual slope * HDDa }
$$

where actual slope is the slope value that corresponds to the measured spaceheating consumption and $\mathrm{HDO}_{2}$ is the heating degree-days based on the actual T-ref.

Mext, we examine the difference between the PRISH-based heating component Equation A.l and the actual heating load and define it as the heating error. This variable is the "heat error" reported in Section 4 multiplied by the actual heating consumption.

$$
\begin{aligned}
\text { Heating error } & =\text { PRISH-based heating component - actual heating } \\
& =\left(\text { PRISH slope } * \mathrm{HDO}_{\mathrm{p}}\right)-\left(\text { actual slope } \mathrm{HDO}_{\mathrm{a}}\right) .
\end{aligned}
$$

Next, we assume that the PRISH estimates of each term can be written as the actual value for that term plus what we might call an error term:

$$
\begin{aligned}
\text { PRISM slope } & =\text { actual slope }+ \text { slope error } \\
H_{0 D} & =\mathrm{HDO}_{\mathrm{a}}+\mathrm{HDD} \text { error }
\end{aligned}
$$

The so-called "error terms" do not correspond to the usual statistical error terms that might result from a regression model (such as the PRISM model itself). The terms here capture the differences between the PRISM-based estimates of the slope and HDO values and the values that apply in a hypothesized model that correctly captures the dependence of heating energy on outside temperature. Specifically, the PRISM slope term inciudes the effects of loads that are correlated (both positively and negatively) with HDD, whereas the comparable term from the hypothetical model (actual slope) is defined to depend only on space-heating loads.

Next, we can substitute Equation A.4 and A.5 in Equation A.3, as follows: 


$$
\begin{aligned}
\text { Heating error } & =(\text { actual slope }+ \text { slope error }) *\left(H D D_{a}+H D D \text { error }\right) \\
& -\left(\text { actual slope } \star H D D_{a}\right) \\
& =\left(\text { slope error } \star H D D_{a}\right)+(H D D \text { error } \star \text { actual slope }) \\
& +(\text { slope error } \star H D D \text { error })
\end{aligned}
$$

Equation A.6 gives a functional form that can be the basis for a model to estimate the difference between the PRISH-based heating component and the actual heating energy consumption.

\section{MODEL SPECIFICATION}

Given the forn of Equation A.6, none of the variables is directly measurable. Dur approach was to identify measurable variables that could serve as proxies for each term and use the avallable data to estimate the coefficients for each proxy. As noted earlier, we sought variables that were from the PRISM procedure, or were easily obtained weather data or housing characteristics, to serve as proxies for the paraneters in Equation A.6.

The approach taken was a heuristic one with the goal of developing an explanatory estimation model which best fit the observed differences between the PRISM term and actual heating consumption (Equation A.3). Our approach was to estimate a relationship that fit the data adequately, and use that relationship as a source of insights into the theoretical, causal relationships and sources of error in PRISM, and provide a means to adjust the PRISM estimates.

The actual slope term in Equation A.6 should be closely associated with the building design total heat loss coefficient, UA, since this slope term by definition captures only the heating load relationship to HDD. Given the component insulation levels, window characteristics, and infiltration characteristics, the design UA can be estimated using standard procedures. We used design UA as a proxy for the actual slope in Equation A.6).

Second, we considered the actual heating degree-day term, $H D D_{a}$. The actual 1 HDD corresponding to individual homes depends on the $T$-ref where heating appears to begin. Without detailed heating data, we could not estimate accurately the outside temperature at which heating began. He chose to use HDD calculated to a standard reference temperature. Both because it 
was readily avaitable, and it provided the best fit of the T-refs tried in our analysis, we used HDD calculated to a T-ref of $65^{\circ} \mathrm{F}$ as a proxy for $\mathrm{HOD}_{\mathrm{a}}$ (a)

Third, the relattve slope error is influenced by how large the heating load is relative to the total load. We would expect the PRISM slope to be larger than the actual slope since the PRISH slope would include the effect of temperature- and seasonally-dependent loads other than heating. As the heating load's share of the total load increases, the error introduced by including the other temperature- and seasonaliy-dependent loads would be expected to renain positive but have a decreasing relative effect on the slope. The observations made earlier about the observed errors for energyefficient howes also suggested that the slope error was larger for efficient homes where heating constituted a relatively smaller share of total loads. To capture the expected behavior, we assumed that the slope error could be represented as follows:

$$
\text { Slope error - } a_{1}-a_{2} * \frac{\text { PRISM-based heating component }}{\text { PRISH estimate of total load }}
$$

where $a_{1}$ and $a_{2}$ are positive constants.

Finally, we considered the HDD error term in Equation A.6. We have very little information to allow us to determine how the HDD error behaves. A study by Hirst and Goeltz (1986) estimated a T-ref based on the metered heating load and found that the average PRISM estimate was less than the Tref based on the load data. Their load-based T-ref is similar to what we call here the actual T-ref and their observations suggested that the PRISN HDD was less than the actual HDD, or the HDD error was negative. Another recent study used daily, weekly, and monthly simulation model data to estimate T-ref with variations in climate and the building load coefficient, UA (Paimiter and Toney 1987). (b) Those results indicated that the analysis

(a) In subsequent analyses it would be beneficial to examine other values of T-ref that are likely to be more accurate for individual homes, such as the PRISM estimate of T-ref. This extension was beyond the scope of our analys is.

(b) Their analysis related changes in UA to differences in T-ref estimates. We assume that their simulation-based observations about differences in T-ref estimates apply to errors arising in empirical data as well, 
using monthly data (comparable to applying PRISM) produced T-ref values less than those from the analysis using daily data (comparable to our assumed "true" mode1) and they agreed with those from Hirst and Goeltz (1986). In addition, Palmiter and Toney (1987) al so showed that the difference between the T-ref estimates increased as T-ref decreased.

Based on this Tinited information, we developed a proxy for the HDO error. The behavior noted above suggested that the T-ref error could be estimated as a negative constant plus a term that was proportional to the PRISH T-ref. Though the relationship between T-ref and heating degree-days is complicated by the outside temperature profile, we would expect the HDD error to behave similarly to the T-ref error: the HDO error would be zero when the T-ref error was zero, it would be negative when the T-ref error was negative, and it would becone more negative as the T-ref error decreased. Consequently, we assumed that the HOO error could be described as follows:

$$
\text { HDO error - - } a_{3}+a_{4} \text { * PRISM T-ref }
$$

where $a_{3}$ and $a_{4}$ are positive constants.

\section{MODEL_ESTIMATION}

Given the proxies and model structure discussed, we next used linear regression techniques to estimate model paraneters. Based on the proxies chosen for the variables, we developed the following model:

Estimated heating error $=\left(a_{1}-a_{2} * P R 1 S M\right.$ heating ratio $) * H D D$

$$
\begin{aligned}
& +\left(-a_{3}+a_{4} * \text { PRISH T-ref }\right) * U A \\
& +\left(-a_{3}+a_{4} * \text { PRISH T-ref }\right) \\
& \star\left(a_{1}-a_{2} * \text { PRISH heating ratio }\right)
\end{aligned}
$$

where $a_{1}, \ldots, a_{4}$ are positive constants and the PRISM heating ratio is the ratio of the PRISM-based heating component to the PRISM estimate of total annual energy consumption.

We made two modifications before estimating the coefficients in this equation. First, we deleted the last two expressions in parentheses in Equation A.9. These terms are the product of the estimated HDD error and

though factors other than UA changes may have an effect in actual homes. B.6 
slope error and would be expected to be second-order adjustments and dominated by the first two terms in the equation. (In addition, their inclusion implies complex constraints on the coefficient estimates because their coefficients are products of the coefficients appearing on the first two lines.) Eliminating them leads to a first-order estimate of the heating error. Second, we rewrote the relationship so that the dependent variable was the measured heating energy consumption and we moved the PRISM-based heating component term to the right side of the equation. He allowed this term to be a predictor and felt that its inclusion on the right side might partially account for the variations due to the term that we excluded from the right side. From the initial regression, we found that the PRISH heating ratio did not have a statistically significant coefficient $\left(a_{2}\right)$ and dropped this term from the regression. The resulting equation was the following:

Adjusted heating estimate $=a_{0} *$ PRISH-based heating component

$$
\begin{aligned}
& +\left(-a_{1}\right) \neq H D D \\
& +\left(a_{3}-a_{4} * \text { PRISH T-ref }\right) * U A
\end{aligned}
$$

We used the measured heating energy data for pre- and post-retrofit Hood River homes and the Tulalip homes in a regression analysis to estimate the coefficients in this equation. The results are presented in Table B.2.

All the signs of the coefficients were as anticipated. All coefficients were significant at the $99 \%$ confidence level. The model fit the data well, with an R-squared value of 0.88 . (a) (b)

(a) To validate this model we generated two randon subsets of the cases used to derive these parameter estimates and re-estimated the model for each subset. We performed an F-test using the three sets of parameter estimates and found that the variance of the residuals was not statistically significantly different for the two estimating relations based on subsets (8). When we tested the hypothesis that the coefficients differed, the test indicated that the coefficients differed at about the $80 \%$ level, which was not considered a statistically significant difference.

(b) An earlier version of this model was applied in the analysis presented in Section 4, but when it was tested it gave estimates very close to those from this refined model. 
IABLE B.2. Regression Results for PRISM Adjustment

Dependent Variable: Actual heat

$\begin{array}{lcr}\begin{array}{l}\text { Independent } \\ \text { Variable }\end{array} & \begin{array}{c}\text { Estimated } \\ \text { Coefficient }\end{array} & \begin{array}{c}t \text { - } \\ \text { Statistic }\end{array} \\ \text { PRISH-based space-heating } & & \\ \text { COMponent } & 0.982 & 8.66 \\ \text { HDO } & -0.841 & -4.46 \\ \text { UA } & 61.8 & 7.20 \\ \text { PRISH T-ref * UA } & -0.850 & -5.65\end{array}$

Number of Observattions

R-squared

45

Corrected R-squared

0.88

0.87

\section{DISCUSSION OF RESULTS AND CONCLUSIONS}

The relationship says that the actual heating energy consumption equals 98x of the PRISH-based estimate plus three adjustments. The slope error is 0.841 , in kWh/degree-day. As anticipated, the slope error is positive. The PRISM slope estimates for the HRCP homes had an average value of about 3 $k$ th/degree-day and our relationship suggested that the true value was about $28 \%$ less.

The HDD error is $-61.8+0.850$ *PRISH T-ref. This term indicates that the HDD error is zero for a PRISH T-ref of $73^{\circ} \mathrm{F}$, is negative for lower values of T-ref, and becomes more negative for smaller values of the PRISM T-ref. The temperature at which the error equals zero is quite close to the results from the study cited earlier by Palmiter and Toney (1987). Since the energy consumption data used to estimate this equation were in units of $\mathrm{kth} / \mathrm{yr}$ and the UA values were in Btu/hr- $-^{\circ} \mathrm{F}$, the HDD error term estimated is not in conventional units. After conversion, the HDD error term is $(-8788+$ 121*PRISM T-ref), in degree-days. For a representative PRISM T-ref of $50^{\circ} \mathrm{F}$, for example, the HDD error would be 2738 degree-days.

He used the estimating relationship to calculate the adjusted PRISMbased heating consumption for the homes in our sample. Table B.3 compares the measured space-heating consumption with the initial PRISM-based estimate and our adjusted estimate. The PRISM-based estimate overpredicts the heating 
consumption by an average of $16 \%$. Our estimate overpredicts by only 5\%. The adjusted estimates also reduce the standard deviation of the percentage error; the standard deviation of the PRISH-based estimate errors (not shown) is $36 \%$ while the standard deviation for the adjusted estimates is $21 \%$.

The adjustment significantly reduces the error based on the PRISM-based estimate alone. The adjustment is based on homes representing a very wide range of thermal characteristics (UA ranges from about 170-700 Btu/hr- ${ }^{\circ} \mathrm{F}$ ), therefore, it can be applied to nanufactured homes representing a wide range of sizes and efficiency levels. Since it is based on data from basically one climate region, however, we do not believe it can be applied directly to significantly different climatic areas.

IABLE B.3. Comparison of Measured Heating, PRISM-Based Estimate, and Adjusted PRISH-Based Estimate (kth/yr) ${ }^{\mathrm{a}}$

\begin{tabular}{|c|c|c|c|c|}
\hline as & $\begin{array}{l}\text { PRISM-Based } \\
\text { Estimate }\end{array}$ & $\begin{array}{l}\text { PRISM-Based } \\
\text {-Measured }\end{array}$ & $\begin{array}{l}\text { Adjusted } \\
\text { Estimate }\end{array}$ & $\begin{array}{l}\text { Adjusted } \\
\text { - Measured }\end{array}$ \\
\hline
\end{tabular}

\begin{tabular}{|c|c|c|c|c|c|}
\hline$\frac{\text { Average }}{\text { Value }}$ & $\begin{array}{r}9638 \\
-.\end{array}$ & $\begin{array}{r}10086 \\
--\end{array}$ & $\begin{array}{r}447 \\
+16\end{array}$ & $\begin{array}{r}9687 \\
-\ldots .\end{array}$ & $\begin{array}{r}49 \\
+5\end{array}$ \\
\hline $\begin{array}{c}\text { Minimum } \\
\text { Yalue } \\
x\end{array}$ & $\begin{array}{r}2660 \\
\cdots-\end{array}$ & $\begin{array}{r}3429 \\
-\cdots\end{array}$ & $\begin{array}{r}-7607 \\
-42\end{array}$ & 2902 & $\begin{array}{r}-436 \\
-2\end{array}$ \\
\hline$\frac{\text { Maxtmum }}{\text { Value }}$ & $\begin{array}{r}18146 \\
\ldots . .\end{array}$ & 17300 & $\begin{array}{r}4497 \\
+102\end{array}$ & 17786 & $\begin{array}{r}3364 \\
+58\end{array}$ \\
\hline
\end{tabular}

(a) Percents are the differences shown divided by the measured heating.

There are several enhancements possible to the adjustment methodology. For example, an adjustment based strictly on PRISM outputs and weather data could be developed, thus eliminating the need for even UA information. With additional PRISM output data the basic relationship in Equation (A.6) could have been redefined in terms of PRISM parameters (PRISM slope and HDD based on the PRISM T-ref) and reestimated, possibly eliminating the need for other data. 
